Portland State University

PDXScholar

Spring 1-1-2013

\title{
Factors Influencing Social, Cultural, and Academic Transitions of Chinese International ESL Students in U.S. Higher Education
}

Akiko Ota

Portland State University

Follow this and additional works at: https://pdxscholar.library.pdx.edu/open_access_etds

Part of the Bilingual, Multilingual, and Multicultural Education Commons Let us know how access to this document benefits you.

\section{Recommended Citation}

Ota, Akiko, "Factors Influencing Social, Cultural, and Academic Transitions of Chinese International ESL Students in U.S. Higher Education" (2013). Dissertations and Theses. Paper 1051.

https://doi.org/10.15760/etd.1051

This Dissertation is brought to you for free and open access. It has been accepted for inclusion in Dissertations and Theses by an authorized administrator of PDXScholar. Please contact us if we can make this document more accessible: pdxscholar@pdx.edu. 
Factors Influencing Social, Cultural, and Academic Transitions of Chinese International ESL Students in U.S. Higher Education

\author{
by \\ Akiko Ota \\ A dissertation submitted in partial fulfillment of the \\ requirements for the degree of
}

Doctor of Education

in

Educational Leadership: Postsecondary Education

Dissertation Committee:

Michael Smith, Chair

Peter Collier

Samuel Henry

Andy Job

Portland State University

2013 
(C) 2013 Akiko Ota 


\begin{abstract}
The U.S. is the leading nation for international students to pursue higher education; the majority of whom are from countries with significant differences in culture and language from American students. As such, many international students start higher education in ESL support programs. While on the surface international students supposedly add cultural and linguistic diversity to American higher education by contributing to the internationalization of campuses, international students' transition into U.S. life and academe is often fraught with challenges including culture shock, adjusting to the new environment and society, adjustment to norms of academic performance, acquisition of academic and language skills, and negotiating chilly campus climates. Such factors can affect academic success, social/cultural acclimation, and even personal/ethnic identity. However, little is researched about international ESL students' transitions into U.S. higher education. This study employs qualitative research with semistructured interview and grounded theory as analytical technique and aims to rectify the existing research literature limitation by identifying factors that facilitate and inhibit social, cultural, and academic transitions among international ESL students that best serve and accelerate their academic career in the United States.
\end{abstract}




\section{ACKNOWLEDGEMENTS}

I would like to extend my very special gratitude to my advisor Dr. Michael J. Smith for guiding, coaching, and mentoring me not only to finish my dissertation, but to become a qualitative researcher throughout the process of dissertation writing. His constant encouragement always motivated me no matter what challenges I faced during the process of completing the dissertation. Even when I was not able to see the directions and outcomes of my data and writing, he assured me the outcomes would be fine. He was my role model of "caring and involving" faculty, which made my learning journey special.

I would also like to give special thanks to Peter Hoffman and Amber Bliss - great editors who spent countless nights reading and editing a seemingly endless succession of drafts throughout six years of my doctoral studies. Furthermore, I would like to acknowledge several special individuals who supported me: Jerry Young, Karen Maxwell, Kim Smith-Ilosvay, and Tatiana Cevallos -my wonderful and supportive doctoral cohort; Christina Luther, Joshua Davis, Mike Turay, Yoko Honda - my coworkers in the Office of International Student and Scholar Services; Michele Miller and Kristi Kang from the Intensive English Language Program; Arjen Sundman, Beatriz Torres, Renee Hoffman, Carlee Salas, Nadine Roya, Juan Carlos Roya Pabon, Javier Salas and my colleagues at the English Language Center at Michigan State University for their great support and encouragement while I was pursuing my doctoral studies and finishing my dissertation. 
Finally, I am most thankful to my beloved parents, Miyoko and Katsuya Ota and my brother Masatsugu Ota for their unconditional love, care, support, and trust in my decision to pursue an advanced degree and become a doctor of education. 


\section{Table of Contents}

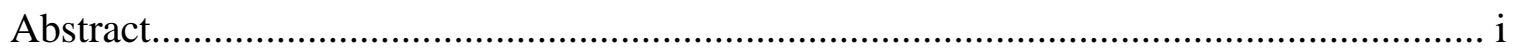

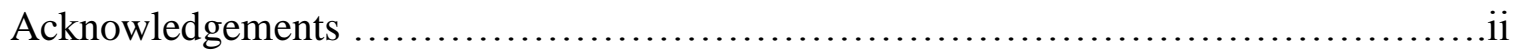

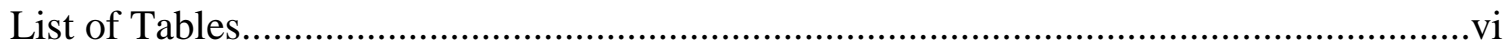

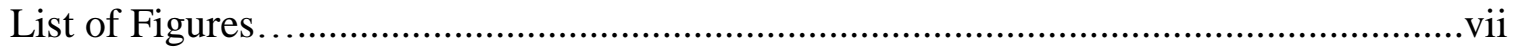

Chapter 1

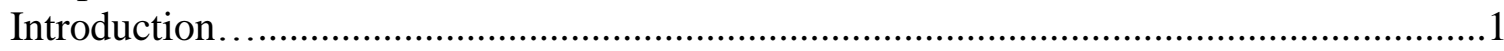

Chapter 2

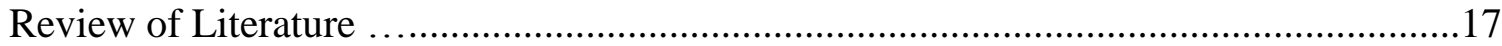

Chapter 3

Research Design and Methodology..................................................................63

Chapter 4

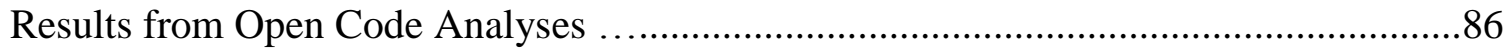

Chapter 5

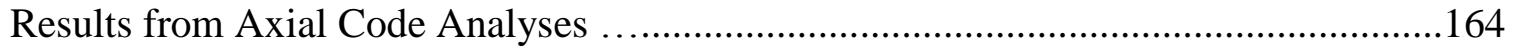

Chapter 6

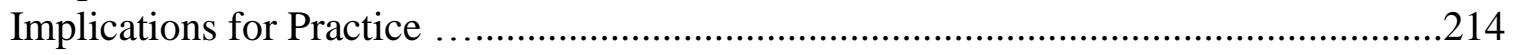

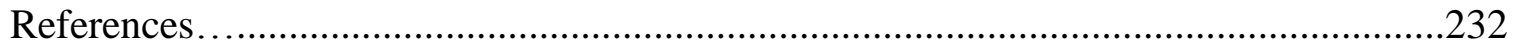

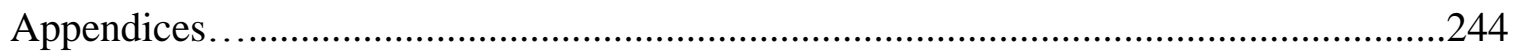

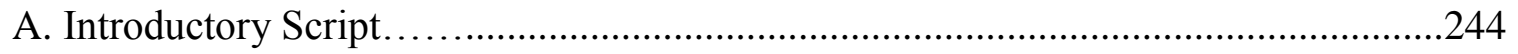

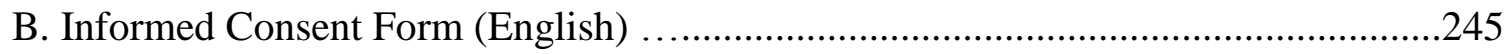

C. Informed Consent Form (Chinese Translation) ....................................................248

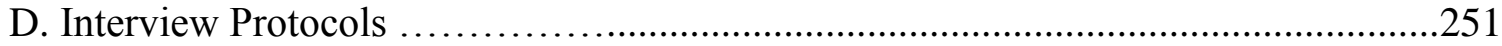

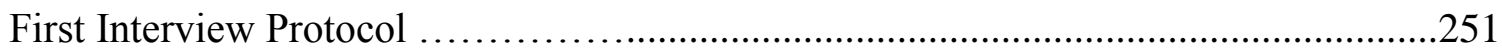

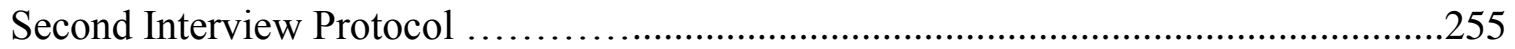




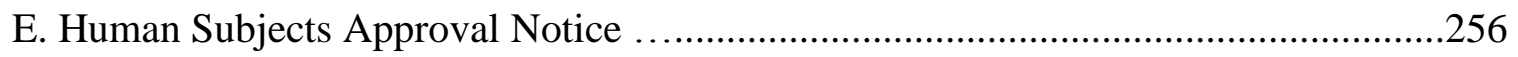

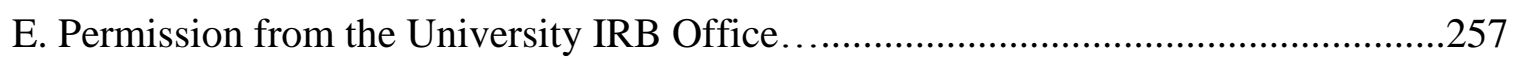

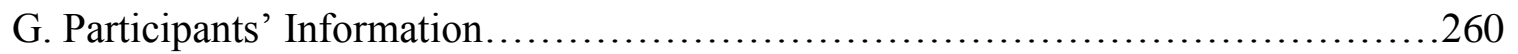




\section{List of Tables}

Table 1: Participant Information................................................ 74

Table 2: Participants' information............................................. 76 


\section{List of Figures}

Figure 1: Chinese International Students at the University between 2003 and $2012 \ldots \ldots 70$

Figure 2: The ESL Program Enrollment by Semesters................................. 71

Figure 3: ESL Level Placement Based on the Placement Test Scores .................72

Figure 4: Detailed Initial Placement Chart Based on the ESL Placement Test............73 


\section{CHAPTER 1}

\section{Introduction}

\section{International students in U.S. higher education}

Although there are regional and institutional variations, it is common to find international students on many U.S. higher educational campuses. In fact, the U.S. has been a primary destination for international students pursuing overseas studies since the post-WWII era. According to the Institute of International Education (2012), 764,495 international students were enrolled in US higher education institutions. This is a 6.7 percent increase from the previous year and makes up 3.7 percent of the total student population $(20,625,000)$ enrolled in U.S. higher education (Institute of International Education [IIE], 2012). Of those international students, 309,342 (6.1 percent increase from the previous year) are enrolled as undergraduates, 300,430 (1.3 percent increase) as graduates, and 69,566 (17.4 percent increase) as non-degree seeking (IIE, 2012). It is worthy to note that 228,467 students are international who are enrolled in the U.S. higher education for the first time, constituting 6.7 percent increase of this population (IIE, 2012), indicating the result of aggressive and strategic recruitment of this target population to US higher education.

In addition, Association of International Educators (NAFSA) (2012) suggests that, as a collective group, international students and their dependents contribute $\$ 21,807,000,000$ to the U.S. economy annually a critical point since their funding comes mostly from overseas and not from U.S. sources; personal and family resources, foreign government or university, current employer, foreign private sector, or international 
organizations (Zhai, 2004; Association of International Educators [NAFSA], 2012). This economic contribution to the U.S. society is not only from tuition $(\$ 15,812,000,000)$, but also from the living expenses, local services, and products international students and their dependents consume $(\$ 14,394,000,000)$ and has, in fact, helped create more jobs in the U.S. (Zhai, 2004; NAFSA, 2012). As noted earlier, American higher education has aggressively focused on recruiting international students (both graduate and undergraduate) and attracting visiting professors or postdoctoral scholars (both supported by their home nations). In all cases, host institutions benefit significantly from the amount of money they bring to campuses and the outlining campus communities, however, in addition to their economic contributions, international students bring diverse perspectives to campuses and help bolster some disciplines (such as in the STEM fields) in which the number of American students is declining (Zhai, 2004). As the movement towards internationalization confers financial, cultural and new approaches to academic work and the production of new knowledge, the pursuit of domestic diversity has hit an ideological and legal snag. Where the imprint of both federal and state legislative and judicial bodies was visible in efforts to address decades of structured disadvantages created by years of actual or defacto racial segregation, recent years have seen gains from the Civil Rights era questioned and reinterpreted.

\section{Problem}

Aside from the economic benefits, the increasing number of foreign students is viewed as a positive trend by most in U.S. higher education, as these students add to the cultural and linguistic diversity of American higher education, contributing to the 
internationalization of many campuses (NAFSA, 2011). Nevertheless, this trend is not a simple matter to be celebrated blindly, since merely having international students on university campuses does not mean the institutions are internationalized and or are delivering internationalized education (Handa, 2004).

The top ten places of origin for international students in the U.S. in the academic year 2011-12 were as follows: China, India, South Korea, Canada, Taiwan, Saudi Arabia, Japan, Vietnam, Mexico, and Turkey (IIE, 2012). Looking at this list, it is significant to note that the vast majority of international students are English-as-a-second-language speakers (ESL) who have grown up in cultural and educational systems that greatly differ from those in the U.S. Another surprising fact from the list is that Chinese international students make up $25.4 \%$ of all the international students, with their numbers increasing creased by $23.1 \%$ between 2011 and 2012 .

It should also be noted that a significant number of international students start their U.S. academic studies in ESL programs, improving their English and developing the skills necessary to comply with the academic rigor of higher education institutions in the U.S. (IIE, 2010). According to the Institute of International Education (IIE, 2011- b), 32,306 international students were enrolled in intensive English language programs in the U.S. in 2010 - 2011. This is approximately $4.5 \%$ of the total number of international students enrolled in U.S. higher education during that period, and in terms of ranking, it is listed as the $8^{\text {th }}$ most popular field of study among international students. Furthermore, it is worthy to note that inn the academic year $2009-10$, the number of international students studying in intensive English language programs increased by 24\% (IIE, 2011). 
The top ten leading countries of origin of ESL students in the United States in 2009 (IIE, 2010) were: South Korea, Saudi Arabia, China, Japan, Taiwan, Brazil, Turkey, Vietnam, Switzerland, and Libya; seven of these countries coincide with the top countries of origin of international students in the United States. Again, the majority of international students, including those in ESL programs, are from countries whose cultural and educational systems greatly differ from those in the U.S.

According to Ting-Toomey and Chung (2005), the U.S. is considered to be one of the most highly individualistic cultures. Individualistic cultures "value tendencies...emphasizing the importance of individual identity over group identity, individual rights over group rights, and individual needs over group needs. Individualism promotes self-efficiency, individual responsibility, and personal autonomy" (TingToomey \& Chung, 2005, p. 59). In contrast, most international and international ESL students are from collectivistic cultures whose values tend to emphasize "the importance of "we" identity over the "I" identity, group rights over individual rights, and in-group needs over individual wants and desires.” (Ting-Toomey, 2005, p. 60). Therefore, members with collectivistic cultural values focus on promoting "relational interdependence, in-group harmony, and in-group collaborative sprit" (Ting-Toomey \& Chung, 2005, p. 60).

To recapitulate, most international and international ESL students are English-asa-second-language speakers coming from cultures with collectivistic values. Since the U.S. individualistic cultural values and collectivistic cultural values are significantly different, this leads international students to encounter significant challenges in 
acclimating and adjusting to new academic and social lives once they arrive on campus (Lee \& Rice, 2007; Trice, 2007). Therefore, higher education institutions cannot simply increase the number of international students admitted and expect them to acclimate and adjust to the new system by themselves (Andrade, 2005). Given the popularity and increase in the numbers of ESL students enrolled in intensive English language programs in the U.S., one may assume that sufficient research on this population in the higher education field has been conducted. Unfortunately, such is not the case; in fact, surprisingly little research has been done dealing directly with students enrolled in intensive ESL programs on higher education campuses.

\section{Competition over International Students}

While the U.S. is still one of the preferred countries for international students pursuing higher education overseas, it is no longer the only choice. Other destinations such as Australia, Canada, the U.K. and New Zealand are becoming more popular. Moreover, it is not only English-speaking countries that are looking to bring in international students; but more and more countries in Europe and Asia have started recruitment of international students, expanding the competition for international students worldwide (Johnson, 2006; NACAC, 2010). In fact, even with the recent increases in the total number of international students enrolled in U.S. higher education, the growth rate of incoming international students here is being outpaced by other countries. Some researchers point out the reason the U.S. has lost its competitive edge in international student recruitment is the lack of policy and collaboration among governmental agencies at the federal level (NAFSA, 2011; NACAC, 2010). 
Specifically, it has been claimed that U.S. higher education is losing its competitive edge in the market of international students largely due to the tighter visa process and policies (Andrade, 2005). In discussions of recruitment and increasing enrollment of international students, the complexity and difficulty of the U.S. visa system is often blamed. Homeland Security, which controls both student visa rules and international student rules, is often believed to be the sole party affecting international students arriving on U.S. campuses. However, there are more players involved in determining national policy (or lack thereof) regarding the recruitment and welcoming of international students. The Commerce Department, the State Department, the Social Security Administration, and the Internal Revenue Service all have their own policies in relation to international students in the U.S., making the U.S. less competitive in the global competition for international student recruitment (Johnson, 2006). For example, one part of the Commerce Department has worked to appeal to international students through partnerships with higher education institutions at the state level, while at the same time, another section of the same department has proposed stricter regulations on international scholars and graduate students in terms of accessing technologies and laboratories (Johnson, 2006). In addition to intra-organizational policy discrepancies and politics, inter-organizational policy differences and politics affect prospective and current international students. Again, even though the Commerce Department has worked to appeal to international students through partnerships with higher education institutions at the state level, Homeland Security may not grant student visas for those prospective 
students, maintaining strict visa regulations regardless of the initiatives that the Commerce Department has taken (Johnson, 2006).

The State Department has begun an effort to eliminate negative impressions overseas regarding the U.S. visa system, and also made an effort to show that the U.S. welcomes international students. Meanwhile, the Social Security Administration has made their regulations stricter, making it more difficult for international students to obtain Social Security Numbers. Without Social Security Numbers, lives of international students become more difficult, as many service agencies - rental agents, for example require Social Security Numbers for their service contracts. Unfortunately, the Social Security Administration claims that the effects of its policy affecting international students are not their concern (Johnson, 2006). It is also interesting to note that the Internal Revenue Service made its regulations regarding the access of Tax Payer Identification Numbers stricter around the same time the Social Security Administration made it more difficult for international students to access social security numbers. In the past, Tax Payer Identification Numbers had been a viable alternative to social security numbers, enabling international students to function well in U.S. society. While these two organizations continue tightening policies that give access to their identification numbers, the State Department tries to welcome students, all of which sends a contradicting and conflicting message to international students: They are welcome, but they are not welcome (Johnson, 2006).

Various contradictory policies and politics among different organizations have affected efforts to recruit more international students to U.S. higher education. In fact, 
such policies and politics have prevented the U.S. from remaining as competitive as it used to be as the leading nation receiving international students world-wide. Whereas the U.S. struggles with its lack of a unified national policy and differing policies and politics among federal agencies in regard to international student recruitment, other countries have created national policies to target increasing international student enrollment, simplifying student visa and university application processes, and developing collaborations between higher education institutions and governmental agencies (Andrade, 2006).

Another important factor to retain its competitive edge is the importance to make international students feel welcome in the United States, as their satisfaction is related to U.S. foreign policy and creates international leadership (The American Institute of Physics, 2004; Johnson, 2006). International students, after returning home, will be a network for the U.S. in making future foreign policy if they return with positive experiences. In addition, international students stimulate the U.S. "knowledge economy" (Johnson, 2006, p.3), adding diversity, innovation, and creativity (Johnson, 2006). International students who complete degrees in the U.S. are also more apt to remain in favor of U.S. businesses and more likely to continue to buy and use U.S. merchandise and services, even after they return home (Andrade, 2005). Recognizing that international students contribute significantly to U.S. foreign policy, education, and economy, the lack of welcoming attitude could be harmful not only to international students, but to U.S. national security interests and the economy as well (American Institute of Physics, 2004; Johnson, 2006). 
In fact, there can be little doubt as to the importance of welcoming international students, not only for the future of U.S. national security and economic growth, but also for giving citizens the opportunity to become more competitive in the global economy through experiencing internationalization on campus. A strong national policy is necessary to make the U.S. the most competitive country in the world-wide competition of attracting international students. When federal agencies, states and institutions follow such a policy, the goal will be achieved. In such an environment, recognition of the needs of international education and accepting international students in their own states and on their campuses can also be achieved. Nevertheless, policy change alone is not the sole solution to make international students feel welcome while they are pursuing their educational goals in the U.S. It is crucial that we take a serious look at what needs to happen at each higher education campus when international students arrive.

\section{Welcoming Campuses Reconsidered}

Certainly varying policies from different federal agencies can affect the views of current and incoming international and international ESL students, jeopardizing the welcoming atmosphere for study abroad in the U.S. Aside from the U.S. governmental policies, however, U.S. higher education itself needs to reconsider just how welcoming it is. If one of the missions of higher education is to help students achieve their educational goals, then merely increasing the number of international students will not be sufficient (Andrade, 2005). The same thing can be said of international ESL students in higher education. The field of higher education should take greater pains to understand, 
appreciate, and make welcome this population of international ESL on campus, representing $4.5 \%$ of all international students.

Some may be of the opinion that this problem is not the responsibility of the institution, program, or the instructors, but the responsibility of the international ESL students themselves to realize and acquire the skills necessary to succeed in higher education, as they are the ones who have chosen to study in the U.S. This may have been the practice at many institutions when much lower numbers of international students were present at each college/university campus, and when campus communities - departments, student services offices, instructors, and administrators -were closer to those students and able to help them out. In fact, for those institutions that have traditionally had international students, new student orientations are in place to deal with international students' academic and social transitions, as well as culture shock. However, it is naïve to make such simple judgments on the issue, given the recent influx of international students. This should prompt us as institutions to revisit our system of dealing with international students. It would seem only logical to consider giving more care and attention to international students through orientations, as some universities have already done. Of course, simply explaining the different systems and the nuances of culture shock in an initial orientation may not be sufficient, given the recent influx of international students. These students need proper assistance in adjusting to their new lives, and to provide such assistance, a more thorough understanding of the issues that international students encounter is required (Andrade, 2005). 
In 2005, Andrade noted that "little interest in international student adjustment and success has been generated in higher education literature, considering the importance of these students to the United States" (Andrade, 2005, p. 103). Six years after her comment, there is more focus given to international students, revealing the needs and challenges of international students in English speaking countries. Literature has focused on the areas of challenge in socialenvironment, academic matters, psychological issues, and language issues, to name a few (Levy, Osborn, \& Plunkett, 2003; Handa, 2004; Hellesten \& Prescott, 2004; Trice, 2004; Andrade, 2005, Andrade, 2006; Turner, 2006; Christie, et al., 2006; Chrisitie, et al.,2008; Owens, 2011). Among these areas, the following themes are recurring:

1. Coping with stress derived from cultural differences in social expectations, such as making friends and understanding spoken language.

2. Coping with understanding differences in the new regional/institutional culture, and making necessary transitions.

3. Learning to appreciate differing concepts or expectations of what constitutes academic success.

4. Failing to understand expectations relating to depth and breadth of cognitive skills. Even though the amount of research focusing on international students in U.S. higher education has increased during the last decade, the majority of the literature focuses only on international students enrolled in undergraduate and/or graduate programs, as well as those students' places of origin, cultural perspectives, and 
expectations. Unfortunately, students enrolled in ESL programs are as of yet underrepresented in the literature.

It is not difficult to imagine that international ESL students face significant cultural, social, and academic challenges similar to the ones faced by international students that have already been documented in the literature. A lack of proficiency and confidence, and other challenges using English have often been found even among international students who have satisfied their English language requirements. Yet for international ESL students, who do not have sufficient language skills to participate in academic classes, the linguistic and other challenges can be even more magnified. The purpose of this research, therefore, is to discover the challenges and needs of international ESL students in the areas of cultural, social, and academic transitions as they embark upon higher education in the United States.

It is assumed that the factors that the literature has already identified as challenges for international students in general should also hold true for international ESL students, so the four areas identified above will be considered a starting place for investigating international ESL students' challenges in transition.

Furthermore, these factors appear to overlap and affect each other, creating complex problems for international ESL students to deal with. For example, students who are unacquainted with study skills and expectations in the U.S. may be tempted to continue studying in ways that they are familiar with, resulting in lower academic success as measured by GPA or test grades. This, in turn, can lead to stress and/or have a negative 
effect on initiating and sustaining social relationships, which may then lead to a personal/social identity crisis.

Currently, many international students who have met all the admission requirements except English language proficiency are admitted to institutions with ESL program restrictions. These students need to take institutional ESL courses until they meet the English requirement set by the institutions. Therefore, as the recruitment of international students intensifies, the number of students entering ESL programs here increases. As these overall numbers grow, the problems of the international ESL students identified above could grow dramatically as well. Thus, it is crucial that research in higher education focus not only on international students in university programs, but also on international ESL students in higher education.

\section{Purpose of the Study and Significance}

This research investigated the challenges that international ESL students face as they begin their program. In particular, it looked at challenges in cultural, social, and academic transitions into U.S. higher education in an intensive English language program at a large research university in the Midwest, especially focusing on Chinese international ESL students, as they make up the overwhelming majority of students in the program. By investigating the challenges faced by international Chinese ESL students, this research aimed to discover the needs of this particular audience and to suggest the best ways to serve and support incoming international Chinese ESL students, helping them acclimate to U.S. academic life as smoothly as possible. 


\section{Research Question}

In order to fulfill the purpose of this study - identifying the challenges that international Chinese ESL students face, their felt needs, and the ways to best serve and support the future international ESL students - the following research question was formed:

What are the social, cultural, and academic factors that positively and negatively affect international students' transition into U.S. higher education?

\section{Definitions of the terms}

\section{$\underline{\text { Collectivism }}$}

Collectivism is a cultural view that emphasizes group harmony, saving face, respecting parents' wishes, and satisfying needs of others (Ting-Toomey, 2005).

\section{$\underline{\text { ESL }}$}

ESL refers to English as a second language, and ESL programs are the institutions that offer classes for ESL students, whose native language is not English. ESL programs include the ones affiliated with universities and colleges and private institutions. $\underline{\text { IELTS }}$

IELTS refers to International English Language System which is managed by University of Cambridge ESOL Examinations, the British Council, and IDP Education. IELTS is one of the international English proficiency tests whose scores can be used as a proof of English proficiency for international admissions. 
$\underline{\text { Individualism }}$

Individualism is a cultural pattern focusing on "freedom, honesty, social recognition, comfort, hedonism, and personal equity" (Ting-Toomey, 2005, p.62). $\underline{\text { International ESL Students }}$

I define international ESL students as international students studying ESL in the U.S. with a student visa issued by U.S. Homeland Security. They are enrolled in full-time ESL classes as the requirement of their visa status. They can be language program only students, whose purpose is to learn English, or students who are provisionally admitted to a university but have not yet demonstrated sufficient proficiency in English, and are therefore taking ESL courses.

$\underline{\text { Provisionally Admitted International Students }}$

Provisionally admitted international students refer to those international students who have met all the admissions criteria except for English language proficiency. They are restricted to ESL programs only until they show sufficient proficiency in English by completing ESL programs at the institution where they have been admitted, or by providing official standardized test scores, such as TOEFL or IELTS.

\section{$\underline{\text { TOEFL }}$}

TOEFL refers to Test of English as a foreign language, which is an English proficiency test provided by Educational Testing Services (ETS). TOEFL is widely used in U.S. universities as a measurement of international applicants' English proficiency, indicating sufficient ability to participate fully in academic courses in the U.S. 


\section{Outline of the Dissertation}

Chapter 1 introduced current facts regarding international and international ESL students in the U.S., contradicting U.S. policies and their effect on American competitiveness in international student recruitment, the issue of creating welcoming campuses, and other recurring issues that have been observed in recent literature on international students. In chapter 2, the relevant literature on cultural, social, and academic transitions faced by both international students and minority students in U.S. higher education is reviewed, as both groups encounter more challenges transitioning into academic life compared with traditional students.

Chapter 3 discusses research questions derived from the literature review, as well as research design, including the methodology of the research, audience, research site, and data analyses.

Chapter 4 introduces the results from open code analysis - the individual themes that arose repeatedly from the data - and discussion of those results.

Chapter 5 discusses results from axial and selective code analysis - the combination of individual data into categories and subcategories by similar properties and dimensions in order to present the themes that represent bigger pictures of the participants' experience as part of a group of Chinese ESL students.

Finally, in Chapter 6, suggestions for disseminating results into practices are presented, along with limitations and implications for future research. 


\section{CHAPTER 2}

\section{LITERATURE REVIEW}

\section{Introduction}

When new students - both domestic and international - arrive at the phase of life known as higher education, the first challenge they face is culture/entry shock. According to Robertson (1988), transitions are experienced in stages. The first stage is resistance, born of the fear of not knowing what will happen next. In the second stage, we grieve what is lost from our previous selves. The third stage is characterized by courage, when we start to explore the "new world" (Robertson, 1988, p. 59). All of these stages of transition are necessary for growth, and having knowledge about the transition process empowers us, giving us the reassurance that what we are experiencing is not unique everybody in transition goes through these stages - and enlightening us about what to expect in the following stage (Robertson, 1988).

Terenzini, et al. (1993) discuss the challenges of students transitioning into higher education as follows:

The transition from high school or work to college is an exceedingly complex phenomenon. The nature and dynamics of the process vary according to the students' social, family, and educational background; personality; educational and occupational orientations and aspirations; the nature and mission of the institutions being attended; the kinds of peers, faculty, and staff members encountered; the purpose and nature of those encounters; and the interactions of all these variables. The process is a 
highly interrelated, web-like series of family, interpersonal, academic, and organizational pulls and pushes that shape student learning and persistence. (Terenzini, et. al., 1993, p.61)

While the transition into higher education involves complex issues for many incoming students, first-generation college students have greater challenges in doing so compared to traditional students (Terenzini, et al., 1993). While transitioning into college is "a continuation of their academic and social experiences in high school" (Engle, 2007, p. 33) for traditional students, transitioning into college for first-generation college students is "disjunction" (Engle, 2007, p. 33) from their previous experiences. For these, first-generation students, transition often requires learning and adapting to new academic and social systems upon arrival on college (Terenzini, et al., 1993, Engle, 2007). Their challenges lie in the fact that these new academic and social systems are not part of their family and cultural traditions. Thus, adapting to new academic and social systems requires them to break away from their old traditions and cultural norms. First-generation students may go through severe crises in navigating the cultural, social, and academic separation from their old selves, putting those students at a higher risk of academic failure (Terenzini, et al., 1993, Engle, 2007).

Having observed the difficulties that first-generation domestic students encounter in their transition to higher education, it is not difficult to imagine how challenging it can be for international students to make the transition to U.S. higher education from their home countries. If first generation students find it challenging to separate themselves from their family and cultural traditions in order to make successful academic transitions, 
then international students must expect to go through similarly difficult - if not more intense - transition processes. This transition can be more complex than it initially appears, with its various cultural, social, and academic aspects. Each of these areas presents significant challenges to international students as they pursue higher education in the United States. In an attempt to understand these challenges, this chapter reviews discussions from the existing literature on the social and cultural factors influencing successful transitions into U.S. higher education. The overall order of discussion is as follows:

1. Challenges in social and cultural transitions

a. Individualistic and collectivistic cultures

b. Power distance value pattern

c. Uncertainty avoidance

d. Self-analysis: independent vs. interdependent construals

e. Loneliness, linguistic challenges, social networks, and help-seeking strategies

f. Understanding the new regional/institutional culture, coping with differences, and embracing change

g. Psychological well-being and managing stress

2. Academic transitions and academic culture shock

a. Pedagogical differences and academic expectations

b. Self-efficacy

c. Being a minority 


\section{d. Language proficiency}

3. Asian learning styles and individual motivations

4. Knowledge of U.S. higher education and student academic success

5. Dominant perspectives

6. Social capital

7. Conclusion

\section{Challenges in Social and Cultural Transitions}

As noted in the introduction, almost all of the top ten countries of origin for both international regular and ESL students in the U.S. during the 2011-12 academic year were countries which do not share the same cultural practices or language as the U.S. (IIE, 2012). Trice (2007) has noted that while the leading nations that receive international students - Australia, Canada, Great Britain, and the U.S. - are the most individualistic cultures, a majority of international students heading to those countries come from collectivist cultures.

\section{$\underline{\text { Individual and Collectivistic Cultures }}$}

Individualism appears as a cultural pattern in "most northern and western regions of Europe and in North America" (Ting-Toomey \& Chung, 2005, p.61). The U.S. is one of the countries with a high level of individualism focusing strongly on "freedom, honesty, social recognition, comfort, hedonism, and personal equity" (Ting-Toomey \& Chung, 2005, p.62). In contrast, more than two thirds of the world's cultures are collectivistic, emphasizing "harmony, face-saving, filial piety (respecting parents' 
wishes), equality in the distribution of rewards among peers (for the sake of group harmony), and fulfillment of others' needs) (Ting-Toomey \& Chung, 2005, p.612).

\section{$\underline{\text { Power Distance Value Pattern }}$}

Power distance value is how individuals perceive power equality or inequality within relationships through personal interaction, within an institution, or within a society (Ting-Toomey, 2005, p.63). Individualistic cultures are small power distance cultures, in which children can speak their own ideas to their parents, and both parents and children make familial decisions democratically. Children are also encouraged to make decisions on their own and learn how to express themselves and persuade others with their ideas and decisions verbally and articulately. In work situations, power equality is expected and "subordinates expect to be consulted, and the ideal boss is a resourceful democrat" (TingToomey, 1999, p.70). In contrast, collectivistic cultures are large power distance cultures in which children are expected to obey their parents, as they possess the authority in the family. In family decision making, parents have the power to make decisions as authority. At work, a boss tells subordinates what to do; a domineering boss is ideal (Ting-Toomey, 1999).

\section{Uncertainty Avoidance}

Ting-Toomey (1999) defines uncertainty avoidance as how the members of a culture react to uncertainty and unknown situations and how much they try to avoid such situations. Collectivistic cultures are strong uncertainty avoidance cultures. Therefore, members of collectivistic cultures feel threatened by and tend to avoid uncertain situations much more than weak avoidance cultures, which individualistic cultures tend to 
be. In weak avoidance cultures, people do not mind taking risks or engaging conflicts; they show more tolerance for ambiguity and encourage innovation and innovative behaviors. In strong avoidance cultures, on the other hand, people prefer clear rules and guidelines but are more suspect of innovative ideas. Conflicts are avoided whenever possible, and there is low tolerance for ambiguity (Ting-Toomey, 1999; Ting-Toomey \& Chung, 2005).

\section{$\underline{\text { Self-Analysis: Independent vs. Interdependent }}$}

How people view themselves is a fundamental distinction between individualistic and collectivistic cultures (Ting-Toomey, 1999). In different cultures with different value orientations, people see themselves as separate from or connected to the society, which determines "independent self-construal or interdependent self-construal" (Ting-Toomey \& Chung, 2005, p. 77). Members of individualistic cultures have independent selfconstrual, viewing themselves separate from others and the situations. "They use their own abilities, characteristics, and ideas as motivational abases rather than thoughts and feelings of others" (Ting-Toomey \& Chung, 2005, p. 77). People with high independent self-construal place high value on and thrive in achieving their own goals, maintaining self-direction and control of their situations, competing against the others, and being assertive in expressing their needs (Ting-Toomey, 1999; Ting-Toomey \& Chung, 2005). Members of collectivistic cultures have interdependent self-construal, which place a high value on fitting in with others, interacting with others in an appropriate manner, conforming to the values of others, maintaining relational connections and harmony, 
avoiding direct conflicts, and interacting in a discreet, thoughtful manner (Ting-Toomey, 1999; Ting-Toomey \& Chung, 2005).

Loneliness, Linguistic Challenges, Social Networks, and Help-Seeking Strategies

Trice (2007) argues that due to cultural differences and differences in expectations between individualistic and collectivistic cultures, international students face multiple challenges in managing their social lives on campus. Previous literature has summarized that the major challenges lie in the following areas: (1) loneliness, social networks, and help-seeking strategies, (2) linguistic challenges, (3) coping with cultural differences, understanding the new regional/institutional culture, and making transitions, and (4) psychological stress.

First of all, social and cultural factors have a strong impact on international students' experiences in higher education, from their initial arrival on campus to their decision on whether or not to persist in their studies (Lee \& Rice, 2007). Learning and performing basic social procedures, such as finding a place to live, are challenging tasks for some international students (Lee \& Rice, 2007). While appearing to stem from a lack of second language fluency or cultural differences, these challenges performing basic social tasks can actually be due to a lack of formal and casual social networks in their new environment. This can produce stress among international students, as they are used to being able to perform these basic tasks in their home countries (Lee \& Rice, 2007; Trice, 2007). In fact, Rajapaksa and Dunes (2002) have observed that international students are more prone to loneliness and homesickness than their domestic peers. 
Trice (2007) has also identified limited connections with domestic students and community members as a source of loneliness, stress, and depression among international students. Due to cultural differences, academic demands, lack of English proficiency, and differences in views and/or expectations about friendship (Trice, 2007), international students are typically isolated from domestic students. Instead, they tend to be alone, together with their co-nationals, or with other international students who share similar cultural values (Trice, 2007).

These challenges do not occur in isolation but build on one another, creating a vicious cycle. A lack of domestic friends can result in an inability to accomplish basic social tasks, leading to stress and loneliness, which then in turn might lead international students to isolate themselves from their classmates; and so it goes.

Lee and Rice (2007) further suggest that international students find it uncomfortable to take advantage of university support systems when they are faced with problems. The general differences in language and culture, along with the specific challenges they encounter, create high levels of stress for international students in negotiating their academic and social lives with domestic students and staff members on campuses (Trice, 2007). Their discomfort is a direct result of the loneliness and isolation they experience due to the factors listed above (Lee and Rice, 2007). International students often feel that student services on campus - whether admissions, registration, residence life, or dining, among others - are ill-equipped to deal with international students' needs, underestimating their greater need for assistance relative to domestic students (Lee \& Rice, 2007). Facing all of these challenges, international students can 
isolate themselves from the wider campus community as a result of feeling they are unwelcome (Lee \& Rice, 2007; Trice, 2007). Consequently, more international students prefer to create social networks among their own nationalities as they network among themselves. Unfortunately, this preference of social networking with co-nationals can be misunderstood by domestic peers and institutions as a lack of interest in integrating and becoming involved on campus, creating further separation between domestic and international student groups (Trice, 2007).

In regard to international students' help-seeking strategies, Zhai (2004) reports similar findings concerning international students' use of student services to those discussed by Lee and Rice (2007), and Trice (2007). When internationals needed help, they only infrequently sought it from student services; instead, they kept the problems to themselves or used friends and family members as resources. They saw student services as lacking in knowledge of international students' problems (Zhai, 2004). In addition, Zhai's (2004) study revealed that "family or friends were the most preferred source of help, and international students were connected with their fellow international students or other international students, and felt very comfortable to share personal concerns with this extended family" (Zhai, 2004, p. 100). This help-seeking strategy is employed not only for tracking down information, but for finding emotional help as well. Zhai's (2004) study showed that international students chose to share their psychological and emotional problems with friends and family members as well, instead of using student services. Shared language and culture are common reasons a majority of international students seek out friends and family members as help sources (Zhai, 2004). In the case of co- 
national students, similar adjustment issues were mentioned as the most important qualification for them to provide the best advice (Zhai, 2004).

Understanding the New Regional/Institutional Culture, Coping with Differences, and Embracing Change

Coping with a new culture and environment is another one of the challenges that must be faced by international students in transition. In Gu and Schweisfurth's (2006) study of Chinese students in the U.K., students identified adjustment to a new diet as a significant challenge. Although they preferred Chinese food, "no real Chinese food was available" (Gu and Schweisfurth, 2006, p.82). In the same research, participants expressed anxiety concerning differing lifestyles, learning styles, and communication styles. Gu and Schweisfurth s (2006) explained that for international students to survive and improve themselves in the U.K. universities, language competency and subject knowledge alone are inadequate.

Another relevant insight from Gu and Schweisfurth (2006) is that Chinese international students who were born under the One-Child Policy in China had grown up under the "intensive care of six adults - four grandparents and parents" (Gu and Schweisfurth, 2006, p.85). As a result, Gu and Schweisfurth (2006) observed that these students lacked competencies to perform such basic tasks as cooking and taking care of themselves. In the end of the research, the students felt more proud of their new ability to cook for themselves and to manage their own lives than they did of their academic achievement (Gu and Schweisfurth, 2006). Although the One-Child Policy was only applicable to Chinese students from a certain era, the idea that international students may 
have been affected by the intensive care they received should not be so easily dismissed. Japanese young adults, for example, also stay home and under the care of parents until they get married. If students grow up under the intensive care of family, transitioning to the relatively independent life of an international student can be very challenging.

\section{Psychological Well-being and Managing Stress}

Certainly, international students' psychological well-being during their transition to U.S. higher education is of great importance. International students are susceptible to stress which "occurs when individuals perceive that they are to encounter harm, a threat, or a challenge that may exceed their resources" (Chen, 1999, p.49). Changes, linguistic challenges, lack of familiarity to the host culture, and difficulties or failure adjusting to a new environment could cause enough stress to be harmful or threatening to international students and their identities during this transitional period (Chen, 1999). Due to such stressful transitions, international students may experience anxiety and/or severe psychological challenges.

The aforementioned social and cultural challenges which international students face in transitioning and acclimating to campus life can be significantly difficult. Due to different cultural and linguistic practices and expectations, the vast majority of international students go through some experience of culture shock, including feelings of isolation, loneliness, or even depression. These challenges should not be ignored or seen as unimportant. Nor should it be assumed that international students will eventually understand the differences between two cultural orientations and acclimate into the new one. Rather, the challenges should be seen as crucial issues and signs that are related to 
international students' academic and social success and welfare in higher education. If institutions, staff members, and faculty are not ready to reach out and help international students meet the challenges, these students may not make a successful transition to U.S. higher education. This may ultimately lead to "departure from college," resulting in lower retention rates on campuses (Tinto, 1993), as their initial experience after arriving on campus and their transition can certainly contribute to a later decision on whether or not to persist in their studies (Lee \& Rice, 2007).

\section{Academic Transitions and Academic Culture Shock}

International students may be under the impression that they need to transition only socially and culturally upon their arrival to campus. To navigate these social and cultural transitions, they must acquire a unique set of ideas and skills, different from their own culture and society. These are not the only transitions that international students must make, however; they must undergo an academic transition as well. In other words, they must learn and adjust to American academic culture (Robinson, 1992). Li, Chen \& Danmu (2010) define academic transition and culture shock as follows:

Academic culture shock is a subset of culture shock and a case of incongruent schemata about higher education in the students' home country and in the host country. Academic culture shock is directly associated with the learning environment of an academic institution, including the education system, lecture style, assessment, relationship between students and lecturers, and so on. International students from Asian countries whose only study experience has been with their home 
countries' educational systems, may feel significant difference when they start their studies at a Western university (p. 394).

As in cultural and social transitions, the success or failure of academic transition is a crucial matter because it is directly related to whether students persevere in their pursuit of higher education (Lee \& Rice, 2007). In the course of transitioning into this new academic culture, international students may encounter "academic culture shock," which is:

...directly associated with the learning environment of an academic institution, including the educational system, lecture style, assessment, relationship between students and lecturers, and so on. International students from Asian countries whose only study experience has been with their home countries' educational systems, may feel significant difference when they start their studies at a Western university. (Li, Chen, \& Danmu, 2009, p.394)

Other literature supports this concept of academic culture shock experienced by international students in higher education. The recurring themes related to the academic challenges faced by international students outlined in the literature include the following: pedagogical differences, academic expectations, learning strategies, self-efficacy, feelings of being a minority, and language proficiency.

\section{$\underline{\text { Pedagogical Differences and Academic Expectations }}$}

Often, coming from a collectivistic background, Asian international students, especially Chinese students, are considered to be more accustomed to and comfortable 
with the lecture method of instruction. They consider teachers as authorities, and therefore knowledge is passed on from teachers to students. In contrast, in individualistic cultures the prevailing view of learning is that teachers and students interact to coconstruct knowledge (Biggs, 1993; Zhai, 2004; De Vita, 2007). In addition, Asian international students are seen as lacking critical thinking skills, preferring to avoid group discussions, not willing to talk during the class, and therefore, passive learners (Biggs, 1993; Zhai, 2004; De Vita, 2007). Similarly, Levy, Osborn, \& Plankett (2003), discussed the cultural differences between Australian academics and international students in regards to what constitutes learning in higher education in Australia, where domestic students and academics place much more importance on facilitating students' learning capacities, focusing on the process by which individual students construct knowledge. In contrast, international students place a higher value on the transmission of knowledge from authorities - that is, professors and instructors - as "knowledge has been considered sacred and learning is controlled, objective, and efficient (Cranton, 1996 cited in Levy, Osborn, \& Plankett 2003, p.3).

Consequently, international students rely heavily on rote memorization; they see themselves as receptacles of transmitted knowledge, and knowledge as a final product, acquired from authority figures. This differing approach means these students have a significant mismatch in learning styles and may not be so successful in academic cultures that require active participation and engagement to construct knowledge through the process of learning. Ultimately, these international students will face challenges not only because their learning strategies are different from locally expected ones, but also 
because their preferred strategies are considered to be lower and inappropriate of order metacognitive skills in host countries.

These preferred pedagogical practices and academic expectations can cause significant challenges for Chinese students upon starting their overseas studies as they "create a mismatch of expectations and misunderstandings that lead to frustration among students and teachers alike (De Vita, 2007, p.157). In other words, Asian international students face significant challenges when they encounter academic expectations in direct contrast to those prevalent in their own society, including participation in the classroom, critical thinking skills, informality in class, and requirements related to attendance, academic honesty, and independent learning (Andrade, 2005).

Turner (2006) has described some of the significant academic challenges that Chinese international students faced in the U.K., the first being the pedagogical differences between the U.K. and China. In her study, Chinese students were passive and struggled to satisfy the conventional expectations of the U.K. higher education system (Turner, 2006). One of the salient examples of Turner's (2006) study is Chinese students' perceptions about writing. According to Turner (2006), English writing in China requires a focus on grammar and vocabulary. Therefore, Turner's (2006) Chinese participants held the view that successful writing consists of good grammar and vocabulary, but not necessarily content. These students found that they were not successful in writing after starting their studies in the U.K., since they did not follow U.K. pedagogical conventions - supporting their topics and ideas, and using a sufficient number of sources. 
Similar accounts were made by Zhai (2004) among international students in U.S. higher education. These students found different teaching methodologies, speed of classes, teacher-student interactions, tasks employed in classes, reading and writing assignments, and study requirements to be challenging. In Andrade's (2006) study, international students found "approaching teachers" (p. 112) challenging, as it was not part of their previous academic cultural expectation.

Pedagogical differences have an effect not only on teaching and learning, but also on assessment. Brown and Joughin (2007) discussed assessment and academic culture specifically, the problems that arise in the assessment of international students. When the assessment is conducted, both international students and faculty members are surprised; for the faculty members, the way international students react to and/or respond in assessment is often seen as unexpected or simply inappropriate according to local norms. Meanwhile, international students may find assessment tools to be difficult, embarrassing, and/or impossible to understand based on their own cultural backgrounds (Brown \& Joughin, 2007).

\section{Self-Efficacy}

The existing literature shows international students studying overseas found the strategies required for studying and assessment in the host countries to be difficult. As discussed previously, many international students are accustomed to rote memorization and demonstration of memorized knowledge on tests (Andrade, 2006). However, outside their own academic contexts, especially in individualistic cultures, international students are required to shift their strategies to adapt to various different learning and assessment 
strategies, such as exchanging opinions, giving presentations, conducting group studies, and writing papers (Andrade, 2006). This mandatory shift between different learning strategies and styles can result in confusion and self-doubt among international students.

Levy, Osborn, \& Plankett (2003) uphold self-efficacy as another academic cultural challenge that international students face. Self-efficacy is "the belief in one's capability to succeed in a particular situation or endeavor and so concentrates on perceptions rather than actual performance" (Levy, Osborn, \& Plankett, 2003, p.4). In transitioning to a new academic environment, international students' self-efficacy and security may be threatened, as their lack of familiarity with the new setting can cause academic challenges. Andrade (2005) makes similar observations in her study of international students; in her study, the students reported feeling insecure about themselves, their academic abilities, and their English proficiency. Levy, Osborn, \& Plankett (2003) also contend that students who have more self-efficacy about their academic performance and capabilities tend to use more cognitive and metacognitive strategies and persist longer than those who do not. International students deal with academic, social, and cultural factors in their new environment, and thus risk a lack of self-efficacy, socially and academically.

\section{Being a Minority for the First Time}

It has been shown that a lack of self-efficacy can add challenges to the transition and academic performance of international students. Nevertheless, this is not the only factor adding to their issues of self-doubt. International students, upon arrival on their host countries, may also be transitioning from majority to minority status for the first 
time in their lives - another significant challenge. In Andrade's (2006) study, some students mentioned that they felt inferior in front of American instructors, lacked a sense of belonging, and felt uncomfortable with other students due to this new sense of being a minority (Andrade, 2006). Of course, in the case of international ESL students, there are only international students in the classroom, so ESL students may not have the feelings of insecurity that minorities often experience. Their instructors, however, are predominantly from the host countries, and as such, are the members of the community at large. As a result, some of the feelings of discomfort or lack of belonging may be still present among international ESL students, just as they are among the international students in Andrade's (2006) study.

\section{Language Proficiency}

According to the existing literature, academic challenges that international students frequently face include: differences in pedagogy, expectations, and learning strategies styles; self-doubt caused by these differences; and finally, insecurity due to being a minority in their host countries. In addition to all these academic challenges, almost all the literature states that international students, regardless of their levels of academic study or proficiency of English, consider language as one of the ongoing challenges in both their academic and social lives. The challenges associated with language cover a wide range, including colloquial uses of spoken language in lectures and classrooms, the amount of reading and writing in assignments to be completed in English, a lack of confidence in both spoken and written English competencies, and difficulties in making themselves understood in English by their professors and 
classmates (Handa, 2004; Andrade, 2006). In Handa’s (2004) research, international students felt they were not free to participate actively due to language and cultural constraints even when they understood Australian academic expectations. In addition, due to lack of language competency and self-efficacy in English, some international students sat and worked together with their co-nationals. Unfortunately, instructors often characterized this action as one of "the most unproductive behaviors" (Andrade, 2006, p.137), causing lack of participation. Other issues related to English competency are instructors and/or tutors' use of expressions and references which are common among the local community members, or the domination of discussions by certain students who did not leave any openings for international students to participate (Handa, 2004).

\section{Asian Learning Styles and Individual Motivations}

Earlier in the academic challenges section of this paper, it was noted that many international students from collectivistic cultures prefer rote memorization as one of their main learning strategies. Given the growing number of Chinese students in ESL programs and universities in the U.S., it is not surprising to find that a preferred learning strategy of a majority of students is rote memorization, regardless of whether it fits course expectations or not. Among instructors in ESL programs where Chinese students significantly outnumber other nationalities, this can be an especially great concern.

Nevertheless, some researchers note that there are varieties even within collectivistic cultures in regard to views of classroom pedagogy and learning strategies. Thus, generalizing about Asian (or collectivistic) culture as one group demonstrating a 
single characteristic can be misleading and dangerous (Hellsten and Prescott, 2004; Gan, Humphreys, \& Hamp-Lyons, 2004; Brown, Gray, \& Ferrara 2005; Gan, 2009).

Gan (2009) researched Chinese university students learning English from mainland China and Hong Kong in regard to their learning strategies. Although both groups indicated rote memorization as their most utilized skill, the Hong Kong group used other strategies in their English learning, such as applying memorized vocabulary to conversation, listening, and reading. The mainland Chinese group, on the other hand, stayed more with rote memorization and tended not to use the memorized vocabulary further in their English learning. Gan (2009) explains the difference between these two groups of the same culture as due to the fact that mainland Chinese students are accustomed to studying English for tests only. In addition, they are used to being in English classes with a large number of students and a lack of resources. Moreover, mainland Chinese teachers emphasized individual effort to pass exams and receive good grades. As a consequence, mainland Chinese students are more likely to consider English classes as ineffective, and as a result, choose to study English outside the classroom using rote memorization (Gan, 2009). In contrast, Hong Kong students had both extrinsic and intrinsic motivations, as Hong Kong is a metropolitan city with many more opportunities to use English. Therefore, Hong Kong students saw the need to learn and improve their English while taking English courses (Gang, 2009). In contrast, the mainland Chinese student group had only extrinsic motivation to learn English; not having the same context as Hong Kong students, English became simply another mandatory test subject requiring 
a passing score on a national exam. Apart from any intrinsic motivation to learn, they did not need to develop learning strategies other than rote memorization. (Gan, 2009).

Gan, Hamphreys, \& Hamp-Lyons (2004) reported on research regarding students in two universities in mainland China, identifying successful and unsuccessful English language learners. In this research, they found that both successful and unsuccessful students used rote memorization as their learning strategies. The successful students, however, used strategic planning to apply memorized vocabulary and knowledge to other English skills, such as reading or speaking, while unsuccessful students did not do any strategic planning, which resulted in forgetting what they had memorized (Gan, Hamphreys, \& Hamp-Lyons, 2004). In addition, successful students applied selfevaluation skills to their learning. Meanwhile, unsuccessful students, who lacked clear objectives, goals and strategy settings, and had no idea how to improve their English, eventually lost interest in studying English (Gan, Hamphreys, \& Hamp-Ylons, 2004). Comparing the two Chinese groups, Gan, Hamphreys, \& Hamp-Lyons (2004) explain that successful students had both extrinsic and intrinsic motivation to succeed while unsuccessful students had only extrinsic motivation, as English was a compulsory subject. Unsuccessful students also tended to blame others for their problems and demonstrated lack of adjustment to university English courses (Gan, Hamphreys, \& Hamp-Lyons, 2004).

Brown, Gray, and Ferrara's (2005) study shows a good example of variation amongst collectivistic cultures. They investigated three different collectivistic cultural groups - Japanese, Chinese, and Turkish - to find out what they attribute their success 
and failure to. They report that while all the three groups identified effort as a key to success, the Japanese were the only group that also named luck as well. The Japanese, unlike the other two groups, also included their own efforts as a factor in failure. This can be related to the Japanese cultural tendency to indulge in self-blame, where failure comes because of a lack of effort, not because of outside factors (Brown, Gray, \&Ferrara, 2005). Interestingly, the Chinese and Turks, who also come from collectivistic cultures, did not identify their lack of effort as a cause of failure. These two groups attributed their failures to external factors (Brown, Gray, \&Ferrara, 2005).

Gu \& Schweisfurth (2006) present similar findings among Chinese international students in the U.K. Looking beyond the characteristics of Chinese learners in general, they found that "...the backgrounds and goals of the learners, their specific motivation for learning, the setting for the interaction, and the nature of the relationship between teachers and learners, are also influential" (Gu \& Schweisfurth, 2006, p.75). Regarding the question of who was able to adapt to the challenges of studying in the U.K. and who was not, they found that determination to learn, willingness to change, and feeling of enjoyment in their change were key to adaptation among Chinese students, regardless of the academic struggles they faced in British academe (Gu \& Schweisfurth, 2006). Gu \& Schweisfurth (2006) also suggest that international students will grow and adapt to their new environment if they have opportunities for critical self-reflection and self-awareness, even though their home and host cultures differ.

Li, Chen, \& Danmu (2010) described characteristics of students from collectivistic cultures, especially Chinese international students. These students 
emphasize effort, endurance, and hard work; they believe their performance is a result of their effort more than of their ability. Chinese international students are likely to struggle with the Western educational environment, characterized by "independent learning and less instructor supervision and guidance" (Li, Chen \& Danmu, p.393). They also portrayed Chinese students as likely to be inactive in class, noting that they "tend to be less keen to participate in group discussions or debate in class and do not like to raise or answer questions (Li, Chen \& Danmu, 2010, p. 393). Their research regarding potential differences between Chinese and other international student groups enrolled in an MS School of Management at a university in England confirmed the fact that "Chinese students were less likely to adopt an active learning strategy and were involved in less social interaction with students from other countries."

It is often believed that East Asian students from collectivistic and Confucian cultures are passive rote learners whose unproductive methods stand in direct contrast to individualistic cultures such as the U.S. and the U.K. (Kingston and Forland, 2004; Tan, 2010). Researchers, however, have questioned this assumption, characterizing the overgeneralization of Asian rote-learning styles as narrow-minded and unproductive. Indeed, the research has found that East Asian students' preferred learning strategy - rote memorization - involves "deep learning" (Kingston and Forland, 2004, p. 7). In addition, their research has found that East Asian students value autonomy and freely express their opinions - characteristics which are in direct opposition to the traditional stereotypes of Asian learners (Kingston and Forland, 2004). 
Gan (2009) raises another question in regard to a concept established in the existing literature - namely, that Asian students from collectivistic cultures always see teachers as authorities. Gan's (2009) research concludes that mainland Chinese students may see English classes as ineffective, and thus, study English independently after class. Gan, Hamphreys, \& Hamp-Lyons (2004) described how some unsuccessful students saw their teachers' pedagogical styles as boring. In Hellsten and Prescott's (2004) research, younger international students indicated that they expected their instructors to provide more "need for care and emotional support, and in a familiar sense tantamount to socalled 'parenting' (p.347) even though they are from collectivistic cultures, where teachers are seen as authorities. The students in Hellsten and Prescott's (2004) research found that faculty in Australia were not reaching out to address the needs of international students, leaving them feel abandoned.

The above literature exposes the dangers of generalizing about Asian students as single category, and thus, exhibiting a single characteristic. Gan (2009) argues that “institutional contexts and social environments rather than cultural traditions tend to determine students' attitudes toward and strategies in learning English, and the cultural stereotypes of Asian students as rote learners, being prone to teacher authority and having a strong inclination for group learning have been overgeneralized" (Gan 2009, p. 53).

The sections above have discussed examples of the challenges faced by international students. On the surface, these challenges may seem like a simple matter of learning a new academic culture and its rules. Academic culture shock, however, can be different from one student to another. Even within national groups, there can be varying 
degrees of challenge and academic culture shock. Some students are more successful in regard to transitions than others. The real issue is the fact that expectations and conventions are often unstated; thus, it is difficult for international students to figure them out and behave accordingly, consequently resulting in difficulties in achieving successful academic performance (Christie, et al., 2006; 2008).

\section{Knowledge of U.S. Higher Education and Student Academic Success}

Certainly, institutions want not only to recruit new international students, but also to retain them, both for the purpose of diversification and for the financial benefits they contribute. Knowing the possible challenges these students encounter on campus while transitioning into U.S. social and academic life, as well as the risks of early departure resulting from such challenges, universities will be better able to consider how campuses can foster international students' smooth transition to ensure their academic success. Equally important is the fact that many international students may not realize the degree to which social and cultural transitions can adversely affect their academic performance, and thus slight their significance. This section, therefore, reviews discussions of social and cultural factors that lead to students' academic success in transition to higher education.

Previous research suggests that one of the key elements in facilitating students' academic success is to encourage their social and academic integration and involvement. Tinto (1993) has suggested that although all new students pass through the different stages of integration - separation, transition, and incorporation - certain types of students face more challenges in this process than others. 
Upon arrival at a higher education institution, students begin to separate themselves from their previous habits and associations from their high school and local communities; this is the first stage of integration - separation (Robertson, 1988; Tinto, 1993). During the second stage - transition - college students start to "acquire the norms and patterns of behavior appropriate to integration in the new communities of the college" and "establish the personal bonds which underline community membership" (Tinto, 1988, p. 444). In the final stage - incorporation - students continue to adjust and start to establish membership in the social and academic college community, with newly acquired norms and behaviors appropriate to colleges.

However, Tinto (1988) warns that the pains and challenges involved in the process of social and academic integration into colleges varies according to students' backgrounds. If a student is from a family or local community that has significantly different social and academic associations, norms, and behaviors, the stages of the integration process will pose more challenges with greater stress, since those students' “...past experiences are unlikely to have prepared them for the new life of the college in the same way as have those of persons who come from families that are themselves college educated" (Tinto, 1988, p. 443). Furthermore, Tinto explains that new college students are required to navigate their institutional life on their own without any assistance. Not being familiar with the new norms and behaviors necessary to competently perform in higher education, students with greater variance from college expectations find it impossible to integrate into college social and academic communities and may end up leaving their institutions (Tinto, 1988). 
This is the same issue discussed by Terenzini, et.al. (1993), who focus on transition and persistence among first-generation college students. These first-generation students, coming from backgrounds unlike those of traditional college students, may find it difficult to adjust to college life. In contrast to traditional students, first-generation college students prioritize studies more than making social connections in order to acquire and adjust to a new set of academic skills and expectations (Terenzini, et.al., 1993). Ironically, however, this lower priority of integration into social life on campus may create a risk of earlier departure for those students.

International students, according to Tinto's framework, may be at risk for early departure due to their unique characteristics as outsiders in U.S. society and academic settings, just as in the case of first-generation students described by Terenzini, et.al. (1993) with regard to how challenging it is for nontraditional first-generation students to transition into higher education. First generation college students, due to their challenges in transition, are more vulnerable to the risk of departure (Terenzini, et.al., 1993).

In a similar vein, Astin $(1984 ; 1996)$ asserts that students' involvement in campus and academic life enhances their cognitive and social learning gains. The definition of involvement is the amount of energy, time, and effort spent physically and emotionally in academic life (Astin, 1984). Some of the examples of student involvement that facilitate students' satisfaction with their experience in higher educational institutions and student academic success are:

- participation in college activities such as intercollegiate sports

- having part time on-campus jobs 
- living in residential halls

- active involvement in academics, as reflected in class attendance, increased interaction with faculty, and regular interaction with peers (Astin, 1984).

These examples, Astin (1984) suggests, can be misunderstood as a simple matter of student motivation, so his research goes on to distinguish between motivation and involvement. Astin (1984) sees motivation as more passive, while involvement entails an active initiation from the student to get involved academically (Astin, 1984). In other words, involvement requires more than just motivation to be successful; it also demands a student's intentional determination to participate in campus life (Astin, 1984).

Involvement theory critiques traditional educational theories, such as content theory and resource theory, for their failure to focus on students (Astin, 1984). Content theory, for instance, postulates that if students are exposed to the content, learning will occur (Astin, 1984). Resource theory, on the other hand, focuses on campus resources, such as facilities and faculty. According to resource theory, the more resources the institutions acquire, the greater the learning that students will acquire (Astin, 1984). However, these theories fail to recognize the importance of student variables. In contrast to these theories, involvement theory focuses on how students behave in their academic and nonacademic lives on campus (Astin, 1984).

Plant, Ericsson, Hill, \& Asberg (2005) suggest important characteristics among students who achieved a high semester and cumulative GPA. Those characteristics are: (1) Studying alone "in an environment unlikely to contain distracters" (p. 111), (2) having quality in their work while studying and previous knowledge shown in SAT, (3) 
attending classes, (4) "keeping diary reports on their actual study" (p. 113), (5) having scheduled plans and goals rather than "primarily cramming for exams" (p. 113). These suggestions mirror Astin's (1984) idea of "involvement": the amount of energy, time, and effort spent physically and emotionally in academic life (Astin, 1984).

Cress (2008) asserts that relationships between students and faculty, one of the factors of involvement, are connected to positive academic outcomes, including "students' persistence in college, intellectual development, academic success, and moral development and personal identity awareness" (p. 107), and therefore suggests that higher education institutions should develop potent relationships between students and faculty members (Cress, 2008).

Involvement theory suggests that learning gains will increase when the surrounding environment encourages students' active participation on campus academically and socially. In addition, it encourages instructors to focus less on teaching techniques and content and more on the students themselves - what they are doing and how they are developing as students while learning (Astin, 1984). Furthermore, involvement theory suggests that faculty and administrators pay more attention to students who are passive or unprepared, as those can be warning signs indicating that the students are not involved. In addition, the theory suggests that the positive experiences that students have are more likely to increase their involvement, which in turn increases their chances of future academic success. Negative experiences that students have may lead to lack of involvement, with a resulting lack of academic success (Astin, 1984). 
Involvement theory and suggestions from Plant, Ericsson, Hill, \& Asberg (2005) and Cress (2008) have important implications for international students' academic success in the U.S. higher education. First of all, due to their collective cultural background (Lee \& Rice, 2007), many international students may be passive or unprepared according to U.S. expectations. These are indicators of lack of involvement (Astin, 1984), and such lack of involvement may affect their likelihood for academic success. Their study habits and expectations may not reflect the characteristics described by Plant, et al. that correlate with high GPA.

Trice (2004) discusses similar notions about international students' social and academic involvement on campus as contact with host national students. According to Trice (2004), having relationships with host national students provides positive academic satisfaction, academic gains, and social adjustment to the host culture for international students. In contrast, lack of involvement places international students in isolation, making them anxious and depressed. Those students experiencing less contact with host national students are less likely to feel academic satisfaction. They are more likely, on the other hand, to report that they are having difficulty adjusting to the host culture, society, and academic studies (Trice, 2004).

From a review of Astin's (1984) involvement theory, it is apparent that international students are at disadvantage when it comes to getting involved, making a continued lack of involvement even more likely. Thus, institutions need to seriously consider how to encourage international students' involvement in order to foster their academic success. It is the responsibility of student services personnel, faculty, and staff 
not only to facilitate the involvement of international students in campus life, but also to develop the talents and skills with which students enter higher education. According to Astin's (1984) involvement theory, when international students are involved more on campus, they learn the unwritten rules about academic and social life more quickly, make more friends, and improve their language and cultural skills.

\section{Dominant Perspectives}

The claims of Tinto (1993) and Astin $(1984 ; 1996)$ regarding social and cultural transition into higher education have significant implications for student services personnel and faculty members alike; we need to encourage students' integration and involvement in campus life, and to actively offer such opportunities. Nevertheless, we should always proceed with thoughtfulness and care. While Andrade (2005) found that international students who joined cultural clubs, churches, and faith-based activities made smoother transitions, other researchers caution against a blind appraisal of integration/involvement on campus due to the hidden assumptions/values behind them. Although integration and involvement theories have been embraced by student services and faculty members, scholars have critiqued the theories of both Tinto (1993) and Astin $(1984 ; 1996)$ on academic/social integration, engagement, and involvement as being based on dominant perspectives, and thus failing to account for multicultural and minority perspectives (Rendon, 1992; Tierney, 1992; Rendon, Jalomo, \& Nora, 2000; Bensimon, 2007).

Rendon, Jalomo, and Nora (2000) suggest that the problem with Tinto's integration model is that it requires cultural and social assimilation, claiming that 
"persistence is contingent on the extent to which students have become incorporated (integrated) into the social and academic communities of the college" (Rendon, Jalomo, \& Nora, 2000, p. 128). Therefore, in order accomplish integration into campus life, minority students are required to go through "a process of separation, a cultural adaptation that required minority individuals to break away from their traditions, customs, values, language, etc.” (Rendon, Jalomo, \& Nora, 2000, p.128).

Another important criticism of researchers who raised questions against integration/involvement theories is an objection to the assumption that concepts such as involvement and integration are culturally neutral. According to the involvement and integration theories proposed by Tinto (1993) and Astin (1984; 1996), the understanding of services and requirements, and involvement in college and campus life are held to be the individual responsibility of each student (Rendon, 1992; Rendon, Jalomo, \& Nora, 2000; Bensimon, 2007). These scholars warn that the knowledge of campus and academic life that is required to integrate and/or become involved on campus is taken for granted, and thus, if institutions target their efforts to help out those who fit into the dominant perspective, they risk failing students who hold minority perspectives (Terenzini, et.al., 1993), as social and academic integration and/or involvement requires “access to resources and opportunities available within an institutional setting are unequally distributed among institutional members" (Trice, 2004, p.672). Therefore, naively believing that institutional support systems are already in place, and waiting for motivated students to take advantage of such support systems may not necessarily work with minority groups, since minority group members may lack understanding, or have a 
different understanding of "academic success" than the notion held by dominant group members (Bensimon, 2007).

Similar to integration/involvement theories, the academic expectations of higher education can create problems for students based on dominant and minority perspectives. According to Christie, et al. (2006; 2008), students from differing backgrounds, such as non-traditional students, may understand and react to the same context in quite different ways since their perceptions about learning or their preference of approaches may differ from those of traditional students. Moreover, their identities may affect how they respond in higher education settings (Christie, et al., 2006; 2008). Therefore, students from differing backgrounds need to transition to new ways of learning expected in higher education (Christie, et.al., 2006). Otherwise, students who struggle with learning and completing tasks are assumed to lack preparation for learning, motivation, or academic ability. Educators tend to blame individual students rather than understanding the different academic preparation those students have received and expectations that they have arrived with (Christie, et al., 2008).

Similarly, Teranishi, Behringer, Grey, and Parker (2009) claim that Asian American and Pacific Islander students (AAPIs) are forced to comply with educational norms based on dominant perspectives, which silences their own experiences or sees their distinct experiences as a "deficit" compared to dominant group members (Teranishi, Behringer, Grey, and Parker, 2009).

It is certainly difficult for students with differing backgrounds to face the challenges in transitioning into new social and cultural perspectives when they arrive on 
campus. It is even more unfortunate when these students are misunderstood as underprepared, and lacking motivation or capability when the blame should not be placed on them. According to Brown and Joughin, (2007) unshared expectations can cause a disconnect between faculty and international students in assessments (Brown \& Joughin, 2007). They suggest that the lack of evidence that international students mastered the materials may be due not necessarily to cognitive abilities but to this lack of shared expectations between professors and students, and what those students bring with them as their background culture (Brown \& Joughin, 2007). In other words, international students may lack understanding of what their professors expect (Collier \& Morgan, 2008). Tha international students have academic challenges, such as a lack of understanding academic expectations, has been well documented (Biggs, 1993; Zhai, 2004; De Vita, 2007; Li, Chen, \& Danmu; 2009). These academic challenges may be a result of the fact that U.S. higher education is based on an assumed dominant perspective, which these international students are not part of.

It is certainly plausible that international students can undergo an academic transition similar to nontraditional students (Christie, et al., 2006; 2008; Brown \& Joughin, 2007; Collier \& Morgan, 2008). What seems to be a simple lack of academic preparation, motivation, or skills among international students may be due to their unique backgrounds. Christie, et al. (2008), add another important aspect of academic transition; nontraditional students with differing backgrounds may go through significant emotional and social pressures in academically transitioning to college, which disadvantages them in comparison to traditional students, whose previous experience mirrors the expectations 
of higher education (Christie, et al., 2008). They point out that being a college student is not just a simple matter of memorization, establishing good habits, and acquiring skills; it also includes creating a new identity as a student in higher education (Christie, et al., 2008).

\section{Identity/Role of College Student}

The academic transitions section identified a lack of self-efficacy as one of the challenges faced by international students. This self-doubt can be related to what Christie, et al., (2008) point out about nontraditional students' experience of emotional challenges while transitioning into higher education. In Turner's (2006) study, a majority of Chinese international students in the U.K. were unhappy with their level of academic success, and some of them showed anger with and rejection of the U.K. pedagogical system. Turner (2006) suggests that an intercultural transition between different pedagogical orientations can cause emotional instability. Such emotional suffering weakens international students' confidence, and in some cases, hinders the ability to move forward efficiently.

Christie, et al. (2008) suggest how important it is for students in higher education to form identities as college students while transitioning academically into college. Collier (2000; 2001) refers to this identity as the "college student role" - a required component for learning and understanding how to navigate the college experience successfully. It involves understanding and performance of higher education's expectations regarding what skills and preparations college students should possess, and how they should behave academically. The college student role acts as an agent of essential resources which students will be able to access. Therefore, students with a 
greater understanding of the college student role will be able to recognize requirements and expectations of instructors, and more easily respond to these expectations appropriately (Collier \& Morgan, 2008). Meanwhile, students who lack or have not yet mastered the college student role may not understand what their professors expect of them, and may perform poorly due to a misunderstanding of class expectations. Unfortunately, unless students understand professors' expectations, they will not be equipped with tools to demonstrate their mastery of the course materials. Such students face the very real. possibility of actually mastering class content but failing academically because of a failure to conform to expectations owing to their lack of a college student role/identity (Christie, et al., 2008; Collier \& Morgan, 2008).

The research by Collier and Morgan (2008) posits a link between academic success and whether students have mastered the college student role or not, suggesting that role mastery is an essential component in the reproduction of the gap between educational "haves" and "have-nots." It is important for higher education to "ensure that the path to academic success depends on students' academic abilities, rather than on their abilities to understand what professors expect of them" (Collier \& Morgan, 2008, P. 449) in an attempt to foster meritocratic society. International students coming from different pedagogical systems may possess college student roles that differ from those assumed in U.S. higher education, resulting in a failure to demonstrate their learning and mastery of content in expected forms, and thus, being mislabeled as failing or unmotivated.

Indeed, it is difficult to understand students' learning processes unless they are fully equipped with U.S. college student roles. Therefore, instruction in such roles should 
be provided, as the transition to becoming a successful learner involves understanding the gap between cultural and educational background between individuals and those of universities (Christie, et al. 2008; Collier \& Morgan, 2008). Similar to the nontraditional students discussed in the literature, international students should be establishing their identities as college students by mastering college student roles, instead of being passive consumers of knowledge fed by professors in their academic transitions.

\section{Social Capital}

As previous sections identified, norms and expectations consist of perspectives shared by a dominant group, putting cultural minority and nontraditional students at a decided disadvantage. One of the resources that help the dominant group maintain its advantage is social capital. Social capital represents the nexus of access and mutually beneficial arrangements that carry heavy expectations of reciprocity (Coleman, 1998). Social capital is "embodied in relations among persons" (Coleman, 1998, p. S118) and takes three forms: "obligations and expectations, which depend on trustworthiness of the social environment, information-flow capability of the social structure, and norms accompanied by sanctions" (Coleman, 1998, p. S119).

Smith (2009) described social capital as "college knowledge" which "is a term connected to pursuit of a bachelors degree that represents familiarity with the ways, purposes, and pathways that expose students and families to the social, psychological, economic, and experiential tools for accessing and achieving success in our higher education system" (p. 176). Being acquainted with "the specific, health-related, financial, and lifelong affective values of a college degree" (p. 176) is crucial part of college 
knowledge, and a lack of, or misapprehension of, college knowledge can lead to underinvolvement among African American and Latino parents' in preparing and encouraging their children for higher education (Smith, 2009).

International ESL students with provisional admissions are certainly collegebound students, yet, whether they or their parents have the sufficient college knowledge described by Smith (2009) can be of question. Since international students have grown accustomed to college knowledge in their own countries with their parents' encouragement, their college knowledge can be different from the "college knowledge" required in U.S. higher education.

The difference between dominant and minority groups - especially with regard to access to knowledge that leads to social, cultural, and academic transitions and academic success referred to as social capital - is "a membership in a group" (Bordieu, 1986 p. 51) and "access to resources and networks that lead to opportunities" (Trice, 2004, p. 672). More explicitly, social capital "includes the social and personal connections or networks that people capitalize on for interpersonal assistance and personal gain, which for youths are often developed in schools in addition to the home" (Wells, 2008, p. 29).

These social and personal relationships and networks provide abilities to understand and access "information about cultural norms, insight into how organizational unites operate, (e.g., chains of command, explicit and implicit rules), and knowledge of the U.S. labor market. Such networks can also provide assistance when students deal with institutional gatekeepers such as rules and expectations that may not be apparent and 
transparent to all the students, as well as valuable emotional and moral support" (Trice, 2004, p. 672).

The problem is that the ownership of social capital enables access to the information necessary for transitions and academic success among white middle-class members who hold this social capital (Trice, 2004). Wells (2008) also points out that one gains the social capital necessary for transitions and academic success during youth because "As children, they acquired knowledge about functioning within the dominant culture, and it is members of this culture that typically control institutional resources and opportunities" (Trice, 2004, p.672). Unfortunately, minority group members often "lack adequate social capital, and thus the power to function well at a college or university" (Trice, 2004, p. 672), as "they learned different linguistic and cultural competencies as children, making it more difficult to develop social networks within the dominant culture" (Trice, 2004, p.672). This lack of appropriate social capital necessary for successful transition and academic performance causes significant social, cultural, and academic challenges for minority students when they enter higher education institutions.

Morgan's (2006) “Organization as culture” metaphor is helpful in describing the current situation in higher education regarding hidden gatekeepers, social capital, and how they work. According to Morgan (2006), patterns of development in organizations reflect society's system of knowledge, ideology, values, laws, and day-to-day rituals. The nature of culture, Morgan (2006) contends, is found in its social norms and customs. Here, Morgan (2006) defines culture as "shared values, shared beliefs, shared meaning, shared understanding, and shared sense making." In this metaphor, colleges and universities 
develop their own patterns by reflecting norms, shared understandings and customs of those who traditionally attend. Therefore, the assumption is that students who enter higher education possess the same shared understanding, knowledge, ideologies, and values. At the micro level, instructors and professors who teach students are those with higher degrees. Thus, it is easy to understand why institutional efforts may not be sufficient to support and retain those who are not from the same shared academic cultural norms, such as first generation or international students.

Another metaphor from Morgan (2006) that can helpful in the discussion of higher education and social capital is "organization as instruments of domination." Morgan (2006) observes organization as “always class-based” (Morgan, 2006, p. 298), and "modern organizations continue to favor and reinforce a power structure that encourages people with certain attributes while disadvantaging others" (Morgan, 2006, p. 304). In the history of higher education, students from different social classes started attending colleges/universities fairly recently. Before the modern era, higher education was limited to those who were from the wealthy class. Higher education institutions, using Morgan's (2006) metaphor of dominance, have favored and reinforced their power structures by reproducing power through obtaining higher degrees, while those who have not had a chance to attain higher education have been disadvantaged socially and economically, as Kalmijn and Kraaykamp (1996) assert.

Tinto (1993) and Astin (1984; 1996) have proposed social integration and involvement as keys to students' successful transitions that lead to academic success. However, when students do not possess the social capital, student identity and student 
roles which campus communities expect, their attempts to integrate and/or involve themselves on campus will not work, as Tinto (1993) and Astin $(1984 ; 1996)$ originally proposed. Unfortunately, capital, student identity and student roles can work as gatekeepers of academic success: Morgan (2006) advocates that leaders of organizations must understand this ongoing process that produces systems of shared meaning and reality within organizations. Therefore, through organization management, it is mandatory that we realize how we process and reproduce our norms - the meanings that are shared by the members within the organizations (Morgan, 2006). This means that we must pay attention to what our higher education norms are, how they are constructed and assumed, and how to manage the current contexts by focusing on the changing demographics of student bodies and their relationship to traditional norms of colleges.

Students within the dominant group, who have acquired social capital, student identity and student roles at home, will easily be able to integrate and get involved within the institutional community, making their transitions much more easily than students from minority groups. Meanwhile, these members of minority groups, due to their lack of social capital, have more difficulties in higher education (Trice, 2004). Without question, international students born and raised outside the U.S., having acquired different linguistic and cultural competencies (Trice, 2004), will more likely be "have-nots" in terms of this social and capital, student identity and student roles, and as a result, more likely to be at a disadvantage when transitioning into U.S. higher education, where norms and rules are based on white middle-class social capital. Furthermore, international students, with their linguistic, cultural and racial differences, are part of the minority 
group, and therefore at a greater risk of dropping out - lacking the social and capital, student identity and student roles necessary for academic success in U.S. higher education.

\section{Conclusion}

When considering international students' successful transitions into higher education as well as their academic success, social, cultural, and academic factors cannot be slighted. The existing literature suggests that international students, especially Asian international students from collectivistic cultures, face challenges in both socio-cultural and academic-cultural transitions. Regarding socio-cultural transitions, international students have difficulty creating social networks and/or friendships with domestic students (Lee \& Rice, 2007; Trice, 2007). They may either lack help-seeking strategies, or have help-seeking strategies that differ from those of local students (Zhai, 2004); this may affect international students emotionally, leading them to loneliness (Zhai, 2004), and eventually affecting their academic success.

Linguistic challenge is another socio-cultural challenge mentioned in the literature (Zhai, 2004). Many international students identify a lack of sufficient English skills as making life difficult, even when they have passed required English tests such as TOEFL (Test of English as Foreign Language) or IELTS (International English Language Testing System) (Zhai, 2004). The literature has also identified coping with cultural differences, understanding the new regional/institutional culture, and making transitions as significant challenges faced by many international students. The above factors, alone or in concert, 
can threaten international students' psychological well-being, which in turn may affect their academic achievement and success in the long run (Chen, 1999).

In regard to academic-cultural challenges, the literature has demonstrated that international students find pedagogical differences, academic expectations, learning strategies, self-efficacy, feelings of being a minority, and language proficiency as challenges while studying overseas (Biggs, 1993; Levy, Osborn, \& Plankett, 2003; Zhai, 2004; De Vita, 2007). At the same time, the literature cautions against a danger of overgeneralizing Asian or collectivistic cultures as a monolithic group when describing individual student motivation among Asian learners (Gan, Hamphreys, \& Hamp-Lyons, 2004; Hellsten \& Prescott, 2004; Gan, 2009).

The third section of the literature review focused on integration/involvement theory and its significance for international students' success (Astin, 1984, 1996; Tinto, 1993). Andrade (2005) reported that after becoming more involved on campus, the students in her study were more comfortable and felt a greater sense of belonging on campus. At the same time, other scholars raise a caution about the hidden perspectives behind integration/involvement theories, especially in regard to its failure to acknowledge minority perspectives. In addition, those theories have tendency to take dominant perspectives for granted, putting minority group members at a disadvantage by forcing them to act according to the dominant group's expectations and rules (Rendon, 1992; Rendon, Jalomo, \& Nora, 2000; Bensimon, 2007).

The final part of the literature review dealt with the source of differences between dominant and minority groups, the significance of social capital, and how resources such 
as possessing student identity and student roles act as agencies to disadvantage certain groups, suggesting that education itself serves as a gatekeeper, fostering such resources held by the dominant group and allowing people with social capital, college student identity, and student roles more advantages while leaving those without them to struggle (Trice, 2004; Christie, et.al., 2006; 2008; Collier and Morgan, 2008; Wells, 2008).

For international students coming from the outside, the social, student identity and the student roles of the host country will likely be different from what they have previously known and possessed. Thus, the struggle of international students to transition into their new social and academic life overseas is not surprising.

As the majority of the literature acknowledged language proficiency as a major academic and socio-cultural challenge, many researchers have suggested ESL or EAP (English for Academic Purposes) courses for international students who are facing linguistic problems or difficulties, and furthermore, that institutions recognize and accommodate the need for those classes or programs. Indeed, university ESL programs already specialize in assisting international students with necessary language skills. Nevertheless, simply referring students to ESL programs does not seem sufficient to ensure their academic success.

First of all, ESL professionals have been trained to teach the English language, but not necessarily to foster socio-cultural and academic-cultural transitions. Secondly, the academic issues stated previously - pedagogical practice differences, academic expectation differences, and self-efficacy issues - will not differ from those that international students face in regular academic classrooms. Furthermore, the existing 
literature fails to address the simple fact that students enrolled in ESL programs are also international students, and therefore, upon their arrival will face the same challenges as those international students reviewed in the literature. In regards to the feeling of being a minority, ESL students have an advantage: all of their classmates are internationals, so they may feel more at ease during classes. Nevertheless, most ESL professionals are native English speakers from the host countries, and once ESL students leave their classrooms, they are surrounded by local students and community members; thus, they may not fully avoid the feeling of being a minority. Finally, ESL students will certainly have language proficiency challenges, as they are the ones who are learning English in the programs.

For the most part, higher education research has failed to address ESL students' transition into U.S. higher education and its potential consequences for their academic success. The field of TESOL (Teaching English for Speakers of Second or Other Languages), in which many ESL instructors receive their training, has similarly failed to address the same issue. Yates \& Muchisky (2003) criticize the recent trend, or "quiet revolution" as they call it (p.136) in TESOL, which puts greater focus on self-reflection and attitudes toward teaching in TESOL teacher education courses, as opposed to practical linguistic knowledge and how language is learned. They dismiss the idea of "the critical roles of L2 [second language - writer added] teachers as cultural storytellers, cultural healers, and cultural workers" (Hones, cited in Yates \& Muchisky.2003, p. 145). "Based on our experience in teaching ESL and in TESOL teacher education, the relative place for language teacher knowledge about language and how languages are learned is at 
the core of whatever the language teacher does and wherever the language teacher is situated" (Yates \& Muchisky.2003, p. 145). As this quote demonstrates, voices in the field of TESOL are calling for less attention to be paid to ESL students' transition into higher education and similar issues, advocating instead a more narrow focus on the nature of language, and how languages are learned by second/foreign language speakers. And so, neglected by two fields, ESL students' transition into higher education is still largely unexplored. 


\section{CHAPTER 3:}

\section{Research Design and Methodology}

\section{Research Question}

In the previous literature, the issues that students face upon entering higher education, especially among minority, first generation college students, and international students were reviewed. Many of them face challenges in understanding college expectations because they did not inherit knowledge and connections commonly shared by traditional students through their families, groups, communities, and cultures. Coming from overseas, international ESL students may face at least to the same or greater degrees of challenges that minority and nontraditional students face. Such challenges entering and transitioning into U.S. higher education include challenges in social and cultural transitions such as cultural differences, loneliness, linguistic difficulties, managing stresses and coping with changes, and academic transitions such as pedagogical differences and academic expectations.

Although much of the literature seems to point out challenges faced by international students, little is documented about international students who started their U.S. higher education in ESL programs. In the literature of higher education, ESL is mentioned as a solution for international students who struggle linguistically during their transitions. In the fields of linguistics, applied linguistics, and TESOL, transition issues are rarely researched, as their primary concern is how languages are learned, how languages are taught, and how languages work (Yates \& Muchisky, 2003). 
Therefore, this research has focused on international ESL students, more specifically, Chinese students who had received provisional admission to a university with an ESL program restriction before commencing their academic studies, as their overall number is significantly increasing every year. In 2012, Chinese international students made up $25.4 \%$ of all the international students studying in the United States, and their numbers have been steadily increasing; in 2009, they increased by $21.3 \%$, and in 2010 , by $23.3 \%$, followed by $23.1 \%$ in 2012 (IIE, 2011; 2012). Like other nationalities, many Chinese students start their higher education in ESL programs with provisional admission to a university. These students have met all other admission requirements except English proficiency; therefore, they are required to complete either ESL classes or demonstrate sufficient English proficiency through TOEFL or IELTS scores while they are in the ESL program.

By narrowing the population, the research can identify fresh perspectives, in contrast to views of international students with more U.S. experience. Through this research, a better understanding of factors that may contribute to Chinese ESL students' successful (or lack thereof) transitions will be sought. Potential findings will contribute to instructors, ESL programs, and institutions in order to make strategic plans to facilitate the successful transition of their Chinese ESL students by providing tools to apply effective strategies in their instruction, curriculum development, advising, and policy making. In order to explore the social, cultural, and academic challenges faced by Chinese international ESL students in their transition into U.S. higher education, this research sought to hear their voices, attitudes, and expectations toward their studies 
through the lens of student roles. To achieve this end, qualitative inquiry appears to be best suited for this study.

This research intended to explore responses from international ESL students regarding their transition experiences in a U.S. higher education institution. Therefore, the following research question was formed to elicit their answers:

- What are the social, cultural, and academic factors that positively and negatively affect international students' transition into U.S. higher education?

In addition, this research used interview protocols (Appendix C) which were developed according to the interview guide outlined in Collier and Morgan's (2008) research. These protocols reflect the challenges in social, cultural, and academic areas that ESL students face.

\section{Research Design and Methodology}

There are different qualitative research designs that could potentially examine challenges and/or expectations among international ESL students. Since this research focuses on Chinese international ESL students' transitions into higher education, it may draw interest from audiences in different fields of study. Consequently, it is of importance to note the disciplinary difference in regard to what research designs and definitions of studies should be applied to the present study. For instance, in the field of second language acquisition and TESOL, this study may fall into the category of case study. According to Longman Dictionary of Language Teaching and Applied Linguistics (Richards, Schmidt, Kendricks, \& Kim, 2002), a case study is: 
The intensive study of an aspect of behavior, either at one period in time or over a long period of time, e.g. the language development of a child over one year. The case study method provides an opportunity to collect detailed information that may not be observable using other research techniques, and may or may not be based on the assumption that the information gathered on a particular individual, group, community, etc., will also be true of the other individuals, groups, or communities. (p. 65) In contrast to the view of second language acquisition studies and TESOL, the field of higher education may categorize this study into the area of ethnographic research. According to Creswell, (2012) ethnographic design allows the researcher to discover, analyze, and describe patterns of beliefs, attitudes, and behaviors that are shared within a group over time. Ethnographic research is also the best choice "when the study of a group provides understanding of a larger issue" (Cresswell, 2012, p.462), and "when you have a culture-sharing group to study - that has been together for some time and has developed shared values, beliefs, and language" (Cresswell, 2012, p.462). The present study focused on a single group - international ESL students who have provisional admissions from mainland China - and studying this group could be a stepping stone to the "understanding of a larger issue" (Cresswell, 2012, p.462) shared by other ESL students, ESL instructors, programs, and host institutions that those ESL programs reside in. Therefore, ethnographic research design was expedient. Among the different types of ethnographic research, this study adopted realist ethnography, which created an objective account of the voices and views of participants using a third-person narrative (Cresswell, 2012). In 
realist ethnography, researchers remain objective and refrain from offering personal reflections, biases, political views, or judgments. Furthermore, realist ethnographic researchers provide their participants' views through thorough interpretation and descriptions, employing edited quotes gained through interviews (Cresswell, 2012).

Indeed, Cresswell (2012) indicates that researchers "often use the term case study in conjunction with ethnography" (p. 465), and case study is "an important type of ethnography although it differs from an ethnography in several important ways" (p.465). Lier (2005) advocates case study, which is primarily qualitative and interpretive and has had significant influence in education. According to Lier (2005) and Cresswell (2012), researchers conducting case studies seek in-depth investigation of a particular case, such as an individual, a group, or a situation in great detail within its natural context and try to probe into its characteristics, dynamics, and purposes. Case study research has frequently been used to look at changes in complex phenomena over time. Although the case study as a research framework has been seen as less vigorous, weaker, and a softer approach than quantitative experimental research, the case study has its strength and advantage in telling real stories of the case, describing and narrating them to bring the crucial points vividly to the intended audience. Such work can be as rigorous and influential as quantitative research (Lier, 2005).

This research intended to focus on a specific case - international Chinese ESL students and their experiences and needs in the context of US higher education at a single institution; at the same time, it seeks to provide the participants' views with thorough interpretation and descriptions presenting edited quotes gained through interviews. 
Therefore, this research was framed as a case study in conjunction with realist ethnography as its guiding research framework.

As a methodology, this research intended to use a semi-structured interview format. Bernard, (2006) says this of a semi-structured interview:

In situations where you won't get more than one chance to interview someone, semi-structured interviewing is best. It has much of the freewheeling quality of unstructured interviewing, and requires all the same skills, but semi-structured interviewing is based on the use of an interview guide. This is a written list of questions and topics that need to be covered in a particular order. ... the interviewer maintains discretion to follow leads, but the interview guide is a set of clear instructions. Even if you do all the interviewing on a project yourself, you should build a guide and follow it if you want reliable, comparable qualitative data. (p. 212) The reason for choosing the semi-structured interview was to have the voice, attitudes, and expectations of ESL students regarding the challenges they have faced in U.S. higher education emerge. As the interviews were semi-structured and allowed for a variety of responses, Grounded Theory (Strauss \& Corbin, 1998) was used as a tool to analyze the data. Bernard's description of grounded theory (2006) explains why it is suited for this study:

The grounded-theory approach is a set of techniques for: (1) identifying categories and concepts that emerge from text; and (2) linking the concepts into substantive and formal theories. The mechanics of grounded 
theory are deceptively simple: (1) Produce transcripts of interviews and read through a small sample of text. (2) Identify potential analytic categories - that is, potential themes - that arise. (3) As the categories emerge, pull all the data from those categories together and compare them. (4) Think about how categories are linked together (5) Use the relations among categories to build theoretical models, constantly checking the models against the data - particularly against negative cases. (6) Present the result of the analysis using exemplars, that is, quotes from interviews that illuminate the theory. (p. 492)

In addition, it was expected that grounded theory as a tool of data analysis would allow ESL students' views, voices, attitudes, and expectations to emerge through their interviews and, therefore, was the best fit tool for this research.

\section{The Research Site}

The research site was an ESL program that is a part of the College of Liberal Arts in a Research I University in the Midwestern United States. This ESL program was one of the first to offer ESL classes to international students in the U.S., having been established in 1961. The program consists of one director, three associate directors, one testing office director, five administrative staff members, 33 full-time instructors, and a significant number of TAs and semester hire instructors. All administrative, teaching, and testing faculty members hold at least a masters' degrees in TESOL or a related field of study. Graduate teaching assistants in the MA TESOL program and PhD Second Language Studies program students teach in this program as well. 
As Figure 1 shows, the university where the ESL program belongs to has experienced a significant increase in the number of Chinese students, especially, undergraduates, many of whom started in the ESL program. Figure 1 shows the increase in the number of Chinese students at this university between 2003 and 2012.

Figure 1: Chinese international students at the university between 2003 and 2013

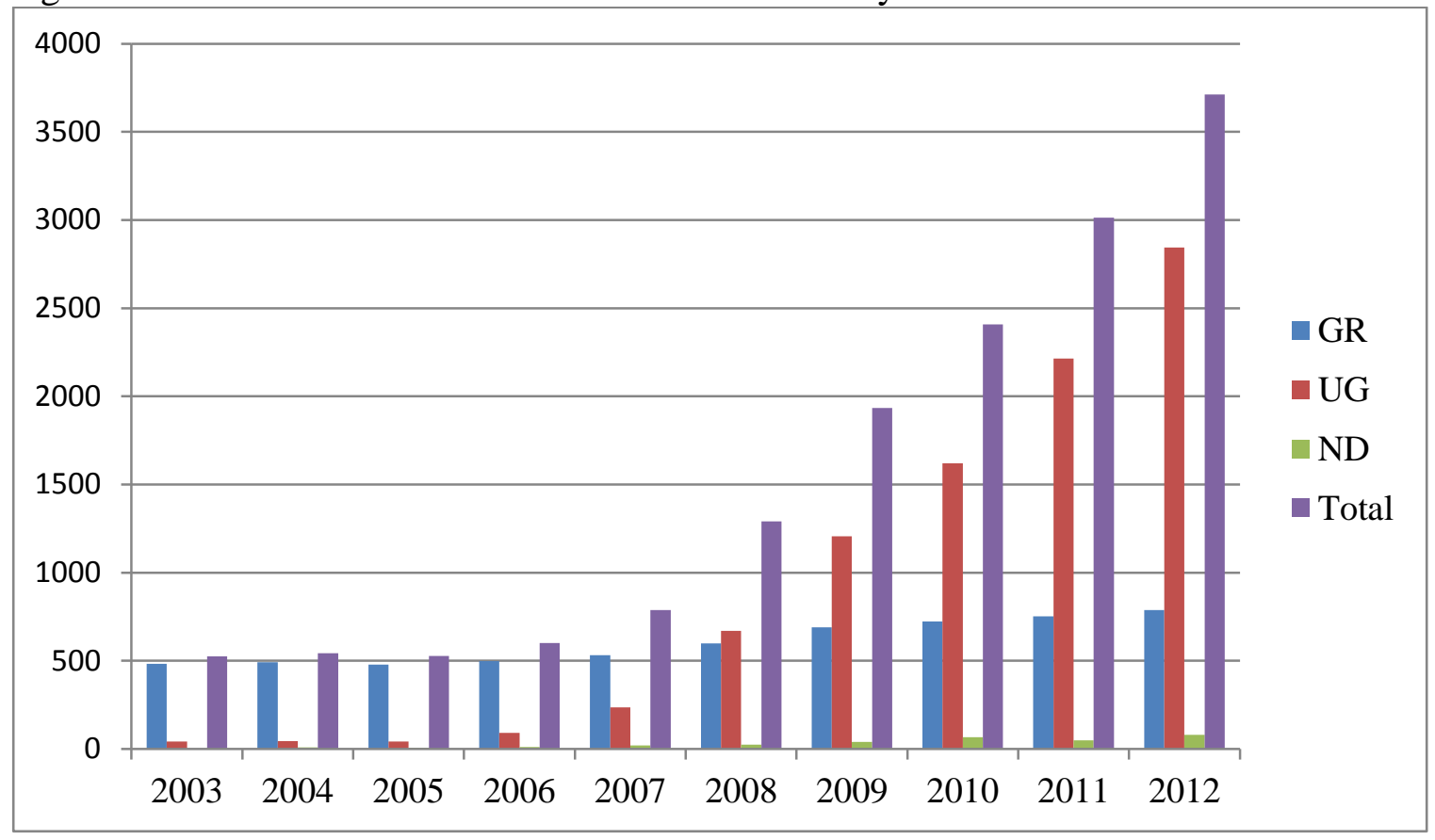

The program had a significant increase in the number of provisionally admitted Chinese students starting in about 2008. To meet the needs of the increasing number of incoming students, the program hired 29 new full-time instructors between 2008 and 2012.

Figure 2 shows the increase in enrollment in the program between Fall 2009 and Fall 2012. 
Figure 2: The ESL program enrollment by semesters

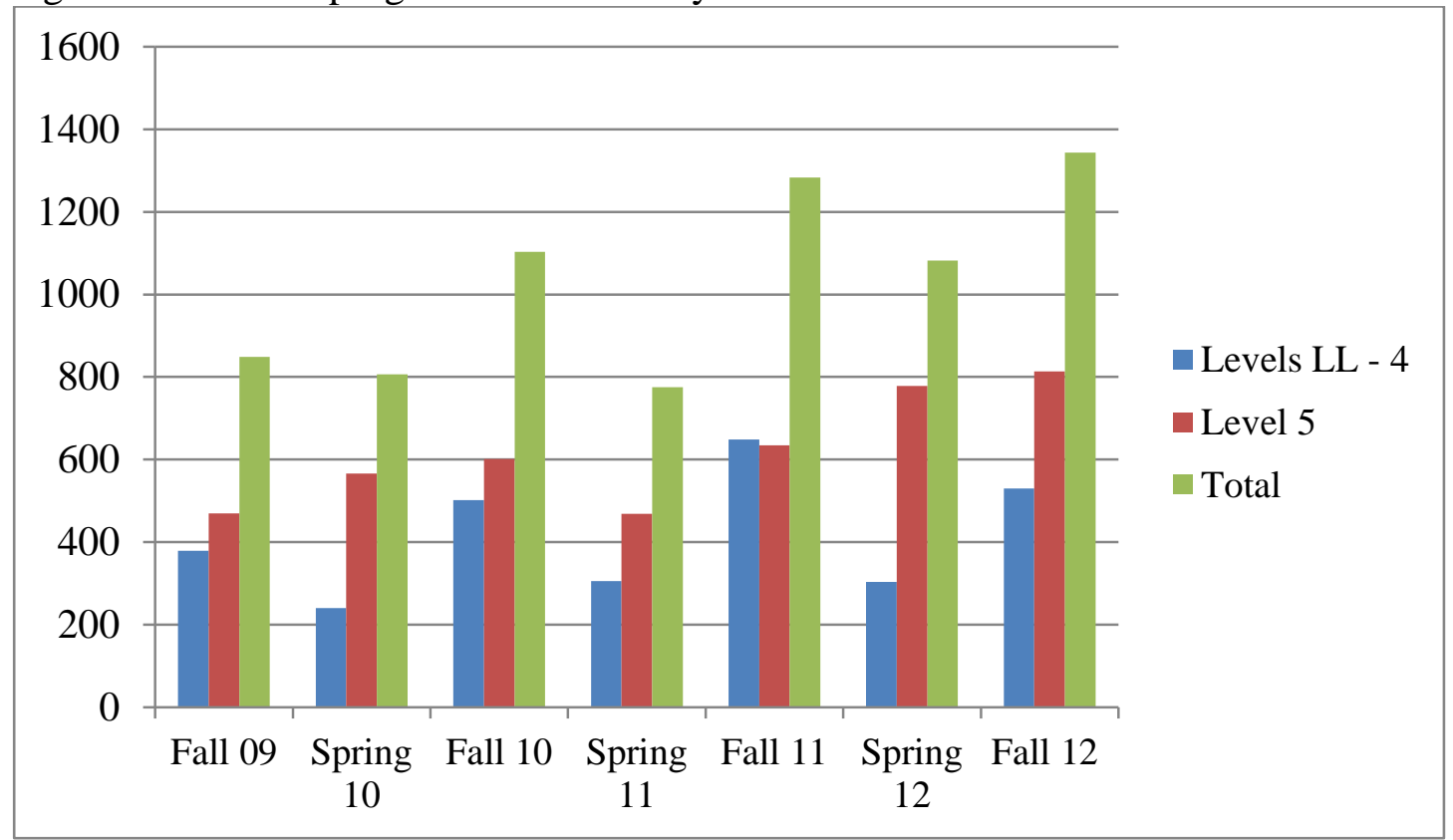

The majority of the student population of the program is Chinese, followed by Middle Eastern students. Other countries of origin of the student population are Korea, Japan, Taiwan, with minimal representation from a few other countries around the world.

There are three categories of students enrolled in this program: (1) provisionally admitted students who have met all the academic criteria to be admitted to the university, yet have not met the English requirement to start academic classes, (2) students who are admitted to this ESL program, whose purpose is either to learn the language and return home, or to learn English before applying to U.S. universities, and (3) international special program students, whose universities in their home countries have contracts with this program for them to study English for a certain period of time (a few weeks, a semester, or a whole academic year). Most of the Chinese ESL students in this program 
belong to the first category - provisionally admitted university students, restricted to taking ESL classes prior to being allowed to start academic courses at the university.

The program offers three semesters of instruction: Fall (August - December), Spring (January - April), and Summer (May - August). At the beginning of each semester, new students take an ESL placement test, determining the level of ESL class to which they will be assigned.

Unlike regular higher education students who have more choices in registration, the students in this program do not choose their classes; all class assignments are made by the program according to their previous semester's grades, placement tests, or apostsemester standardized test. Figure 3 and 4 show the ESL program's level placement system based on the ESL placement test scores.

Figure 3: ESL level placement based on the placement test scores

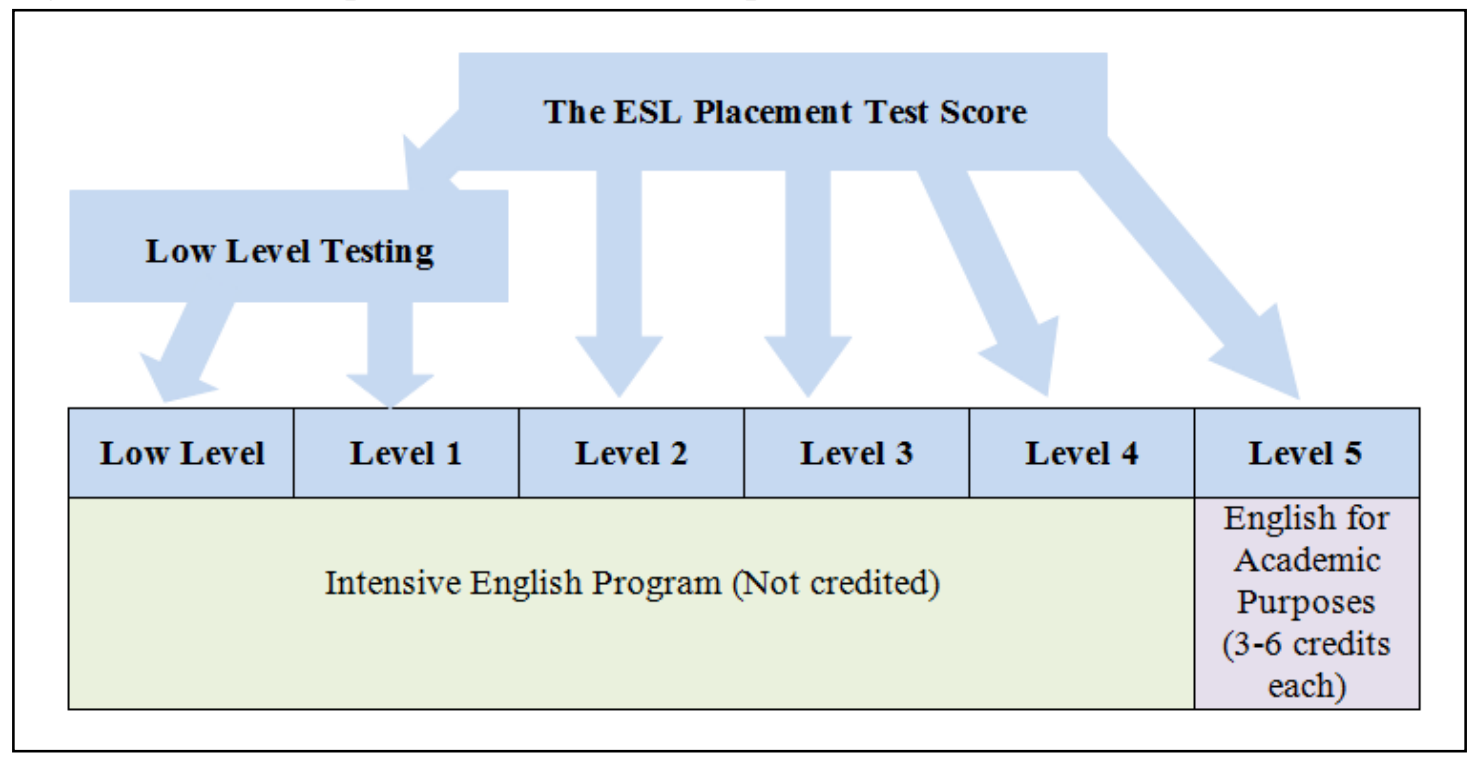

Once student levels are assigned, the students are given three days to make section changes at the beginning of each semester. Another difference between regular 
university students and the students in this program is that the students in Levels Low to 4 are in a cohort system; students will be in the same section with the same classmates all semester. Table 1 shows the levels and the skills offered at the ESL program.

Figure 4: Detailed initial placement chart based on the ESL placement test

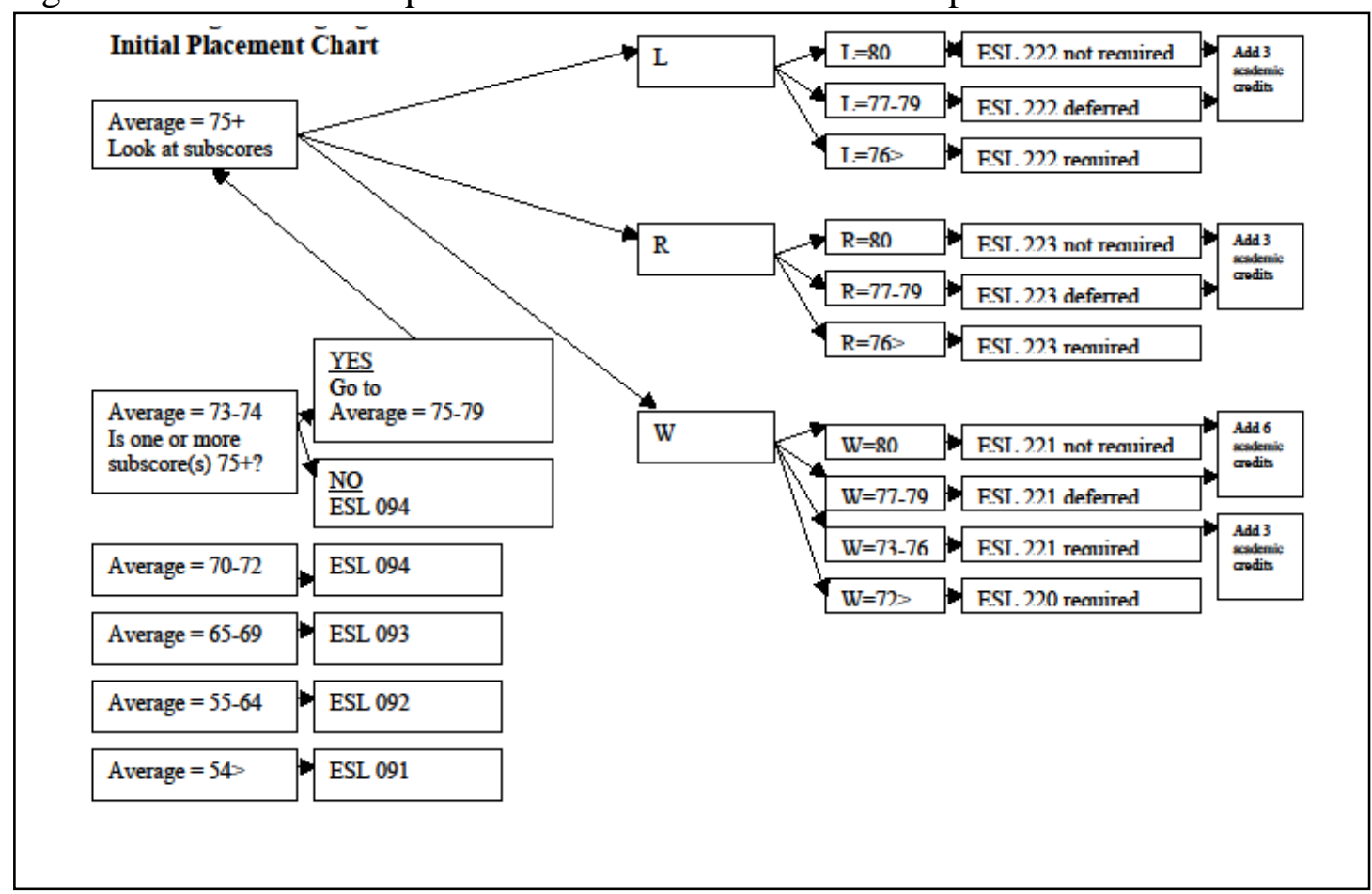

Students in levels Low to 4 receive 16 hours of instruction, four days a week; students in Level 5 may be full-time ESL students, taking three courses, or they may be part-time students taking ESL and regular university courses concurrently. 
Table 1: The Levels at the ESL Program

\begin{tabular}{|c|c|c|}
\hline Level & Approximate ACTFL Proficiency Level & Skills \\
\hline Low & Novice Low/Mid; True Beginners & $\begin{array}{c}\text { Grammar/Reading/Writing } \\
\text { Grammar/Listening/Speaking }\end{array}$ \\
\hline 1 & Novice-High & $\begin{array}{c}\text { Grammar } \\
\text { Reading/Writing } \\
\text { Listening/Speaking }\end{array}$ \\
\hline 2 & Intermediate-Low/Mid & $\begin{array}{c}\text { Reading/Writing/Grammar } \\
\text { Listening/Speaking/Grammar } \\
\text { Content }- \text { American Culture } \\
\text { Reading/Writing/Grammar } \\
\text { Listening/Speaking/Grammar } \\
\text { Content - American History }\end{array}$ \\
\hline 3 & Intermediate-Mid/High & $\begin{array}{c}\text { Writing/Content } \\
\text { Reading } \\
\text { Listening/Speaking }\end{array}$ \\
\hline 5 & Intermediate High/Advanced & $\begin{array}{c}\text { Writing/Grammar } \\
\text { Writing } \\
\text { Listening/Speaking } \\
\text { Reading }\end{array}$ \\
\hline
\end{tabular}

\section{Participants}

As mentioned previously, there are two types of ESL students enrolled in ESL programs in higher education in general: 1) short-term students who only wish to study English and then return home, and 2) international students who receive admission from an institution but are restricted to ESL programs before beginning academic classes due to a lack of English proficiency. This research focused on the latter. The subjects were Chinese students enrolled with provisional admission in an ESL program in a Midwest Research I university and were considered to have met all the other admission requirements except for English proficiency. The researcher currently works at this program and had inquired about the research with the program director as well as the ESL office testing director in charge of all research conducted in this program. 
Permission to access the students for this study was granted, provided that Human Subject approval through Portland State University was obtained. With the program's permission to access its students, the researcher was able to visit target classes and recruit subjects after the required Human Subject approval had come through.

The researcher acknowledged potential biases that she might bring to this research, which will later be described in the section on researcher's role.

Eight Chinese ESL students who were in their second semester of study and enrolled in Level 5 were recruited to participate in this study, since Level 5 students are actually deemed ready for university after completing that level. They were all at least 18 years old or older, full-time ESL students in the previous semester, and undergraduate students. Half of the participants were males and the other half were females in order to have balanced perspectives. The participants were recruited through the researcher's visits to the classrooms and instructors' class announcements until a sufficient number were obtained.

The choice of students' level was solely based on their linguistic abilities. Students in lower levels would have greater difficulty expressing themselves adequately in English. Having students from the highest level helped minimize misinterpretations and miscommunications between the students and the researcher.

The students' participation was voluntary, however, payment was offered. The program had agreed to compensate student volunteers for this research ( $\$ 20$ per hour), provided that they agreed to be interviewed for however much time was needed. The payment was used as an incentive for interviewees to complete the interviews as 
scheduled. Since participation was voluntary, it was not a random sampling, but efforts were made to select a completely representative sampling.

In order to fully understand students' perspectives and where such perspectives derive from, some personal background questions were asked at the interview, such as age and previous English educational experience (see protocol in appendix for full list).

Although this study asked for voluntary participation, only students from mainland China were selected, as the researcher was not familiar with the fine cultural distinctions between mainland China and Hong Kong. Although the researcher acknowledged the potential bias that this study might not represent a well-rounded picture of Chinese ESL students as its number was limited and sampling was voluntary, the researcher still expected that the participants would provide important information that would be valid for discussion. Table 2 presents the eight Chinese participants' personal information. (For more detailed information regarding each participant, see Appendix E).

Table 2: Participants' information

\begin{tabular}{|c|c|c|c|c|c|c|c|c|}
\hline & Lucy & $\begin{array}{c}\text { Trace } \\
\mathrm{y}\end{array}$ & Elaine & Emily & Jeff & Tom & Anthony & Steven \\
\hline Age & 18 & 19 & 19 & 20 & 19 & 20 & 19 & 19 \\
\hline Origin & $\begin{array}{c}\text { Beijing / } \\
\text { Guangzhou }\end{array}$ & Nigbo & $\begin{array}{c}\text { Chang } \\
\text { Zhou }\end{array}$ & Changsa & $\begin{array}{c}\text { Yan } \\
\text { Cheng }\end{array}$ & Beijing & $\begin{array}{c}\text { Chong } \\
\text { Qing }\end{array}$ & Shenyang \\
\hline $\begin{array}{c}\text { Fall } \\
\text { Level }\end{array}$ & 3 & 4 & 4 & 3 & 2 & 2 & 2 & 4 \\
\hline $\begin{array}{c}\text { Spring } \\
\text { Level }\end{array}$ & 5 & 5 & 5 & 5 & 5 & 5 & 5 & 5 \\
\hline $\begin{array}{c}\text { Parents: } \\
\text { higher } \\
\text { education } \\
?\end{array}$ & No & Yes & Yes & Yes & Yes & Yes & Yes & Yes \\
\hline
\end{tabular}


The Role of the Researcher

The researcher had been working as a faculty member for approximately three years in the program in which this research took place. Therefore, students in two Level 4 classes that she was teaching at the time of data collection were not selected to be participants in the study to avoid bias. This precaution was taken to avoid any possible misunderstanding and/or misinformation that could have affected the researcher as an instructor, to keep students neutral in terms of grading and other classroom related issues, and to otherwise avoid any conflict of interest.

Since participants in this study were ESL students whose English skills were still in progress, language proficiency may sometimes have been an issue. However, with the researcher being an ESL instructor for approximately ten years, and students being in the highest two levels of the program, the researcher was alert to protect against the possibility that there would be any significant misunderstanding or miscommunication that could have skewed the results of the study. Nevertheless, in the case of some challenges in regard to interpretation and clarification of data, the interviewee was contacted and asked to verify the intention of his/her remarks. In addition, a third party who is an ESL professional with no knowledge of or relationship to the interviewee, was called upon to analyze the intended meanings.

Another potential influence on this study was the researcher being a minority - an Asian non-native English speaker. It has been observed that ESL students have a tendency to react negatively towards non-native speakers (Amin, 2004; Mahboob, 2004). Furthermore, as a majority of the students in this program are Chinese, the researcher 
being Asian could cause expectations from Asian students that the researcher would be sympathetic with and understand their accounts. As both Japan and China are collectivistic countries, the researcher, who is of Japanese origin, was more likely to understand the participants' remarks relating to collectivistic cultures or collectivistic cultural backgrounds. However, it may have been disadvantageous if the participants expected the researcher to understand all the underlying cultural aspects, as these two countries differ significantly in their traditions, rituals, and social/cultural practices. Therefore, the researcher informed participants thoroughly that she would take a neutral position, while asking for detailed explanations of participants' remarks. The researcher also constantly reminded the participants to answer the questions without regard for the researcher's nationality.

One big challenge in the researcher's role was the political situation between the researcher's native country, Japan, and that of the participants, China. These two countries have historically been involved in politically sensitive situations, and Chinese students may have harbored hidden political views against the researcher's country of origin. However, the researcher fully explained her identity, including her country of origin, as well as the scope of research to the participants, who were given the choice to volunteer for this research. Therefore, it was expected that those who decided to participate did not have personal problems with the researcher's country of origin.

Having described those potential challenges, the researcher remained confident that her professional expertise as an ESL instructor and as a former international student office staff worker, and her careful and sincere explanation of this research before and 
throughout the interviews helped to circumvent any possible resentment or hesitation from the participants.

\section{Data Collection Strategies}

Each interview used the interview protocol described above and was digitallyrecorded. The researcher took notes during the interviews. The notes provided additional information regarding the transcribed data, including impressions and observations of the researcher that the recorded data may not have been able to provide. Although the protocol was used to guide the interview, the researcher did not fully control the interviewees' responses so that their responses could be spontaneously developed throughout the interview. In fact, the interviewees were asked to explore and expand stories related to the protocol questions as much as they could instead of giving one word or short answers to the questions. Their stories were highly encouraged as it was the scope of the study and purpose of the semi-structured interview, and these stories may carry important information that simple answers may not have revealed regarding their social, cultural, and academic challenges in transitions. The interview recordings were transcribed, and then analyzed together with the interview notes to identify the general tendencies of challenges that the participants experienced. Based on the interviews and their transcripts, a second interview was called for in case of a need for clarification or further development of themes and/or discussions. After both interviews were completed, the researcher started the analyses using grounded theory as the analytical tool since grounded theory allows for themes and ideas to be gleaned from the transcribed texts during the process of open coding and axial coding. 


\section{Data Analysis Procedure: Grounded Theory Technique}

\section{Open coding}

Once interview data were transcribed, analyses of the data were begun using grounded theory technique. The first step of analysis was "open coding”, which used both word-by-word and line-by-line analyses. Charmaz (2011) states that word-by-word analysis allows researchers to focus on "the structure and flow of words, and how both affect the sense you make of them, as well as their specific content" (Charmaz, 2011, p.50). Word-by-word analysis was adopted as the participants were Chinese students speaking English, which was their second language and the target language that they were still learning. Word-by-word analysis helped clarify some Chinese-English translation issues and other linguistic issues as well (issues related to their grammar, pronunciation, and choice of vocabulary).

Line-by-line coding required the researcher to be open to the data without imposing her own ideas, and to be able to see "nuances in it" (Charmaz, 2011, p. 50). By analyzing the data line-by-line, researchers are able to look at the participants' viewpoints, which helps identify both implicit and explicit ideas that participants spoke about. In addition, line-by-line coding helps provide new ideas to pursue for future analyses. Most importantly, line-by-line analysis prevents researchers from imposing their own preconceived notions on the data that they are working on. The researcher is from Japan, which shares some of the cultural characteristics as the Chinese participants. The researcher also started her U.S. academic career in an ESL program, and some of her experience transitioning to the U.S. social, cultural, and academic environment was 
similar to the participants. Therefore, line-by-line coding helped the researcher to be neutral and reduced the risk of imposing preconceived notions, thus allowing the data to present the participants' viewpoints and voices without the researcher's own experience interfering.

During the second interview analyses, focused coding, in addition to line-by-line coding, was adopted. Focused coding is "more directed, selective, and conceptual than word-by-word, line-by-line coding" (Charmaz, 2011, p. 57). It uses the codes that were identified as significant in the earlier analyses. According to Charmaz (2011), researchers are required to make decisions on "which initial codes make the most analytic sense to categorize your data incisively and completely" by conducting focused coding analysis ( $\mathrm{p}$. 57). Since the main purpose of the second interview was to elaborate and clarify some of the points in the first interview, line-by-line coding using earlier codes that emerged from the first interview analysis made more sense.

\section{$\underline{\text { Axial coding }}$}

The second phase of the data analysis used axial coding analysis. Charmaz (2011) summarized the axial coding process that Strauss and Corbin (1998) defined: “Axial coding relates categories to subcategories, specifies the properties and dimensions of a category, and reassembles the data you have fractured during initial coding to give coherence to the emerging analysis" (Charmaz, 2011, p. 60). Strauss and Corbin (1998) define categories as "for a phenomenon, that is, a problem, an issue, an event, or a happening that is defined as being significant to respondents" (p. 126). Subcategories provide answers to "the questions about the phenomenon, such as when, where, why, 
who, how and with what consequences, thus giving the concept greater explanatory power" (Strauss and Corbin, p.126). However, axial coding is not a completely separate process from open coding; Strauss and Corbin (1998) describe the process of axial coding as beginning during open coding as researchers are establishing properties of a category and their dimensions. Strauss and Corbin suggest using paradigm to sort and organize data. Paradigm includes (1) conditions, which address "a conceptual way of grouping answers to the questions why, where, how come, and when (p. 128), (2) actions/interactions which "are represented by the questions whom and how" (p. 128), and (3) consequences, which are outcomes of actions/interactions" (p.128).

As the literature indicated, the second phase of analysis involved relating categories and subcategories by their properties and dimensions, observed while conducting open code analysis. Then those categories and subcategories were analyzed using Strauss and Corbin's (1998) paradigm, identifying conditions by asking where, how come, and when, actions/interactions by asking whom and how, and consequences by asking what happens or what will happen to these actions/interactions.

\section{Selective Coding}

The third analytical stage was selective coding analysis. Selective coding is "the process of integrating and refining the theory" (Strauss and Corbin, 1998, p. 161) by relating and organizing categories around a central explanatory concept. Storylines were written to build "a larger theoretical scheme that the research findings take the form of theory" (Strauss and Corbin, 1998, p. 161). 


\section{Potential Risks and Safeguards}

The researcher made every effort to protect all the collected data with subject pseudonyms. All the digitally-recorded data, written data, and signed informed consent letters were stored and will be stored in the researcher's research drawer in her home for three years after the completion of research, after which time it will be discarded. Only the researcher will have access to the data. No personal records, digitally-recorded data, or written data will be shared with any individuals who work in this program.

There was minimal risk that someone could learn the participants' names and find out what their answers were. However, pseudonyms were used for all publications and presentations of this project. Every effort was made to strictly protect the confidentiality of the participants. In addition, there was a risk that participants would feel uncomfortable answering some of the questions. In such cases, the participants had the right to pass on any questions that they did not want to answer. When the analysis was complete, participants was asked to participate in member checks. Through the member check process, participants were able to judge whether their voices were accurately interpreted and represented, as well as if their pseudonymous quotes successfully concealed their identity from the readers of this dissertation.

\section{Schedule}

The researcher started interviewing participants in early to mid-February of 2012, and completed all the first interviews by the second week of March. The process of transcribing data commenced with the completion of the first interview, with the intention of finishing all transcriptions by mid-April. Second interviews based on the first 
interview data to clarify certain points were conducted in the end of April to early May. All participants except one male student - Steven - returned for their second interviews.

\section{Validity of the Research}

The data collected for this study came from two interviews from each of the participants. Even though the data came from a single source, the researcher made every effort to maintain its validity by going over the data numerous times with both open and axial coding processes, comparing and discussing open and axial codes that she created with her advisors to make sure that she remained objective and interpreted participants' voices accurately. The researcher also consulted with an experienced grounded theory researcher as well as the participants to clarify certain cultural notions expressed through the interviews. By going through such an in-depth process, the researcher is confident about the validity of the study.

\section{Conclusion}

This research intends to shed light on what international Chinese ESL students struggle with, how they feel, and what they expect upon arrival in the U.S. to pursue their studies. It also intends to explore how international ESL students see the potential gaps between their own expectations and those of their instructors, programs, and institutions here in the U.S. Through this research, the researcher intends to identify issues that were not yet fully appreciated in terms of international ESL students' academic and sociocultural transitions into higher education. In the next chapter - the first stage of data analysis - the results of the open code analysis will be presented to illustrate the eight 
individual students' stories and voices concerning their transition into the U.S. ESL program. 


\section{Chapter 4}

\section{Results of Open Code Analysis}

\section{Introduction}

The eight participants in an ESL program in a Research I university in the Midwest were selected to participate in this study. The ESL program consists of six levels, 5 levels of Intensive English Program (IEP) which offers non-credit courses and 1 level of English for Academic Purposes (EAP) which offer 3-6 university credit-bearing courses; writing/grammar, writing, reading, and speaking/Listening courses. All of the participants entered this program in the fall semester 2011, and they were full-time ESL students at that time. At the time of the interviews, they were taking at least one EAP course. Some of them were still full-time ESL students, while the others were taking ESL and university courses.

In this chapter, the Chinese ESL participants are portrayed with regard to their backgrounds, characteristics, and individual stories as gleaned from the interviews and open code analysis. The five most frequent themes emerging from these interviews are introduced in order to give voice to their experiences in the university ESL program. In addition, several insights from the participants about how to help the ESL program better understand its students, as well as other important implications are summarized.

$$
\text { Lucy }
$$

\section{Bored in Guangzhou}

Lucy was enthusiastic to be part of the study - she was the first interviewee in the both first and second round of interviews. Her major is psychology, and her reason for 
participating in the study was that she was interested in what kind of research another international student (the researcher) was conducting, as she herself is pursuing research in psychology to help other international students.

Lucy is an 18 year-old female student from Guangzhou, in the southern part of China. Her family lived in Beijing until she was 6 years old, when they moved to Guangzhou. As a child, Lucy spoke Mandarin, the main dialect in Beijing, until her family moved to Guangzhou, when she had to learn Cantonese, the main dialect spoken in southern China. At the age of 6, Lucy had already experienced culture and language transition and adjustment, as she explained:

I know if you come to a new place, it's a new culture, you feel uncomfortable, this definitely [makes] you feel uncomfortable. The only thing you need to do is make yourself, don't always feel negatively, making a change to yourself, being outgoing, and... if you want to make friends with them, they will make friends with you.

This experience in adjusting to a new culture would prove helpful when she enrolled in the university years later.

Lucy's family was living off her father's earnings from a bar he owned, and Lucy went to public high schools, which in China are decidedly regarded as superior to private schools.

Her high school had a special focus on English and by her senior year, she had five 90-minute English classes per week, as well as two 45-minute English classes per week. The high school had eight classes per day, so most students arrived at school at 
7:30 am and finished their last class around 7 p.m., but seniors had more classes in the evening and didn't return home until around 9 p.m.

During the interviews, she shared with me that her English class experience was boring and lecture heavy. Lucy explained that English instruction in China was mainly teacher-fronted lecture in classes that averaged 50 students. While the teachers talked, some students slept or otherwise failed to pay attention in the class. Lucy recalled that some teachers did not bother to address this misbehavior as there were so many students to teach.

Nevertheless, the English classes were rigorous, requiring approximately four to five texts and workbooks per semester, mostly chosen by the English teachers themselves, who considered the standard textbooks to be inadequate. Grammar was secondary to vocabulary, and the English tests in her high school focused on vocabulary questions which resulted in intense vocabulary study. Lucy was a motivated student, maintaining elaborate notebooks on vocabulary and developing her own system of study. Lucy came to the university with solid English vocabulary skills, experience with cultural adjustments, and a good deal of enthusiasm.

\section{Initiative, Courage, and Self-Motivated to Succeed}

The willingness to meticulously prepare and go beyond "boring" course requirements in her Guangzhou high school indicates a high degree of self-motivation.

Interviewing Lucy and reviewing her transcript, I noticed that she wanted to communicate her "self-motivation to succeed," studying beyond required course 
assignments both in China and in the ESL program. She was determined to show me examples of her drive to succeed.

I know I am always thinking about what's wrong, what I should improve [in order] to live here, I am always thinking I should do something, do something here [in the U.S.] I will try something new. I will try to ask them to understand [my English].

She also mentioned that "if it is impossible for them to understand me at first, it is my responsibility as a foreigner to adjust."

Lucy has incredible initiative and courage perhaps born from the childhood transition from being a Beijing child to a Gangzhou teenager. She seemed to not wait for cues or encouragement from adults in her effort to experience success with learning English. She explained that:

...I have that experience, so if you don't understand the language in the new place, you need make change by yourself. You need to find understand why they [Americans] are doing that. You need to find out what the differences are... So if you understand the difference, you can do it [speak English] better.

I was impressed with her determination, courage, and willingness to take responsibility to improve her English. Lucy was unhindered by any fears about a new environment and genuinely excited about the daily challenges of learning and living in a new culture with a new language. 
Meta-Analysis of Learning: the Desire for More American Social Space

Lucy not only has initiative, courage, and self-motivation for success, but an uncommon ability to conduct meta-analysis of her own learning and her cultural adjustment:

I think it's very useful if she [an instructor] introduces new vocabulary that we don't know, if she explains [it] in English because we always use the dictionary, we remember the Chinese meaning. But if you know the English meanings, you can understand that... And I think the English meaning is more useful.

She felt that the ESL vocabulary tests should use utilize English as a default explaining, "in vocabulary tests, you should require students provide English explanations, I mean, that's more useful, English words to help us understand."

The ESL program at the university strongly recommends that students use an English-English monolingual dictionary, and its homework and tests on vocabulary require English explanation. However, as a faculty member in the program, I am aware that students tend to eschew monolingual dictionaries in favor of bilingual dictionaries of their own choosing. It is also a common practice among students in the ESL program to write vocabulary definitions in their native languages while studying for homework or on their own. Lucy, who is willing to take a hard but definitely beneficial route to improve her English, is a rare find among her peers, the majority of whom do not seem to care no matter how insistently their instructors tell them to use monolingual dictionaries or provide English explanations for vocabulary tasks. Definitely, Lucy's ability to conduct a 
meta-analysis of herself and her study habits helped her to get a step ahead of the other students.

Lucy's prosperity for self-analysis for her learning led her to the realization of how she views the relationship with the university Chinese student community. From the perspective of meta-analysis, Lucy exposed a desire to "separate from Chinese students" at the university for the sake of learning English. She felt that there are too many Chinese international students at the university and in the ESL program, and desired to have learning and living experiences apart from the overwhelming numbers of Chinese students at school:

I feel just I don't know what I should do and just one more thing, cultural thing, at the university, [there are] so many Chinese people... In my roommate and suitemate they're all Chinese... Teachers require us to speak English, but the classmate are almost all Chinese, so I ask teacher to put the students from different countries, different students together. Then when you're discussing, you will have to speak English to someone not Chinese.

What Lucy is suggesting makes perfect sense. Under the current practice of the ESL program, however, students choose their sections in the beginning of the semester as the online registration system of the university allows them to. Consequently, many students tend to choose to be in the same sections with their friends, causing certain sections to have a Chinese-heavy demography. Chinese is already the majority of population in this program, with many fewer students from other countries. Therefore, 
the practice of letting students choose sections causes an issue that Lucy has identified in her desire to "separate from Chinese."

The distances from her Chinese classmates that Lucy seeks is converted to her desire to take risks and cultivate relationships with Americans in order to be fully immerse herself in the English experience. Lucy clearly communicated her longing to have American roommates, suitemates, or friends to practice English with, and her hope to have more interactions and relationships with American students at the university:

[In the university, there are] so many Chinese people. [Before I came here] I knew there will be Chinese people, but I don't know [the population would be] that big, that huge. My roommate, suitemate, they're all Chinese, [and] it's impossible [for me to] speak English [at home since] we speak Chinese. You may be able to do it [speaking English] a few minutes, but you can't do it every day. And actually I think more of us want to make more native speaker friends, but [it is] kind of hard because the class has a lot of Chinese.

She also used her current living situation to illustrate how little opportunity she has had to interact with domestic students:

Especially, me and my roommate, my suite-mate are Chinese, I think a lot of people are like that. Chinese people are too much (too many of them). It is easy to make our own group. Friends are Chinese, so we don't have opportunities to speak English, so presentation can let us, if you have a presentation, you must be worried about your pronunciation. 
Lucy was clearly frustrated with lack of opportunity to interact with American students. Through meta-analysis, she understood the link between social exposure and cultures as conduits to language. Classroom learning can only go so far, and as she shared with me, "You will try to practice, in your dorm, that is the way you can improve." However, without contact or regular interactions with Americans in the student housing, in fact, learning English became a more hollow and incomplete experience for Lucy.

\section{$\underline{\text { Parental Education, Guidance and Control, and Competition }}$}

So much of Lucy's successful transition can be attributed to the influence of her parents. She felt that parental control played an important role in the lack of progress among her classmates. She explained, "I think they become lazy, I think is because some of the Chinese when they in China their parents will control them." Upon their arrival in the United States, some of them become lazy or lose motivation to study as they are on their own without parents' guidance or control. This lack of discipline among those students who suddenly became free from parental guidance and control, however, is not limited to the realm of studies, but also extends to money management. Lucy told me that “if they go to the foreign country their parents can't control them anymore. And their parents will just worry about them. They think, 'oh, my children don't need to worry about money they can live better here'." Therefore, her classmates may ask for and receive more money than necessary from their parents and as a result, they may not be interested in studies any longer since they are free from parents' supervision and have large amounts of cash at their disposal. Lucy explained, "So they have enough money and 
...they will do something. They want do maybe something they wanted to do but they before they didn't have chance to do."

Essentially, Lucy told me that her Chinese classmates were out of control drinking, partying, and enjoying the freedom that came from becoming free and from being beyond their parents' guidance.

From what Lucy explained, some Chinese ESL students are unprepared to handle the transition from overly strict parental involvement in their lives the total excesses that come from the complete freedom from parental supervision. This negatively affected their attitudes not only to their studies, but also to their management of money, time, and lifestyle in general. Further analysis, however, reveals that this is not a problem with one simple solution. In fact, there appear to be other underlying reasons why some students lack self-discipline and money management skills - reasons that are beyond their own control.

While transcribing and analyzing the interview data, I could not help noticing the fact that parental guidance and control are very important for these Chinese students. Chinese students are often the only child in the family, and most of the students who participated in this study made frequent remarks about parents. Lucy commented that parental guidance and control caused certain Chinese students to struggle academically. She also mentioned that her parents had given her a "parental education", which indicates that she was raised to be humble, responsible, and more mature than her age would indicate. For example, she explained why she would not ask for more money than necessary compared to her Chinese classmates: 
...my mother always taught me that even though you have enough money to buy expensive things, you still need to keep your money. Keep your money. She always said to me that you never know what will happen in the future so it is better to keep your money and don't waste it... I learned from my parents that making money is not easy. So I don't waste their money.

For Lucy, setting aside a sum of money in case of future emergency was something she learned from her mother. She also appreciated how hard her parents worked to save up for her education, and therefore, she did not feel that she possessed the freedom to use all the money her parents gave her to study abroad, or that she needed to ask for more money to enjoy her freedom apart from her parents, as some of her compatriots did. However, not all Chinese parents teach their children how to be frugal so that they would be prepared to handle emergencies. She explained, "Maybe some in the class and some other children wear very beautiful shoes or maybe clothes because they [students' parents] don't want their children feel inferior, or they don't want their children become weak." In other words, Lucy felt that some of her classmates' parents spoiled their children with money instead of teaching them how to manage it well. Therefore having a lot of money to spend may be a result of their parents' competitive nature and a desire to assert their children's status over other Chinese students.

Imposing English Only Instruction as Acclimation to the University

It is a common dilemma among ESL instructors at the university to deal with lack of willingness among Chinese speakers to use English in class. The ESL Instructors at 
this university have different strategies to encourage Chinese students to speak English during the class, including oral encouragement to speak English in class, deducting participation grades if they speak in Chinese, and mixing different nationalities in discussion groups, among others. Since Chinese students comprise the majority of this program, and since there are many more Chinese students than the other nationalities in the program, it is often the case that Chinese students don't feel compelled to speak English. As a result, instructors continue to struggle to get Chinese students to speak English in class. When I asked Lucy her opinion about speaking English with Chinese students in class, this was her perspective: “I don't feel like it works because maybe you speak English and you are wrong like the Chinese grammar way ...they can understand you and they will not feel you are wrong. And you will keep doing this."

The first reason Lucy thought that speaking English with Chinese students is not a good idea is because each Chinese person will keep repeating their mistakes since they will not receive opportunities for recognizing errors as when interacting with native speakers of English. She further explained, "Some words [that Chinese students use] are very old words still used in China, but Americans don't use them anymore."

I questioned the participants whether they felt the ESL program and the courses they had taken were useful and informative, and I was surprised to learn that many Chinese students did not like - and some even hated - the ESL program. The idea of Chinese students' not liking or even hating the ESL program was strongly grounded in the interview data and confirmed in my experience as an instructor in the program. 
My suspicion is that some of this dislike came from the ESL program efforts to force students to use English. Lucy saw this as a positive practice. Lucy responded positively to the question about whether she found the ESL classes to be useful and informative. She said, "I think that ESL class just let me know how American university classes look like. Because I was also enrolled in other university classes this semester and I thought that they just look like the ESL class. And actually the academic lecture looks like that ESL lectures, and I felt that 'yes, this is the same'. And since I was exposed to the ESL class, I was comfortable studying for the other courses."

Clearly, according to Lucy, the ESL program helped her to acclimate to the university and to the prepared for American style lectures. Lucy also realized that she had received not only language instruction and academic preparation, but also cultural information through the ESL programs - tools that would make her transition into the university academic climate easier.

\section{Tracey}

\section{$\underline{\text { Practiced English with her Mother }}$}

Tracey was formerly my student in a level 4 reading class during fall semester 2011, and at the time of our interviews, she was 19 years old. She was born in Chang Zhou, Jiangsu province. Her mother, who now works in the Public Prosecutor's Office in China, was a graduate of Temple University in Philadelphia, where she studied law. Her father graduated from a Chinese university with a majoring in engineering. She also has an aunt and uncle who live in the Detroit, Michigan area and work for Ford and General Motors. 
For Tracey, studying abroad was encouraged by her mother (her father was against it), who strongly felt that she should study in the U.S. I remembered her as having been reserved in class, but individualistic and independent from her Chinese peers. What Lucy had to work at came more naturally for Tracey.

Unlike other Chinese participants, Tracey lived with her parents while attending schools in China. She received about 30 hours of English instruction per week, which consisted of listening to teachers and remembering what they taught. Tracey remembered that homework in her Chinese English classes consisted of reading articles and working on grammar exercises. She didn't think her Chinese English teachers' English skills were very good, and like Lucy, she did not think the ways of English instruction or study that were encouraged in China were particularly helpful. As a result, she practiced English with her mother, who had better English skills than her teachers. Tracey put it this way: “because my teachers' English is not so good, and also, I don't think the way they teach is good for studying English."

When I interviewed Tracey for the first time, we met at a nearby restaurant. Unfortunately, the restaurant was noisy and busy with the Sunday morning brunch customers. Maybe because of this, Tracey was quiet and unelaborative during the interview, typically giving short answers. As a result of the bustling restaurant, Tracey's quiet nature, and her parsimonious responses, I didn't learn as much from her as from the other participants. What typically was a 90 minute interview lasted about 30 minutes, by far the shortest interview of this study. 


\section{$\underline{\text { Language Issues as Victimization }}$}

One important issue for Tracey was how much language differences and not having a good command of English prevented her from bonding with non-Chinese ESL students, as well as the Americans on campus. Nevertheless, Tracey shared interesting commentary and overall similar experiences with other Chinese participants. She felt that she had language issues that hindered her effort to establish relationships with other international and domestic students and her ability to access the university's student services:

When teacher's teaching us, if I have something don't know like XXX [inaudible] or like uh questions I don't know how to explain to teachers then just connect with my friends. When we use teamwork to solve some problems in class, I don't know how to connect with my classmates. I don't know what they mean and when I speak, they don't know what I mean. Also, it is hard to communicate with the local language [English]. I don't know how to say it, and they [the sales clerk] don't understand what I mean. Also, when I want to eat something, I don't know how to tell people what want to eat, so I just say this one or that one.

The language barriers faced by Tracey were not unique to her. However, where Lucy was fearless and saw language issues as a necessary challenge, Tracey appeared to feel victimized.

The differences in instruction styles between her Chinese language courses and those at the university also served as a barrier for Tracey. In her mind, Chinese pedagogy 
conflicted with the ESL pedagogy - especially the contrast between the lecture-based English classes in China with the student-centered classes in the U.S. She commented on this pedagogical difference:

Because in China, we just listened the teacher talked and we never connected with them or raised my hands to ask some questions. I think a teacher seldom asks Chinese students to raise their hands and ask questions. I think the teacher should explain more to us if they time to ask us questions or ask as students to raise their hands.

She explained the differences between the use of blackboards in China and the ESL program, as ESL teachers used the blackboard less frequently than Chinese teachers with the result being that note-taking was more challenging. Tracey explained that, "I think that sometimes they should just write something on the blackboard to help us understand more easily because in China, the teachers always write whole things on the blackboard, and we take notes."

Clearly, Tracey was bothered by what she felt was an absence of direction which was experienced by her as instructional ambiguity as. She was used to being told what to focus on and what to do.

Like many other classmates, the influence of Tracey's parents was strong and obvious. For Tracey, her mother was the primary English instructor and mentor. She explained how she practiced English in China.

I practiced my English with my mother, because my mother's English is good. She graduated from an American university. [I preferred my 
mother] because my teachers' English was not so good. And also, I don’t think the way they teach is good for studying English.

It appeared that Tracey appreciated her mother's instruction more than her Chinese English instructors, and most likely to ESL instructors at the university. Unintentionally, however, this dependence on her mother may have undermined her adjustment to the university. She preferred direction - being told what to do - which conflicted with the student-centered ESL approach common in the U.S.

Part of the student-centered instruction common here is the practice of teachers asking clarifying questions such as, "Do you have any questions?" This happened far too often for Tracey, who preferred that the teachers explain or keep talking about the course contents.

... don't ask questions, just talk. They should just write something on the blackboard to make me, to help us understand more easily because in China, the teachers always write whole things on the blackboard and we take notes.

Language barriers can be caused by the differences in pedagogy between East and West, and Tracey frequently got confused.

Because the teachers talked so fast, and when they ask, 'do you have any questions?' we all get nervous. In China, we just listened to teachers and never connected with them or raised my hands.

As the above excerpt shows, Tracey explained that she used to receive instruction in which Chinese teachers kept talking and would not check to see if students had any 
questions. Instead, they simply continued giving their lectures. Being more comfortable with Chinese instruction, Tracey preferred thorough explanations, with teachers going over the content or assignments. I asked if she would like it more if ESL instructors would explain rather than asking students if they had questions, and she replied that she would prefer instructors to keep talking and explaining instead of asking students questions. According to Tracey, ESL instructors' questions to Chinese students had the effect of causing nervousness.

The first interview with Tracey revealed much about the difficulties in transitioning from home to schooling to Chinese instruction to American student-centered pedagogy.

The second interview was conducted in my office and revealed a more open and relaxed Tracey. Like Lucy, Tracey mentioned the importance of family and how parental guidance and pressure influenced Chinese ESL students. For instance, Tracey mentioned that she frequently felt pressure from her parents to complete ESL studies as soon as possible, stating, "Our family is not very rich so we almost put all the family's money into my studies... I feel pressure to get a good job and bring the same money back home." In this statement, Tracey confessed that she felt a pressure from her parents and that her education cost the family a lot of money; thus, it was her duty to do well while studying abroad. For Tracey, getting good grades and expanding her knowledge in the university were a payback for the money that her parents had invested in her. Another pressure from her parents is evident in her choice of a major. She originally wanted to pursue a degree in veterinary medicine, but her father did not approve. Therefore, she eventually changed 
her major to computer science, which her aunt and uncle living in Detroit had majored in while attending American universities.

[Her aunt] thinks with the computer science I always can get a job in America. My first my major was veterinary medicine, but I changed my major to computer science this semester. My father was angry about my choosing veterinary medicine. He thinks veterinary medicine is dirty and bad for me and that it would cost so many time [and money] in school.

\section{As Parents Indulge, Students Disengage from ESL}

As seen in Tracey's example, pressure from parents can alter students' decisions and future direction, as she changed from veterinary medicine to computer science to please her father. It may be surprising for students from an individualistic culture like the U.S. to see Chinese students yielding to parental pressure even though the students are over 18 years old. Yet, in Eastern collectivist cultures, heavy influence from parents needs to be recognized since that is what Chinese students carry in their subconscious every day while studying in the U.S.

Tracey came from a family in which parents saved up money to support her higher education in the U.S. In contrast, some Chinese classmates come from families where money is not an issue at all. She explained that such students "have parents who own companies, so they don't worry about a job [after college].” Rich students whose parents own a company and have a lot of money do not need to worry about their expenses and future jobs. Consequently, Tracey and Lucy were both of the opinion that 
rich Chinese classmates did not always have motivation to study well or were not concerned about transitioning into new academic and social settings.

She further explained that she usually did not hang out with those students saying "because they are different; they have cars, or live outside campus." As Tracey noted, the differences in family backgrounds may affect friendship groupings among Chinese students, and may also create a separation between some rich Chinese students and the university student community as a whole.

Tracey continued that she had heard an American student in her dormitory make negative remarks against Asian international students on campus.

It was not my roommate, but she was living next room. She is American. At first, her roommate was Chinese, but they always argued, so the Chinese roommate moved out and another American student moved in. I think they don't like Asian people; I didn't listen it clearly. But they talked next door and I heard them saying [bad things about Asians].

While this comment in itself may sound as if the American student was ethnocentric and not accepting of a Chinese roommate, Tracey clarified that the race, culture, and nationality were not the only reason for problems. She commented, “...but I think I can understand them [American students] because some of the richer [Chinese'] behavior is bad. If I am American, I will hate them too." Yet she noticed some chilly receptions for Chinese students among other Asians in the university community, explaining, "Some people in supermarket, they sell things to people, but when they meet Asians, they will not smile and don't like to talk to them." While it is difficult to find the 
source of chilly reception in the university community, Tracey's narratives point to a combination of racial, cultural, and language bias, and misbehavior borne of wealth and a particular brand of Chinese arrogance.

$\underline{\text { Separate from Entitled and Arrogant Chinese }}$

Tracey is repulsed by the arrogance of some of her Chinese classmates. She expressed her desire to separate from the entitled and arrogant Chinese, as there is a noticeable presence of Chinese students on campus, especially in the ESL program. Tracey mentioned:

[Having too many Chinese in classes] is bad for our attempt to learn English language because when teachers talk about some new concept that we do not understand, we [Chinese] talk to each other rather than using English to figure out with other international students.

Not only did Tracey want to separate from her Chinese classmates, she told me that she desired more diversity in the ESL classes, both socioeconomically, with less wealthy Chinese, and ethnically, with more international students from other nations. She explained:

I don't care about because almost, most Chinese here are rich. They live differently from me as I prefer to study, and do not prefer to eat out. I think they [rich Chinese students] are trouble, so I need to keep away from this kind of rich person.

Like Lucy, Tracey noted that there are many students from China on campus, and a good number of them are consumed with exploring their new found friends by partying 
and misbehaving. Tracey implied that they are rich and spoiled with money, and that they do not have any pressure for their futures. While both Lucy and Tracey are independent young women, the former distinguishes herself by not having contacts with them outside class and relying on her family virtues of valuing money and not wasting time. For Tracey, family values and financial status are the big factors behind her repulsion to the wealthy students around her. She did not identify with such students, but she may not have needed their support, as her aunt, uncle, and mother provided all the support and advice she needed about negotiating an American university. More City Social Support net

Tracey expressed that her aunt and uncle who studied abroad and live and work in the U.S. were as influential as her mother. Both live in the Detroit, Michigan area, and have helped her adjust to the U.S. society and academic life. "I have my father's sister who live in Detroit, and stayed with her for maybe ten days." She also told I me that she talks with her aunt once a week and receives tips on attire as well as academics, and university life. She asked for information about "how the winter looks like, what I should do, and what clothes I should wear, and how to how to get along with my friends and my professors."

\section{Elaine}

Elaine had also been my student in level 4 reading class during the fall semester. At the time of our interview, she was 19 years old. She is from Ningbo, a seaport city in Zhejiang province. She attended a public high school away from home and lived in the school dormitory. According to Elaine, the school was one of the top three schools in the 
country. In the dormitory, she shared a room with 11 other students. They all followed a schedule that included waking up around 6 a.m., doing morning reading or homework between 6 and 7:30 a.m., then doing physical exercise until breakfast at 8 a.m. Classes started between 8:30 and 9 a.m. and ended between 4:30 and 5 p.m. The students in her school had dinner in the evening, and after dinner returned for two to three night classes or homework labs. After those night classes, they went back to their dorm rooms and studied on their beds, for as Elaine explained, there were no desks in the dorm. A Grueling Schedule but Worth Attending High School So Far Away from Home Elaine was one of the few students who took Gaokao, the National Higher Education Entrance Examination. Scores on this exam determine which university successful students will be allowed to attend.

Elaine had nine years of English education in China, taking two to three classes totaling six to eight hours of English instructions per week in elementary school. Her middle school provided six to seven 40-minute English classes; in addition, she attended after-school English classes, as her father wanted her to be good at English when she entered high school. The after-school English classes were about six hours per week. In high school, she received six to eight 40-minute English classes per week. Elaine explained that in high school English class, the teachers always focused on textbooks and workbooks. She said "We always focus on textbooks, so there are many books and we just read articles [in the textbooks]. Maybe the ESL does the same, but we had extra books and a workbook. And teachers ask different kind of questions.” 
Elaine explained that there were fifty to sixty students in a class in her high school, and that not all the students were attentive during English classes. She said that the students had a large amount of homework from all the classes, and they focused on finishing those assignments. She also explained that her ways of studying English were to focus on grammar, memorize vocabulary, and recite articles.

\section{Father's Wish to Learn Western Culture}

Like Lucy and Tracey, Elaine's parents figure prominently in her academic journey. Like Tracey, Elaine had a strong father who guided her through a rigorous high school experience, the Gaokao test, and on to an American university. Elaine explained how her father had given her a push and encouragement when studying for Gaokao, the national college entrance examination:

I really didn't want to take the Gaokao because I was so nervous and afraid. But my father told me it would be a big challenge for me because I was afraid of taking exams. But in my mind after during and after taking Gaokao, I didn't feel stressed out very much.

She attributed her overcoming the fear of taking Gaokao to her father's continuing motivation and encouragement. He also strongly encouraged her to attend an American college:

In China many students took extra classes, and parents don't want their children play all the time. He said he would like me to learn many Western cultures. He just wanted me to come to America to learn western culture and get along with many American people. He encouraged me to 
learn a lot of things like how they eat, how they live their lives, and how they work. He just wanted me to learn a lot of things about Western culture.

Elaine's father seemed quite confident in her ability to succeed in the face of the many challenges he presented to her. His specific instructions appeared to lay out a trajectory that would result in success in the West. Elaine was programmed by her father to work at an intense pace in order to achieve success.

\section{Expectation of Academic Rigor and Reward}

Intensity and a heavy work load did not intimidate Elaine. When I asked whether Elaine liked the high school she attended, she answered, "Yeah, it was very busy every day. Yeah it was very busy but I was very happy." When asked about adjusting to the university and the ESL program, she replied, "I think we should have more homework to improve our GPA and extra points (for hard work)."

Elaine mentioned the satisfaction she found in heavy academic rigor and rewards. Her Chinese K-12 schooling was intense, and required a high degree of discipline and motivation. Like Lucy, Elaine spoke often about motivation but in ways that invoked differences between Chinese ESL students. Like Lucy and Tracey, she recognized a lack of motivation among many of her Chinese ESL classmates. She observed that "Some of them are not in are not good at studying because they don't want to study, so they don't listen to the teachers." Lucy, Tracey, and Elaine pointed out that many of their classmates saw ESL as an inconvenience and a burden, and thus did not invest their time and energy. 
Whereas these three young women embraced the opportunity to use ESL to prepare them for success, many of their classmates simply didn't apply themselves.

\section{$\underline{\text { Chinese English Classes }}$}

Even though Elaine applied herself to her ESL schoolwork with enthusiasm, she still felt that the instructional approach was lacking. She found it difficult to connect with the materials and preferred Chinese instruction even while critiquing her Chinese high school classes. Elaine recalled her English classes in China this way:

[English class] It's boring just a read it. And they told us some grammar. Many people didn't listen to the teacher while in High school because we just the read article. So the homework and knowledge are from books. Grammar and exams are also from books.

She continued by explaining the prevalence of text generated examinations which support the fact that the English curriculum in China is thoroughly based on the textbooks and did not allow for flexibility and creativity from instructors she experienced in the ESL program at the university.

\section{Chinese Student Community in the University}

As similarly noted by Lucy and Tracey, Elaine commented on the large Chinese student contingent at the university. The presence of these Chinese student organizations, independent groups, and individual Chinese students has a significant effect on Chinese ESL students' experience here, both directly and indirectly. Elaine has found this Chinese community helpful, stating, "When I arrived, I didn't know how to get around, but in the ESL, there are many Chinese students, so it is easy to get along with them." In addition to 
the help she that she was able to receive from her co-nationals adjusting to day-to-day living, she benefited from academic support as well, explaining that "Because we have the same class and if we, we don't know we can share ideas. In level 4, we have a group in QQ, and we can chat with together in in the QQ. And people take part in that group."

While grateful for the benefits of the on campus Chinese community, Elaine did not hesitate to critique its disadvantages, noting that the existence of a large Chinese community is not always beneficial to Chinese students. In fact, Elaine experienced a change in motivation and study habits after becoming involved in her Chinese community:

I studied hard in China but once I came here, and I became lazy because others don't do homework, and I thought, oh, I don't want to do homework, either."' At first I always did homework after class because I thought if I finished my homework first, I would be free. But now, I play first and the night before the classes, I remember I have so much homework to do, and I stay up late.

According to Elaine, the propensity to work hard for the rewards that are the product of rigor is undermined by the social temptations of the university Chinese community. One could argue that all college freshman experience motivational challenges at some point, and it may be that after years of intense study and parental pressure, a break is needed. Either way, for Elaine the struggle to stay focused while maintaining connection with her Chinese classmates was highly problematic. 
Gratitude that Comes with Understanding

Problems staying focused aside, Elaine found ESL writing instruction at the university to be useful and superior to her Chinese high school. She said, "In writing I think, she [the instructor] told us how to write and you use the quotes and how to paraphrase, and I think I had never done it before."

The writing instruction she received in China did not require the same skills that are required in the U.S. because back home, "In the test we just write our own thinking." Elaine complimented other ESL classes, "Reading and listening are also helpful. Listening class helps me with my speaking, listening, and note-taking skills. [In reading class] we read many long articles, and the teacher told us [in university classes] we will read hundred pages a day."

Elaine "gets it" and has developed an appreciation for the pedagogical goals behind the lessons. Here, it seems that her work makes sense in the context of the end game, being able to read 100 pages per day. (It is important to note that at the time of the interview, Elaine was almost finished with the ESL program)

Although Elaine understood the usefulness of ESL classes when she looked back at the end of her ESL program, not all the Chinese students agreed, especially those who were not near the end of the program. As Elaine observed, "Some students say that they have too much homework and that the class is boring. Some students said that the homework is boring and not useful in daily life or in the future." It seems reasonable, therefore, that gratitude and appreciation of the ESL program is more likely to occur as students near the end of their program. 
$\underline{\text { Patience, Pacing, and Other Characteristics of Good Teachers }}$

Elaine commented that instructors' characteristics affect who Chinese students see as their favorites. Her favorite instructors were those who:

always make the classroom active by having us play many interesting games. The pace of [favorite teachers'] courses is very detailed and well planned with teachers' showing models on activities. Plus those teachers are kind to us; if we don't know something, we can ask them, and then they will explain in a patient way. Whatever help we need they will help us.

The characteristics Elaine used to describe her favorite teachers - patient, fun, and aware of pacing - appear to be a part of their teaching philosophy. When considering her descriptions of instructors she did not like, however, it is difficult to determine whether it is because of their teaching philosophy or Chinese students' misunderstanding of what American college learning is about. She mentioned, "The bad teacher... some are who ignores us and always assigns boring work, like always reading, reading, reading, reading, so, it's so boring." While students should not be ignored, the concept of "boring work" should not be taken at a literal level. In my experience as an instructor in the program, what students call "boring" or uninteresting may actually be critical skills that need to be understood.

Demanding and Strict Becomes "Mean and Unfavorable"

Some Chinese students saw strict instructors as "mean to students." Elaine explained "because they got the low GPA, they think the teachers are mean to them." She 
herself, however, would not agree with these students, stating that "if they work hard, they can get a high GPA." From her statements, what can be understood is that some unsuccessful ESL students may see the instructors who gave them lower grades as "mean" and "unfavorable." This is a telling observation, and it is important for ESL programs to be aware that instructors who are strict may receive lower teaching evaluation scores since some Chinese students tend to see those instructors negatively.

As Elaine noted, many of her Chinese classmates wanted good grades for minimal effort. She mentioned that students who lacked commitment to hard work still expected to pass courses. She told me that "They want to pass because they have some pressure from their parents, if they don't, pass the course, their parents will be mad at them." She also shared the example how her father would have reacted to her if she hadn't passed the course:

If I didn't pass my class, my father will be angry with me. He will feel that I don't have the ability to study in the American university. He said if I don't have the ability to study, I just can go back to China because China is easier for me to pass.

Parental pressure and influence were key storylines for Lucy and Tracey, and the same can be said at Elaine. One could assume that fear of failure and its resulting penalties (including having to return to China) would motivate Elaine and her classmates for their grades, yet the idea did not seem to universally register with these Chinese students. Instead, they were likely to see low grades as the result of their teachers' negative characteristics, such as being "mean." 
To Be More American, to Be Less Chinese

As previously shown, Lucy was convinced that American friendship was connected to learning the language; creating distance from Chinese classmates appeared to be a strategy to pursue this goal. Whether they utilized opportunities to pursue American friendships depended on their personalities and their motivation to cultivate relationships. The ability to cultivate these friendships was related to where they lived, as certain dormitories provided more opportunities to interact with American students.

Regarding this point, Elaine explained:

Now I live in H Hall [where majority of Chinese students live], but last semester I live in C Hall, where there are many Americans. We are Facebook friends, and they post things like 'are you doing well?' 'I miss you.' I even have taught one American student some Chinese. He let me help him do some homework (laugh) He felt very happy and we are got close with each other. The floor leader in C Hall was very friendly and he always let me watch the movies with them.

Away from the presence of Chinese classmates, Elaine was able to connect with Americans and expand her comfort zone. Prior to moving to a dormitory in which many Chinese students live, Elaine had multiple opportunities to interact with American students in a dorm where there were very few Chinese students. Her statement indicates Chinese students would explore opportunities to cultivate relationships with more American students if proper opportunities are given. It doesn't take a rocket scientist to figure out that being placed in a dormitory full of Chinese students with a majority of 
roommates/suite mates being Chinese makes it difficult to find and cultivate relationships with Americans.

Lucy earlier observed the tendency of Chinese students to speak Chinese during the class, and Tracey explained why Chinese students do not feel comfortable speaking English with other Chinese students in class. Elaine added another dimension to the same issue, namely peer pressure, specifically as it relates to identity and in-group/out-group behavior. She explained that if "other Chinese students are speaking in Chinese, and you just use speak English to them, they will think you are different and [less Chinese]." Elaine's comments imply that when Chinese students use English with their Chinese classmates, the classmates take it as an insult, as if the English-users are trying to flaunt that they are more American, and thus, less Chinese. Her comments seem to suggest that identity is the culprit behind Chinese ESL students addressing each other using Chinese in class rather than English.

She offered the following opinion about the case of a Chinese student who continues speaking English with other Chinese students who are speaking to him/her in Chinese. "I think they may have some thoughts in their mind (dislike or disgust), so I think they will talk with them with Chinese."

As she commented, her Chinese classmates insist on using Chinese with their fellow Chinese during the class, even though teachers instruct them to use English. Students who comply with the teacher's mandate to use English only may be stigmatized as "strange" or "different" from their co-national peers. Consequently, this peer pressure 
effectively secures Chinese as the first language at all times, overriding ESL instructors' demands to use English in class.

\section{Emily}

\section{$\underline{\text { Parents Sacrificed for a Better Education }}$}

Emily is from Changsha city, the capital of Hunan Province. Like Elaine, she took Gaokao, however, she is the only participant who studied in a Chinese university, majoring in art for a year before coming to the United States to pursue a degree. She decided to pursue studying abroad in the U.S. instead of graduating from the Chinese university so that she could become proficient in English. She excelled in and enjoyed her high school English classes but felt that by pursuing a degree in China, she was "throwing it away" and "would never touch it again."

She attended public schools and lived in the school dormitory during her freshmen year of high school, but in her second year, her parents moved closer to the school and rented an apartment even though this meant her father would have a long commute to get to his workplace. Emily said that her parents decided to move closer to her school and live with her because both Emily and her parents missed each other a lot, and she would not be able to get good sleep or maintain other healthy habits if she was in the school dormitory. Furthermore, the head teacher in the high school played an important role in this decision, telling her parents that she would do much better both academically and personally if the family were together. As Emily recalled, "my head teacher told them [her parents] if I lives in an apartment with my family maybe both academic and life would be better." 
I believe that this example demonstrates the extraordinary lengths that these parents may go to ensure the success of their children in the pursuit of their dreams.

Emily studied English for about ten years in China, starting in elementary school. She recalled the turning point of her becoming interested in English in middle school:

Learning English in junior high was a big step because our headmaster, head teacher [homeroom teacher] was teaching the English. She's responsible for the whole class from when we entered the school and when we graduated. After school, she would have us to just sit in the classroom and do some exercise or learn vocabulary by ourselves in order to remember it. I think she was really important in my whole learning English process.

While this Chinese teacher taught in a very traditional way, Emily also had guest lecturers from the U.S. to connect students to the language while in her high school. When we were freshman [in high school], we had one foreign teacher's English class per week. This teacher came from America to teach us. They were volunteers from Yale University. The Yale guest teachers made the courses more interesting by organizing activities or audio visual content connected to learning English. Sometimes she let us watch movies, and then we talked about the situations in the movie. And sometimes she gave us a couple of games to play with, but it was also related to English. I think the main purpose for the school to have that foreign teacher was to stimulate our interest to English. 


\section{Memorization and the Chinese Way}

While American English teachers in her high school did not assign homework and provided English instructions in a relaxed and fun atmosphere, English classes taught by Chinese teachers required more traditional methods of studying - especially memorization for the tests. About Chinese instructions, Emily recalls, "I memorized for the test. We always had three big parts. The three parts are listening, reading, and writing, and they [teachers] sometimes put multiple choice like four answers, choose one that is correct." She further explained how memorization shaped her study of English in China: I went through the whole passage when I looking for some unfamiliar words. I used the dictionary to find the answer, and then I chose the exercise book to look at a sentence where the word was used. I then remembered that vocabulary, reciting it with the sentence. I sometimes listened to some English songs and if I found good sentences [in the songs], I copied them to my diary or notebook. I am just accustomed to do this.

Memorization is not simply a personal study strategy in China; Emily explained that Chinese English classes required memorization for the tests. When asked what kind of assignments she had received from English teachers in China, she responded, "I can't remember detail, but I mean, I can memorize them for the test.” Emily’s comments suggest that Chinese students may enter the university holding the belief that memorization is the best or only way to study. In the U.S., many other study strategies, such as critical thinking skills, are required both in class and for homework assignments, so focusing on memorization only is less beneficial to Chinese ESL students here. 
Emily came to the university with a good deal of exposure to English through the traditional Chinese high school experience. Although she had some exposure to American guest instructors, the exposure was limited and possibly misleading. She might have concluded that non-Chinese instructors are always relaxed and fun but less demanding. While Elaine revealed that her classmates saw strict and demanding instructors as "mean," it is possible that Chinese students who had foreign instructors giving more relaxed and fun classes in China may have formed such false expectations toward U.S. instructors and therefore, misjudge their strict and demanding instructional style as "mean."

With her experience receiving more fun and relaxed English classes from American instructors in China and her possible misbelief about what the U.S. instructional pedagogy entails, it appears reasonable that she had critical comments about the ESL program and its instructional methods. It is interesting to note that Emily frequently expressed the opinion that she needed more explicit instruction in the ESL classes. According to her, ESL teachers ask students too many questions when they really should tell them what to do in very specific and clear terms. She prefers her instructors to be more explicit like Chinese teachers even though this might be seen as hand-holding and elementary by instructors in U.S. higher education. She said:

I think ESL teachers should focus on steps that the students are in and go through the whole process like Chinese teachers. In China, they will go through the whole thing. But in ELC class, teachers skip some steps, and I 
will feel a little confused. My classmates and I were confused about what they're talking about.

She connected with the idea that she and her fellow Chinese students need explicit instruction because of cultural expectations among Chinese that cause them to be shy about asking questions. Along with obedience to authority, humility is an important part of Chinese culture. Emily explained it this way: "I think the teachers ask if we have questions or don't understand. But most of the students are shy, and they will never ask questions. So teachers skip to the next point, and it is kind of tough to understand." It can be difficult for ESL teachers from the United States to understand the role culture plays in how Chinese ESL students keep quiet in spite of their desire to have course contents, activities, and assignments explained more explicitly. When I asked about this, Emily responded that she expects teachers to have the skills to solicit students' questions; "I think maybe it takes skills to stimulate students to ask questions. We should be able to say 'Can you explain to me in detail?'”

Furthermore, she commented that she would rather her teacher "just stay on this question or problem" rather than moving forward because nobody is asking questions. In effect, Emily said, “Don't ask us if we have questions, tell us all we need to in complete in detail." This is another telling comment, especially given the impact of Chinese culture on student class participation, and how students engage with classmates.

\section{$\underline{\text { Placement Testing, a Raw Nerve, and Humiliation }}$}

One issue that brought an emotional response from Emily involved the placement test for the ESL program. She displayed first anger and then sorrow when retelling the 
story of her placement test, often conveying deep frustration. She took the ESL placement test in August, 2011, just prior to beginning her first semester in the university's ESL program. Emily explained, "When I got the score, it's kind of low, and it made me kind of crazy because I didn't think it was my right level.” She continued, "I should be in Level 4 not in Level 2. I felt like packing my belongings and going back to studies at my Chinese university." Obviously, for Emily, being placed in the second level of the five level ESL program was not acceptable and caused a strong negative reaction, making her want to quit immediately and go home. She was shocked by her low placement, expressing great disappointment and a severely bruised ego.

I knew I should improve my English but I didn't think I should take so long to finish for ESL. It's crazy. I only took Level 2 for one week, and I was just disappointed and depressed. Every day I thought I was in level 2 and it would take four years to complete ESL. I thought it was a waste of my time.

Emily considered her low placement as unacceptable. It not only hurt her pride, but would block her from moving into academic studies for several semesters. Based on my experience as instructor in this program, the negative reaction and denial experienced by Emily was not an exception. It is not uncommon that Chinese students who are newly tested complain that their placements do not reflect their English abilities, and that they are humiliated to be placed into their assigned levels.

After several interviews, I found that the Chinese students blamed the poor placement test results on the program instead of faulting themselves for a lack of fluency 
in English. Curious about this issue, I asked Emily why she thought she had placed lower than her perceived English abilities. In response, she mentioned that jet lag was a big issue for her. As she recalled, "I came to the U.S. on August $18^{\text {th }}$ from China to here, but because of jet lag (I did poorly) since the test was on August $19^{\text {th }}$ in the morning."

In retrospect, Emily's travel arrangements revealed a failure to consider the effect international travel might have on her ability to perform well on the placement test. If she had foreseen the negative impact, she could have arranged to arrive earlier. At the same time, if the university had provided a clear explanation of the importance of placement testing in addition to the test dates, Emily's experience might have been different. Nevertheless, the conversations with Emily show her dependence and trust on the agency which took care of her application to the university. There was an obvious communication glitch between the agency and Emily, and an information gap left unfilled by the university that resulted in Emily's not receiving crucial information about when the ESL placement test would take place.

\section{“The Main Thing is I Don't Know" - The Story of Emily's Adjustment}

In the U.S., students who pursue higher education are generally expected to be responsible for knowing all the crucial information and to be well-prepared. At a bare minimum, they are expected to be responsible for placement tests and orientation at the beginning of the school year. It is clear that Emily, like many international ESL students, did not operate with these assumptions. Placement agencies used by Chinese ESL students are not always adept at conveying this information. Emily told me, "Yeah, that's [adjustment issues] bad. The main thing is, I don't know." 
Like Tracey, Emily also provided insights into Chinese students' cultural adjustments in general and her own cultural adjustment in particular. She mentioned the importance of maturity, stating, "I mean going to study abroad kind of makes you more independent. Not everybody [matures], just depends your parents." In other words, she thought that not every Chinese student would automatically mature and adjust during their study abroad experience. She further explained:

I think not all (the students), like 30-50\% have the same feeling with me. I have friends who don't want to change themselves. They do everything the same way as they were in China. I admit it hard to really put yourself into the US culture. I have a friend never made friends with Americans even though she has been in the U.S. longer than I have been.

According to Emily, many her Chinese classmates insist on carrying on their accustomed ways of living even while on a U.S. university campus. They may be able to prolong adjustment to their host culture or environment indefinitely because the university has a significant population of Chinese students. Yet, it is interesting to look at the reasons some Chinese students would choose not to adjust culturally, especially those reasons related to Asian culture:

I don't think I'm independent yet but I just want to be independent. Actually I'm a dependable person, because sometimes at first, when there is no friend or classmate to have dinner together, I will be disappointed because I don't want to be alone. I always want to stay with my friends, no matter if they're Chinese or American. I just don't want to be alone. It's 
unlike Americans because they can do everything by themselves.

American and the Europeans, tend to be independent, so they can do anything by themselves from very young to old. They have this ability.

But most Asian people they're shy. They don't want to hang out with anybody if they are not from the same place. They don't want to communicate with people, even the teacher and professor. I mean this kind of difference is according to culture because American people are more outgoing, and Asian people are more shy and don't want to share or to show themselves.

In the above excerpt, Emily expressed her desire to become more independent like American and European students, but she also analyzed how her Chinese culture casts a large shadow on her efforts to adjust. She expressed that in her collectivist culture, students tend to be shyer than students from other countries, and thus, they may not connect well to students from individualistic cultures. Nevertheless, Emily possessed the desire to become more independent and was able to self-analyze how differences between her culture and individualistic cultures need to be negotiated.

Meanwhile, some of her Chinese classmates were not willing to adjust or had no desire to become more independent.

They [Chinese students] just don't want to communicate with American and other international students, but they just want to hang out with people from China because they think academic studies are the most important. 
So they think "I don't need to get along with them [Americans], and it is none of my business."

Clearly from Emily's response, it seems her Chinese classmates may not fully comprehend the importance that campus involvement, social/academic connections, and college knowledge have as factors that can facilitate their academic performance. At the same time, they may not feel "welcomed" or included enough to believe that campus involvement is an option for them. Emily's comments indicate that she decided to get along with other nationalities because she needed resources to be able to function well in the U.S. - about moving from "I don't know" to "I understand."

When I came to the U.S., I knew I was not independent enough. So I thought going to the U.S., the most important thing I should change was to be independent because in China, everything was provided by my family. You can know my family spoiled me. Like they [her parents] rented an apartment near my school, like those kind of things. But in the U.S. they can't, touch any of the things like that. So, everything, I need to depend on myself.

Emily's comments indicate a focused intentionality to adjust to the university in order to know and understand American college student life. At the same time, she let me know the some Chinese students lack the intention to adjust themselves to the host culture. They would rather continue their Chinese ways isolated within the large community of Chinese students present at the institution. However, as previous research from Astin (1996) shows, campus involvement affects their academic learning. Therefore, 
the question arises as to how institutions, programs, instructors, and student services personnel can help students like Emily and her classmates realize the need to accept and adjust culturally to the new environment.

$\underline{\text { Reliance on Chinese Language and Differential treatment in University Classes }}$

Finally, adjustment for Emily and her classmates is complicated by the tendency to rely on the Chinese language instead of experimenting with English. She shared that:

I think the majority of the students in the ESL class are Chinese, right?

They are speaking Chinese because they know that each other is Chinese and they use the mother tongue first... I mean they just want to speak Chinese. Maybe they think speaking Chinese can communicate better, but when the teacher say 'stop speaking Chinese', we are little uncomfortable. Her ideas regarding speaking Chinese in class coincide with Tracey's contention that the use of their native language is due to its convenience. The Chinese language helps them understand class content while getting around the uncomfortable feelings associated with using English.

Emily was taking university classes as well as ESL classes at the time of interviews, and in her view the perceived hostility of some professors did not help with language adjustment. She suspected some professors discriminated against Asian international students:

You have the same age with American students, but the professor always discriminated as if they say, 'you're Asian, you're Chinese'. The result is that he will never spend the same amount of time on you than he does with 
American students. Even though America is a democracy, there is discrimination still exists, I often have this feeling.

The perception of discrimination is amplified by how instructors treat students differently. She explained that a certain instructor "treats the students in different ways and sometimes we think he is unfair." She continued:

He [the instructor] just gives the GPA, according to his feeling. Like he just thinks, 'oh that student looks good during my class. So I give him 4.0'and another student 'he's not active in my class, I should give him 2.0 or 2.5 something like that.

Again, Emily felt that teachers were treating students differently, favoring smarter students while ignoring students who were struggling. In her view, they were doing this without knowing whether successful students were actually meeting instructors' expectations and completing assignments, or whether struggling students were passive or not performing well on assignments.

There are, of course, alternative explanations, and it would be unwarranted to take Emily's conjecture as gospel truth in this situation. It is possible that the issues of discrimination described above have more to do with Emily's perceptions of the situation rather than the actual behavior of the instructors involved. It is possible that instructors were not discriminating, but instead, providing students with instructions when Asian students did meet their expectations. Regardless, the important matter to be noted here is the very fact that Emily perceived that she was treated unfairly, and felt she was 
discriminated against by her instructors. This finding is significant and worthy of further elaboration in the later review of all the eight participants.

\section{Jeff}

$\underline{\text { Parents Fostered his Desire to Study Abroad }}$

Jeff is from Yan Cheng city, Jiangsu province, an eastern coastal province of China. Like Lucy, he was an enthusiastic participant and was excited to share a lot of stories about himself and his study abroad.

Like all the female participants, he went to a public high school; he attended a local high school in his city for the first two years but transferred to Jian Ling High School in the city of Nan Jing before he started his senior year. Jian Ling High School offered study abroad preparation and emphasis on English instruction with American instructors. Jeff made his choice to transfer high schools, "because Jing Ling high school had the programs to improving your English more quickly, and they had American professors." His parents also played an important role in his decision, saying, "My parents got the information about Jian Ling High School through their friends. They asked me if I wanted to go there to study, and I said OK because I had a plan to go outside China [to study]." It was a social connection led Jeff and his parents to the information about Jian Ling High School. Jeff's parents also fostered his desire to study abroad by suggesting he attend this high school, enabling him to receive instruction to prepare for studying abroad.

Jeff learned English in both middle school and high school in China. During middle school and the first two years of high school, he had English classes taught by 
Chinese teachers approximately four and half hours each week. The typical English lessons taught by Chinese teachers consisted of reading, comprehension questions, and do some "practice with the multiple choice questions." Middle school English classes also included listening classes, but very few speaking lessons were offered. However, when he transferred to the study-abroad focused high school, he had a discussion class with American teachers. In the discussion class, Jeff watched movies and documentaries such as a program from Discovery Channel, President Obama's speech, and a documentary about President George W. Bush. In addition, Jeff received academic essay writing instruction that required writing long essays with complex topics such as comparing American and Chinese policies, topics which were rarely tackled in traditional English classes in China.

\section{Meta-Analysis of Learning: Challenge of Time Management}

Lucy was the first participant to mention the challenge of suddenly having too much freedom in the United States, and like Lucy, Jeff felt that there was too much freedom in the ESL program. He explained, "Lots of people from China don't spend time for studying because they have lots of free time. They have party or play with computers." Jeff reckoned such free time to be beneficial "to practice your English by talking to all the people," but his Chinese classmates did not have the same interest, and he was frustrated with their time-wasting, saying, "They always go to party or play with Chinese, and they don't practice English because there is too much free time." Another frustration for Jeff came from not being accustomed to having so much free time. He said it like this: "Maybe [Americans] has the different cultural idea [about free time], but I have four 
courses this semester, and even though I'm doing service learning [volunteer work], there is too much free time."

Jeff felt many of his Chinese classmates were partying a lot due to too much freedom; like Tracey and Lucy, he wanted to distance himself from other Chinese students. Jeff noticed the presence of an overwhelming number of Chinese students when he first arrived at the ESL placement test and described it this way, "I was very surprised when I came here. I thought, 'Is this China?'”

His dormitory on campus was no exception - having large number of Chinese students as well - and Jeff was not happy about this, recalling, "[Some Chinese] are not good because they play games in the study room. Why do they play games in the study room? So I moved out to an apartment now." The large number of Chinese students and their misbehavior in the dormitory influenced Jeff to move off-campus, away from their negative influence to his life and study.

\section{Independent Culture and Dependent Culture}

While observing his Chinese classmates in and out of classes, Jeff became aware of several cultural differences between the U.S. and China. In the U.S., independence and taking responsibility is very important, while in China, it is not uncommon for parents to take care of everything for their children. Once Jeff arrived in the U.S. and started his studies, he noticed that he was on his own without parents or teachers telling him what to do or how to do it, explaining:

Your teacher cannot tell you what to do. You must do that by yourself, and it is the most difficult thing for me. My parents have the experience for 
life, and they know what to do, what is good, and what is bad. But they cannot help me because they do not live here. Everything is new here, and Americans have different views and different culture. And I have to start everything on my own.

It is apparent that Jeff discerned that the students in American higher education need to be independent in thinking, behaving, and making judgment regarding their studies and life matters. For this reason, Chinese classmates who partied a lot or were always playing games without studying or practicing English really bothered Jeff and influence his decision to leave the school dormitory.

\section{Initiative, Courage, and Self-Motivated to Succeed}

Like Lucy, Jeff had a strong self-motivation to succeed in his studies and to experience in American life as much as possible, "In the United States, when you have problems, you must deal with them by yourself. And you need to be able to stay responsible because we are not here for one year, but four years." Jeff was clearly motivated and willing to make the adjustment to American ways. He was aware that his life in the U.S. would continue for four years, and learning and adjusting to American culture and norms was something that needed to be done. He further explained, "I like talking to others and watching movies. I sometimes go to Mormon Church because my friends joined the church. And I think going to the Church is interesting to understand different culture.” Learning American culture was important for Jeff. He was convinced that the ESL students should learn American culture during their free time, saying, "ESL students can learn [American] culture, and that helps remember vocabulary. It's good.” 
Interaction with Americans is necessary for learning and adapting to American culture, but these interactions are no always positive. For students like Lucy and Jeff motivated not only to study and improve English, but also to learn and adjust to a new culture - it must be disappointing, then, to have interactions with people treating them in an inappropriate way. Unfortunately, Jeff was one of the few participants who experienced harassment from some less-than-friendly people. He told me about two incidents that happened when he first got to the university campus:

During the first week, some American people were driving a car around school. When they saw us [a group of Chinese students], they call the name in Chinese. I don't know where they learned the word. Maybe they thought it was funny, but I didn't feel good about that. At another time, I got on the bus and some white people were talking about Chinese using F [word] and I was really bothered because they knew I was there. They were sitting around me.

It is sad that newly-arrived Chinese students experienced such an encounter. Incidents like this rob these students of the excitement and motivation of embarking on a new academic life here in the U.S., cultivating relationships with local people, and adjusting to local culture and language.

\section{$\underline{\text { Reliance on Chinese Language }}$}

Elaine gave an insight into the reasons Chinese ESL students continue speaking Chinese in their ESL classes, and Jeff weighed in with his own views on the matter. He suggested a lack of diversity in ESL classes was one of the reasons why Chinese ESL 
students used their native language instead of English in class, sharing his experience in one class with more diversity: "My writing class has a lot of non-Chinese from Korea, Arab and Spanish-speaking countries. So, my Chinese classmates don't speak Chinese in that class." However, not all the ESL classes are as diverse as he would have wanted. He continued, "In other classes, most students are from China and speak Chinese. The main problem is there are too many Chinese in these courses."

According to Jeff, when there are diverse groups of students in class, Chinese students do not use Chinese language with their Chinese classmates. Having diverse nationalities allows student groups to be mixed, with the result that students speak English. However, when classes consist of predominantly Chinese, the necessity of "having to speak English" disappears. Earlier, Elaine told me the peer pressure plays a big role affecting Chinese ESL students' decision not to speak English with their classmates. Jeff agreed with Elaine, saying, "If you use English and show you're different from others like you have high skills, they will be jealous [and will not be happy].” In other words, Jeff confirmed what Elaine had explained earlier - speaking English in classes where there are many Chinese is seen as an act of arrogance, showing off their skills, or possibly even a declaration of the differences - grounds for jealousy and alienation from Chinese classmates.

\section{$\underline{\text { Curious about Religions and Meeting Americans }}$}

Jeff found opportunities to learn American culture and meet people by attending the Mormon Church, which his Chinese friends had decided to join, and he shared his feeling about religion, "Chinese do not have religions, but we respect every god. We just 
do not believe in it. But when we came here, Churches invited us to join church and gave me bible.”

When Chinese students cultivate relationships with American students, many of them find their new friends practice a religion. Some of these 'friends' can be aggressive about evangelizing Chinese students, while the others are not. Likewise, some students may be genuinely curious about religion, while others may simply want opportunities to have relationships with Americans. In Jeff's case, he started visiting Mormon Church because he was curious. He commented, "I am really interested about Mormon Church. It's not pressure [from the Church] but I can get a kind of experience from them."

For Jeff, it was interesting to explore more about the Mormon Church: "When I first heard about them, I thought they do some ridiculous things like having many wives. But when I learned a lot of things deeply, I learned why this happened in the history. They do not do bad things."

His curiosity and desire to cultivate relationships with Americans might have led him to know more about the church. He also found joining the church had helped him learning about culture as well. He said, "Although I came to the U.S. because this country has advanced education, I am learning different religions, different cultural background and different family values, and lots of things. I am learning lots of things that I did not know before."

Overall, Jeff found cultural learning opportunities through going to the church. Clearly, interaction with religious groups or individuals who are reaching out to Chinese students is one opportunity for Chinese students to connect with Americans beyond the 
classroom or dormitory. Yet the question remains whether the university or the ESL program is offering enough opportunities for Chinese students to get involved in a wider campus community or local community apart from joining specifically religious groups, for as Jeff mentioned, Chinese students do not believe in religion generally, and having more opportunities provided by the university or the ESL program may provide different outcomes.

\section{Befriending among Chinese}

As all the female participants mentioned, there are a large number of Chinese students in both the ESL program and regular academic courses in the university. Among such a large student population, Chinese students certainly developed a pattern of befriending each other. Jeff explained how Chinese students tend to sort themselves, especially by the economic class. He described some affluent Chinese girls in his ESL class, saying, "I really don't like these girls in my class because they speak Chinese [in class]. They talk about their dresses, dating some boys, cars, and houses. Those things is the most important for their life but not studies." Jeff was of the opinion that although to him studies were more important and carried more priority, his Chinese female classmates showed little concern for studies, focusing instead on clothing, houses, cars, and boys.

Another significant insight that only Jeff mentioned was that Chinese friendship circles can be formed according to geographical areas where the Chinese students come from. "China is a very big country, and people, they have different culture background and characteristics. The northern Chinese people do not like the southern people." 
In light of China's size and population, the cultural and linguistic diversity must be considerable. It is not surprising, then, that grouping among Chinese students in the U.S. is widespread. Pride in their regional culture is something that Chinese students regularly compare with other Chinese students and has a significant impact on how they interact with each other. In fact, Jeff is from the Shanghai region and as a consequence, he had some rather unflattering opinions about students from Beijing, saying "They just talk more about the money and look down on other people. Beijing people [think] they are the center of China and upper class. So the [other] Chinese people do not like that.”

In the above excerpt, Jeff characterized many students from Beijing as thinking they are better than students from outside Beijing. In addition, Jeff implied that the students from Beijing are richer, and further speculated what these rich students might be thinking or doing in the U.S., "Some of them use a lot of money a month like one hundred thousand dollars. They first buy a house, and they buy a car. And some people want to show their money and they are rich." If affluent Chinese students are really spending thousands of dollars a month as Jeff explained, it is no wonder why there will be different groups affiliating by social class and/or regions due to the wide variance among these students in attitude, action, and lifestyle.

$\underline{\text { Patience, Pacing, and Other Characteristics of Good Teachers }}$

Elaine shared that her favorite ESL teachers' had patience, good pacing in instruction, and good characteristics. Like Elaine, Jeff found it important for ESL instructors to possess good characteristics. He described his favorite teacher in this way: “She's very friendly and loves students, spends a lot of time with us. She invited us to her 
house. If we had problems, we could ask her for help. She checked homework carefully and paid attention to us."

Jeff's favorite instructor in the ESL program had the following desirable characteristics - she paid close attention, was very kind, helped students in both academic and social matters, and rewarded hard-working students. This instructor gained Jeff's trust by being available to his questions as well as being strict and fair to reward his hard work. In contrast, Jeff described an instructor he saw as unfavorable, "I do not like one teacher because she does not remember things. One time, she couldn't find my test paper and gave me zero point even though I remembered that I gave her the paper that time." In Jeff's view, this instructor was unfair to punish him for her own mistake. Jeff went on to explain how other instructors' practices were unfair. He said that he had prepared a lot for a certain presentation assignment because he was a self-motivated serious student. His classmates, whom he felt had not prepared well at all, nevertheless received "very high grade about." Jeff was unhappy with his instructor, stating "Maybe she's friendly, but I do not feel like it is fair. If students do not prepare and practice their speech enough, the instructor should not give high grades." He saw his instructor as unfair because she wasn't strict and gave high grades to students without preparation. In his thinking, only hard work should be rewarded. Jeff's opinion stands in stark contrast to some of the participants mentioned earlier who do not like teachers who they consider to be too strict and give higher grades grudgingly. Those students consider the stricter instructors to be mean and unfair, treating them according to their personal negative feelings. These contrasts demonstrate that the interpretation of a teachers' strictness and fairness depend 
as much on the students' preconceived notions as upon the actions of the teachers themselves.

\section{Tom}

\section{$\underline{\text { Studying English since Elementary School }}$}

Tom is from Beijing, the capital city of China. He attended a private kindergarten which taught English, but went to public schools from elementary school to high school. During his kindergarten, elementary school, and high school, he lived in the dormitories living with his parents only during middle school. He did not take Gaokao, as he already knew that he wanted to study abroad. His high school, Beijing Foreign Language University High School, offered international classes to prepare students for study abroad. As Tom reported, "Half of my classmates went to Canada and half of them come to U.S."

Tom had eleven years of English instruction in China, starting around the age of six or seven. He recalled that he had both Chinese and foreign English teachers in his elementary school. In middle school, he had about six and half hours of English classes per week. Unlike middle school, his high school provided seven out of eleven classes in English each day.

Up to middle school, his educational experience in China was quite influenced by his parents, who chose both his elementary and middle school. He made his own choice about where to go to high school, as he himself explained, "I choose that high school because I wanted to study abroad." When asked why he had chosen this path, Tom responded, "When I was in my middle school, I always thought that the education in China sucked, so I really wanted to study abroad and to see something new." He also 
explained that his interests in studying abroad were influenced by movies and media as well.

Regarding types of English activities or lessons taught in China, Tom explained that in elementary school, teachers read American books "like the gingerbread girl or gingerbread boy, and I remember there's a cat wearing a hat."

English taught in his middle school was different, however, because there was no foreign teacher. The English classes focused on exercises for students to receive good grades because the middle school wanted their students to "attend a pretty nice high school." Bored with traditional Chinese middle school and its classes, Tom went to the study-abroad preparatory high school where there were five Chinese English teachers and five foreign English teachers. He considered his English classes to be of a quality similar to those of American high schools.

Tom also recalled being a good student in China, but sometimes changed how seriously he studied depending on how strict the teachers were. He confessed that "If I was interested in the homework or the project, I participated a lot. But foreign teachers' English classes were not that strict, and I sometimes didn't hand in homework."

\section{$\underline{\text { Unfamiliar and Confusing ESL System }}$}

When asked about the challenges he encountered in the ESL program, he confided that one challenge came from being unfamiliar with the system - specifically, his confusion with the ESL registration system when he tried to register for the second semester: 
"[In the beginning of] this year, the ESL office told me that I was a fulltime ESL Level 5 student and my classes were already assigned. But my friend told me that I could choose the courses. Then I talked to an ESL advisor, and she told me that I have to go to pick up registration sheet for Level 4. I was confused and didn't know what to do. I went to pick up the registration sheet and found that I was a part-time ESL [and part-time regular academic course] student. So, I was pretty confused."

Not knowing the system well and receiving different information from different people made Tom very confused. Had he not solved the problem early enough, he might have been unable to take classes that he had wanted.

\section{Chinese Community and Peer Pressure}

While a confusing new system was certainly a big challenge for Tom, like Lucy, Elaine, and Jeff, the large Chinese community and peer pressure from the Chinese contingent were even bigger. He considered the big Chinese community on campus to be a problem, one example being his involvement in "Chinese students' housing stampede." When the incident happened, he was a new student who “just arrived and didn't know much about the situation here." He was told by other Chinese students that he needed "to find off-campus housing and sign a contract for next year." Without knowing the local environment or situation well, he just followed his fellow Chinese students and rented an apartment off-campus, which he later highly regretted; much to his chagrin, the apartment was far away from campus and would require a car. Although he thought he was saving money by living off campus, any savings were negated by his need to buy a car. Tom, 
explaining why he rushed into his decision on renting an apartment off-campus without knowing much about the new environment, said, "Because everybody [every Chinese student] did it. At that time, everybody wrote on the internet, 'Who wants to be my roommate?' So I talked to my friend and we found a cheap apartment that's pretty far way." His unfamiliarity with how housing and the local environment work, together with pressure from his Chinese peers, made him rush into his decision. He then told me "We made a too quick choice and many of us regret about it. And this year we want to sublease our apartments. [Also] my mom told me that I should not just follow people."

Previously, Lucy, Elaine, and Jeff all mentioned the large amount of Chinese students in ESL classes and on campus, and the peer pressure coming from them. Interestingly, the Chinese community Tom mentioned was both physical and online. Although Tom certainly was part of the housing stampede he said, "Actually I don't know who started it. There's a Chinese social networking site, and everybody talked about off-campus housing and tried to find a place to live next year." From Tom's response, it is apparent that not only the physical Chinese community, but also the virtual Chinese community can significantly affect Chinese ESL students' lives, in either a positive or negative way.

\section{Managing Money for the First Time}

Another challenge for Tom was the issue of economic adjustment. Being homesick, he sometimes wanted to “taste my home or hometown's taste. So I just went to [Chinese] restaurants. [And] I like shopping and bought lots of clothes." He sought comfort by shopping and eating out at Chinese restaurants in town. However, he faced a 
challenge in money management because "I spent a lot of money last year, and I don't have much left this year because of food and shopping."

By the time we met, he had used much of his annual allowance from his parents on eating out and shopping. After that experience, he learned how important it was to manage his money, which he didn't have to do in China because "Myy parents usually controlled money, but [after coming here] they just gave me the money for the whole year."

In the previous section, Jeff discussed his realization of the importance of selfresponsibility in the U.S., in contrast to China, where his parents took care of everything. Tom came to the same realization of self-responsibility about managing money, but he had to learn it the hard way by spending most of his annual allowance in one semester and having very little left to spare.

\section{$\underline{\text { Self-Motivation and Hard work to Succeed }}$}

Like Lucy, Emily, and Jeff, Tom was self-motivated and focused on hard work as the path to success. As previously observed, Tom had difficulties adjusting to the new system that was unfamiliar to him, dealing with peer pressure, and learning how to be financially independent. As a result, he matured in his first year while studying in the ESL program, coming to the realization of what would make him a successful student. He concluded, “This year I am taking water and environment class, and it requires professional vocabulary and it's a little hard for me. But if I practice a lot of vocabulary, it's going to be easy." Motivated to succeed and willing to work hard, Tom said he was trying "to finish all the homework, have eye contact with teachers, and just try my best to 
focus on the on every class. And I participate in every class and communicate with teachers in the classroom a lot." Tom was clearly doing everything he could to work hard and succeed academically.

Joining a Fraternity

He had two hard lessons when he arrived at the university. He learned that he should not blindly follow his Chinese compatriots and that he must manage his money wisely. Having matured from these hard lessons, he became more independent and did not align himself with classmates who hung out only with Chinese. Instead of sheltering himself among the Chinese community on campus, he decided to join a fraternity to cultivate relationships with American students. He said, "I joined a fraternity and they all speak English. They have many events and I need to talk to people at some events. So it helps me to improve my English.” Tom found an opportunity to join the fraternity by chance while walking one day on campus. He was recruited to join the fraternity at that time, but they also "kept calling me and I thought I should see what's going on and I took part in some events."

Like Jeff, who was curious to knowing more about American culture and religions, Tom's curiosity motivated him join the fraternity. That, and the fact they were also Asian sealed the deal. Tom said, "They are Asian Americans, so it's a lot easier for me to get to know their cultures because they're still Asians and some habits are a lot different from white people. I think it's pretty cool to join fraternity."

Meeting fraternity members on campus by accident and receiving their persistent calls led him to become part of the fraternity. Their Asian background also helped 
because it made him lower his guard and identify with the members much more easily than the other racial groups on campus. His self-motivation to succeed was satisfied as well because relationships with Asian Americans in the fraternity helped his English and cultural learning.

\section{Advice from an Agency}

Tom used a study-abroad agency, which helped him apply to the university. He not only had help to apply, but also received crucial advice. He said:

I wanted to be a movie director, but I figured out it's hard to find a job.

Then my adviser in the agency introduced me to adverting major.

American advertisements are interesting, and many commercials on the internet are very funny. I think that is what I'm going to do in the future like creating new advertisement or commercials.

The study-abroad agency's advisor influenced Tom a lot by guiding him to the right major; taking into account his interests in movies and creating things, they suggested majoring in business/advertising so that he could continue to pursue his passion of creativity but have more security finding a job and making money in the future. Certainly, the use of an agency can be a life-changing experience, as Tom changed his mind and major according to their advice. 


\section{Anthony}

Summer Camp in the U.S. Determined his Mind

Anthony is from Chongqing, one of the national central cities and direct controlled municipalities in southwest China. His mother graduated from a two year college, while his father went to graduate school.

Anthony was not directly recruited from the same pool as the other participants. He was Jeff's friend, however, and met the criteria for this study. Jeff introduced Anthony because he was interested in being part of the study when he heard about Jeff being interviewed. As I needed another male participant, I decided to have him be part of this study.

Like all the other participants, he attended public schools in China, and he expressed the high regard with which public schools are viewed in China, stating, "There are very few private schools in China, and public school are much more respectful [than private schools]. Lots of people know those schools like Ivy league [schools] in the U.S."

Anthony went to local schools and lived with his family until the second year of high school. Like Jeff, who transferred to a better high school, Anthony also transferred to another high school for his senior year and lived in the school dormitory, stating, "I chose to go to overseas and study abroad, but my first high school couldn't provide better English courses for me.”

Anthony was determined to study abroad while he was in high school. In fact, he participated in a summer camp in the U.S. earlier in high school, when he made up his mind to study abroad in the U.S. Through the summer camp, he thought the U.S. offered 
"the best education in the world, the better environment [for the study because] the libraries are much bigger, the professors have a good communication skills, and you can communicate with the students who come from the all over the world." Anthony thought being able to learn from the best of the world and making connections with students from different countries would provide him not only with the educational excellence, but also "can help me get more the social experience."

Anthony studied English for eight years in China, but before deciding to study abroad, he was not focusing on studying English very much. He explained, "I had to study other subjects at the same time, so I didn't concentrate on just study English. I just studied for two hours for studying English every week."

Anthony also agreed with all the previous participants regarding traditional English classes in China. He told me that his classes were big with 64 students, and teachers just followed the textbooks and lectured about the contents while students listened passively.

\section{I'm their Favorite Chinese}

While most female participants struggled to make friends with American students, both Jeff and Tom found American groups to interact with. Like the other guys, Anthony was also successful in cultivating relationships with Americans. He told me that he had very good relationships with his roommate, domestic students in the same dormitory, and his roommate's parents. He also felt that he was liked more than the other Chinese students living in the same dorm. He said, "even though my [dorm] floor has three other 
Chinese students, American students just like talk with me. When I feel the study English is hard and boring, I usually talk with them, and they encourage me."

\section{Low Placement but Hard Work to Advance}

In her interview, Emily confessed her shock receiving a low placement from the ESL test. Similarly, Anthony, who was determined to study abroad and transferred to a study-abroad focus high school where he received more English focus instructions, was shocked about his low placement and struggled to accept it. He said, "I arrived [here] twenty days before the test because I wanted to be familiar with the new environment to prepare [for the test]. However, I didn’t do very well. I was [placed into] just level 2."

Certainly disappointed that he was placed into much lower level than he had anticipated - he "thought (his) level would be level 4" - Anthony did not let his disappointment get him down. He worked really hard to move forward "because I must use next three semesters to get to the highest level. So I just studied every day, listened to music [in English], practiced English, and wrote paper. I didn't waste time.” He also found a classmate, Jeff, who was in the same situation, wanting to advance as quickly as possible. As Anthony put it, "I just studied very hard last with my friend Jeff. And we both jumped the levels from level 2 and 5 this semester."

\section{Expectation of Academic Rigor}

Anthony's hard work allowed him to jump from level 2 to 5 after one semester without taking the other levels in between. While Anthony worked hard so that he could finish the ESL requirement as soon as possible, he shared his perception that the ESL 
program had a much lighter workload, commenting, "To be honest my English homework in China was much more than [the homework] ESL gave me."

Like Elaine, Anthony was used to receiving more intense coursework and/or homework, which made him happy. I, however, noticed that Anthony seemed to have compared the whole K-12 school experience - including many different subjects in China - with the ESL program here. Also, the fact that he was comparing Chinese K-12 school with U.S. higher education should not be overlooked. In this sense, there are two unique contrasts being made - one, cultural and regional, and the other, K-12 vs. higher education. There is a danger of misinterpretation when taking his comments at face value. A simple comparison between two different systems in terms of the intensity of the workload seems neither feasible nor fruitful.

\section{Being Confident and Strong; No Worries about Discrimination or Becoming}

\section{$\underline{\text { Americanized }}$}

Certainly, Anthony is confident - perhaps even a bit overconfident at times. The fact that he holds a dualistic view regarding certain phenomena also became evident through the interviews and analyses of the data. For example, when asked if his parents were concerned about his becoming Americanized, Anthony responded, "You have to change habits [like] eating American food and waking up late because Americans usually wake up late and sleep late. You have to spend more time hanging out and playing with your friend instead of studying."

Interestingly, for Anthony adjusting to the campus and local community was more a matter of changing daily habits to behave like Americans do, not necessarily a gradual 
psychological change. Of course, few of the participants interviewed in this research appeared to have been experiencing more advanced stages of epistemology described in Perry's (1981) epistemological development - recognizing multiple complex views regarding how people become adjusted to the new environment and culture - as Anthony evidenced with definite confidence in the tone in his response.

Another example of his dualistic views was demonstrated in his feedbacks about discrimination. When asked whether he experienced discrimination from campus or local communities, he responded, "I don't feel discrimination because discrimination is [what] other people let you feel but you cannot feel by yourself." Indeed, being confident about himself, he did not let others make him feel weak or discriminated against. He continued, "I just think Americans are different. They are stronger and taller, their hobbies are different and, they play basketball better, it's different. But we [Chinese] are smarter, harder workers, and make more money than them [Americans]."

Anthony acknowledged that Americans are physically better (taller and stronger) than Chinese, however, he was confident that Chinese are better academically and in the business world. With confidence that Chinese are better in the area of academics and business, he did not let himself become a victim of discrimination. His confidence also came from the fact that he made friends with a lot of American students, as he further explained, "I just feel Chinese and Americans are different. If everybody is nice to you, you don't feel discrimination because I make lots of friends."

For Anthony, discrimination was something you let the others do to you; his view is dualistic - either you let it happen or not. In addition, his responses revealed that he 
believes people are either friendly or not. When you become friends with others, there will be no discrimination. This is another example of his dualistic view - classifying other people as friends or not friends. Furthermore, toward the end of his responses, he mentioned that Chinese are smarter and make more money than Americans. Here again, his dualistic view appeared; for him, success is contingent on whether you are American or Chinese, not a complex personal achievement with other complex factors contributing to such achievement.

Earlier, Elaine, Emily, and Jeff gave me insights into how they see their teachers, especially their favorite and not-so-favorite teachers. Friendly and kind teachers are favored more than teachers with good techniques but not necessarily seen to be caring about students; strict graders, meanwhile, were seen as very mean. Unlike the others, Anthony told me that he and his classmates regarded the ESL teachers as "not good enough", stating that he and his classmates didn't like the ESL at all:

Some teachers did not prepare for classes, or didn't prepare well because during the courses, we feel it. They are much different from the teacher who prepared a lot. For example, last semester, I had a writing teacher who just came to the class, asked us to do some reading and discussion. I just didn't study for her course because teacher was not good enough.

For Anthony, some instructors did not meet approval; they seemed to be underprepared for classes, making him feel they were unqualified to teach. Of course, underprepared instructors, if they exist, are an issue for the program to address. Of course, exactly what "being underprepared" means should be carefully examined, as Anthony 
was of the opinion that assigning students to read and discuss with classmates was a characteristic of being an "unprepared" teacher. Yet, the ESL instructors use more discussions as pedagogical technique than traditional Chinese teachers, whom all the previous participants concurred would lecture without allowing students to ask questions or discuss the lecture contents.

Anthony continued his opinion about some teachers' lack of qualifications in this way: "Not being strict because if you didn't finish homework, teacher didn't care about those students. Not good teachers don't care about every student."

What Anthony described appears to be the pedagogical difference between K-12 and higher education. ESL instructors, as members of higher education institutions, do not usually 'hold the hand' of students who are unwilling to talk it upon themselves to study to a great extent. Of course, it is also a difference between cultures - individualistic cultures tend to put greater emphasis on self-responsibility than collective cultures, with the result that instructors here leave it up to the students whether they do their homework or not. However, for Anthony, this difference was indicative of "not caring for students" and being "not good enough." His responses may be born not just out of his geographical and cultural transition from China to the U.S., but also crossing the gap from K-12 to higher education.

\section{$\underline{\text { Reliance on Chinese Language }}$}

As did all the other participants, Anthony related that his Chinese classmates want to speak Chinese during the class because "It is easy to communicate to and common 
sense [among Chinese students]. If you want to prevent students from speaking Chinese, you should separate Chinese students into different groups.”

What was interesting from his response to this question was that he did not appear to feel guilty to be speaking Chinese during the class, even while other participants acknowledged that speaking Chinese in class can be disrespectful to their instructors or something should actually be avoided. Nevertheless, he would speak English if the context allowed. He said, "If my [Chinese] classmates use Chinese to me, I will use Chinese, but I do start speaking Chinese first because if they use Chinese and I answer in English, they will think, I am different."

Being labeled as different by using English with Chinese classmates who want to speak Chinese in class was consistent among all the participants. The peer pressure to be "Chinese" and not to stand out is certainly a value of collectivist culture. Speaking English while others are speaking Chinese would certainly go against the benefits of group cohesiveness that collectivist culture highly respects (Ting-Toomey \& Chung, 2005). To obey his cultural practice yet to be able to improve himself, Anthony strategically waited until somebody else started speaking Chinese, but he would not initiate conversation either in English or Chinese. Since the other participants also mentioned that they employed this strategy to avoid being called "different" or "strange," this must be one way of negotiating the cultural adjustment and conflict between collectivist and individualist cultures.

At the same time, Anthony did not seem to fear the peer pressure and potential consequences if he had insisted speaking in English with his Chinese classmates, stating 
that if he had used English, "my classmates will be very scared and surprised." Indeed, his self-confidence and refusal to let the others put him down on any occasion helped to free him from the peer pressure the other Chinese students felt so strongly.

\section{Steven}

Steven, 19 years old at the time of the interview, is from Shenyang, a city in Liaoning province which shares a border with North Korea. He was my former student in a level 4 reading class in the fall of 2011. Although his participation in this study was his own choice, he was the only participant who did not return for the second interview. When I contacted him several times for the second interview, he did respond to my messages, leading me to assume that he had decided to discontinue his participation in this study after the first interview.

Steven went to public schools in China, and he lived with his parents from elementary to middle school. In high school, he moved to the dormitory: "Because it is school's rule, but if you have some problems, you can talk with the school, and you go home."

His parents decided to send him to that high school because "...this high school is the best high school in my hometown" and "it is very famous and it will get very brings champion in academic, technology, and means a lot of different field."

Steven studied English for 12 years in China. But he was exposed to English four years earlier than the school English lessons were given; his parents taught him very basic information such as the alphabet and simple words when he was young even though they had not studied abroad and didn't really speak English themselves. As he recalled, 
"My parents taught me because they knew $\mathrm{ABCD}$ and some simple words like apple and banana."

Teacher-Centered Classes in China, Student-Centered Classes in the U.S.

His elementary and middle school had about 50 students in each class. Steven confirmed what all other participants told me about English classes in China - that teachers lectured, and students "just took notes." He also described the difference between English classes in China and the ESL program here, saying, "In the ESL [in the U.S.] the students are the focus, but in China, students weren't the focus because teacher talked more than students. Here, students talk all the time and teachers help us help speak."

In such a teacher-fronted classroom with the students' role being passive, the concept of asking questions is different from that of the U.S. Steven explained students would answer questions "because my teacher point to specific students to ask" instead of any individual volunteering to answer questions.

\section{Exam-Driven Participation}

Steven reported that he volunteered to answer occasionally in classes. He explained that he volunteered to answer "if I found the question very interesting." Interestingly, he decided to speak up or not depending on whether the question was interesting or not. When asked to describe what made "interesting questions", Steven answered, "[the question] is important for my test," adding, "I thought if question was boring, not related to test, or too difficult, I didn't ask." 
It is an interesting to note that Chinese students may judge whether the question is interesting or not is based on whether the question will be covered on the exam or not. Steven further revealed the reason why they judge teachers questions in relation to exams is because "Our homework was about test." According to Steven, teachers only assigned homework that would be on their tests. In other words, Chinese students are trained to think about what questions might be on the test and focus only those, not paying much attention to those not appearing on the tests. Ironically, Steven thought that tests were not useful and told me, "I think test is boring because I think I can't learn a lot from them," yet he was the one who decided to answer a question based on whether or not that question would be relevant to the test.

Steven recalled that English teachers in China focused heavily on grammar, explaining, "The grammar was the most important component in Chinese English classes, and we studied high level grammar which native speakers may not know how to answer."

Since his schools had traditional teacher-fronted classes with a lot of emphasis on difficult grammar, Steven did homework and memorized notes to be successful in his English classes, concluding, "The most important way to study is memorization by reading and writing [the contents] again and again. This was the way to get high grade." $\underline{\text { Strong Bond with Chinese Teachers and Caring for More Attention }}$

Steven also spoke about the differences between English teachers in China and the ESL teachers here, noting two major contrasts. First, he mentioned that Chinese teachers knew their students, while the ESL teachers here did not. Second, Chinese teachers controlled their students, while the ESL teachers gave them freedom. He said, 
"Chinese teachers really knew me. They know all the students because they teach us for a long time. But ESL teachers don't know me.” Having lived in the school dormitory, he had a distinct advantage being with teachers all the time. However, in the ESL program, he felt detached from his teachers because "when they finish classes, they all go back to their offices." Steven implied that he missed his close relationships with his Chinese teachers but had pretty much given up hope of establishing closer connections with his ESL instructors. He felt the strong bond he had enjoyed with his Chinese teachers could not be reproduced here, saying, "Even though we [the ESL teachers and the students] get together for dinner, we will know more about teacher, but teacher will don't know about you. They cannot know all of us."

Earlier, Emily expressed her desire for her ESL teachers to pay more attention and give more explicit instructions to Chinese ESL students. Steven, like Emily, thought that Chinese teachers gave him much closer attention, but in the way of controlling and monitoring. He explained, "Some teachers had another role. They monitored our study. When we studied alone during the free time, they monitored us and forbade us playing with phones. If they saw us playing with phones, they will throw them [phone] away." Having become used to being closely monitored by his Chinese teachers, Steven felt more relaxed and free in the ESL program, saying, "Here, ESL teachers don't do it [monitoring students]. If a student is playing with a phone in class, they say put it away and it's over."

Surprisingly, the control of Chinese teachers was viewed positively, while the freedom allowed by American teachers was given a negative spin, being interpreted as 
teachers' not paying attention to their students. Steven reiterated this idea, saying, "[ESL] teachers don't care whether we don't go to class or hand in homework because it is our responsibility, not theirs." He strongly felt that he would like to have his teachers show more care for their students by connecting more with them even when the students are being irresponsible - not coming to classes or handing in homework. The expectation of ESL instructors that their students to be independent and responsible for their actions was seen as cold and harsh by Steven, who had experienced much closer care from his high school teachers.

Having much shorter time to spend with his instructors and the expectations of the ESL teachers being very different from Chinese teachers contributed to Steven's perspective on the ESL program as being cold. Furthermore, Chinese collectivist culture - which values the avoidance of losing face - affected him as well. He expressed the idea that Chinese students do not like to admit to their teachers that they don't understand. He put it this way, "Chinese students won't say they have no idea because it is very embarrassing to say I have no idea. It is like telling you're stupid.”

In all probability, experienced Chinese teachers who had spent long hours with their students and knew them well would have provided more chances for them to ask questions in less threatening context. American ESL teachers, on the other hand, whose only interactions with students are during the class, may not receive questions from Chinese students in class even when those students don't understand the class content. Since the ESL teachers are accustomed to teaching in the U.S. - one of the most 
individualistic countries - they may not be familiar with Chinese students' tendencies to avoid public humiliation by asking questions in class, and thus, leave students at a loss. As he struggled to make closer connections with his instructors, Steven was not able to obtain the relevant advice he desired from his instructor. He recalled:

Last semester in my writing class, my GPA was low. I had no idea what to do and talked to the instructor, but the advice was not useful because he just told me you can do better, work harder, and try my best. But I knew all these, and I didn't get advice to solve this problem.

Steven's experience regarding his instructor did not provide any useful techniques for addressing his situation - a low GPA sounds similar to what Emily frequently expressed about the feeling that students needed more explicit instruction. What Steven probably expected from his instructor were specific steps he could take to improve his GPA, so he was disappointed when he did not receive the explicit advice and care that his Chinese teachers would have provided.

\section{Discussion is a Waste of Time}

Although all of the previous participants were constantly comparing their Chinese teachers' instructions with their American counterparts Steven appeared by far to be the most partial to Chinese teachers and classes. In fact, Steven felt that giving too much time to discussion tasks was a pointless waste of time, saying, "[ESL] teachers shouldn't give too much time for Chinese students to talk during the class. They can teach more [instead of discussion] because Chinese students are used to this way [being lectured, but we don't know how to do discussion." 
Steven was still attached to the way he had become accustomed to studying in China. His idea echoes the view of Tracey and Emily who said, “Don't speak, just explain." He definitely aligned himself with those Chinese students who still prefer to be passive recipients of knowledge, rather than being asked to take the initiative in discussing class content, which tends to leave them feeling lost. Although discussion is a common format in American ESL classes, ESL instructors should understand how it is viewed by Chinese ESL students and recognize the struggle these students have adapting to it.

\section{$\underline{\text { Exams as incentives }}$}

It is important for ESL instructors and programs to appreciate the reasons newly arrived Chinese ESL students may find discussion to be a waste of time. Instructors also need to be aware that Chinese students expect their homework to be directly connected to tests, and they participate more actively in the tasks that are certain will be related to tests. Earlier, it was noted that Steven had decided whether to speak up in class or not based on whether the question was directly relevant to the test. He also recalled, "My teachers always told us when the final test was coming and gave a new book and told us to finish it in two days." The exam was the incentive that motivated Steven to answer questions in class and actively participate. Since discussions often do not appear to be directly related to tests, Chinese students will usually judge them to be a waste of time. Therefore, without exams as incentives, Chinese ESL students studying in the U.S. may not appreciate the critical importance of certain tasks commonly used in American classrooms. 


\section{Conclusion}

The backgrounds of the eight participants and the frequent themes emerging from their interviews were outlined in this chapter. Although each participant expressed different ideas, desires, disagreements, and life-stories, several similarities among participants emerged.

All the participants' parents played an important role in their decisions to study abroad in the U.S. Their choices to study abroad were fostered and encouraged through parents' efforts and sacrifices making sure their children would be on the correct route to enter a U.S. university.

Six participants - Tracey, Elaine, Emily, Jeff, Tom, and Anthony - shared their opinions, experience, and stories about the prevalence of the large Chinese student community at the university, frequently focusing on the negative influences from the community such as peer pressure, heavy reliance on Chinese language during ESL classes, and lack of diversity and opportunity to meet non-Chinese students in and out of class.

Interestingly, most of the male participants - Jeff, Tom, and Anthony successfully cultivated relationships with American students or local Americans, whether through on campus housing, a religious group, or a fraternity. Their relationships with Americans helped them learn English and American culture, and gave them confidence living and studying in a new environment.

Lucy, on the other hand, longed for establishing friendships with American students but wasn't able to do so. She felt she was not accepted by American students due 
to her limited English proficiency. Other female students did not cultivate relationships with Americans or gave up such opportunities; in the case of Elaine, an opportunity presented itself in her first dormitory, but she felt uncomfortable due to linguistic and cultural differences and challenges. Consequently, she did not take advantage of the opportunity that Lucy so desperately wanted to find. Elaine decided instead to seek comfort from her Chinese friends on campus. The fact that three male students successfully cultivated relationships with Americans while none of the female students were able do so suggests the possibility of different practices regarding the formation of international friendships along gender lines. Although this research did not focus on finding such gender difference in acceptance of international friendships by American students, future research should explore this question, as the results will be significant for understanding and assisting international ESL students in establishing relationships with Americans.

Lucy, Jeff, Tom, and Anthony demonstrated that they were self-motivated to succeed - socially, culturally, and academically. Their stories reflected their courage to take risks, do extra work outside that which was assigned, and remain flexible and open to the new social, cultural, and academic opportunities in American university life. This stood in great contrast to the other participants, who appeared insistent on continuing to practice Chinese academic strategies and ways of life in spite of their immersion in an American university.

Indeed, while the insights each participant shared independently contain their own meanings and tell their own stories, they also reflect the bigger themes that interconnect 
and influence the lives of Chinese ESL students. At the same time, they can offer the program, the university, and the instructors better insights into how to best work with these students and make their experience a success.

The following chapter will discuss results from analyses of axial codes of the data which combined individual codes by their dimensions and properties to present bigger concepts that represent factors affecting international ESL students when they started their journey of transition from China to the American university. 


\section{Chapter 5}

\section{Axial and Selective Code Results}

This research asked, "What are the social, cultural, and academic factors that positively and negatively affect international ESL students' transition into U.S. higher education?" To help address this question, chapter 4 presented results from line-by-line analysis of the interview transcripts and open codes that emerged frequently through the analysis. These results were described as the participants' individual stories and experiences with representative quotes. Their stories uncovered a wide range of experiences and challenges, such as their K-12 studies in China, their decisions to pursue studying abroad in the U.S., cultural differences between the U.S. and China, challenges in adjustment to U.S. social and academic life, and difficulties faced in ESL classrooms, campus communities, and friendship groups to name a few. Indeed, the interviewees freely divulged their journeys - coming from China to study ESL and adjusting to the new social, cultural, and academic environment.

While Chapter 4 focused on individual journeys through the analysis of open codes, the current chapter focuses on all eight participants' experiences as a whole, combining individual themes and stories into categories and subcategories that share the same ideas and properties. In accordance with grounded theory analysis, axial codes were created that reduced individual open codes into stronger, more robust categories and subcategories based on the properties of each individual open code (Strauss and Corbin, 1998). These codes are theoretical distillations of all eight Chinese participants' experiences transitioning into the U.S. and U.S. university life. Specifically, two of these 
codes addressed two important issues. The first issue is the consistent, ever present influence of social capital in shaping each students preparation for the transition from the ESL program to the U.S. university and the ability to create a language learning environment outside of class. Social capital represents the nexus of access and mutually beneficial arrangements that carry heavy expectations of reciprocity (Coleman, 1988). For these students, the social capital of their parents and families, and the social networks they had created facilitated their arrival, adjustment, and survival. Another issue is Chinese students' perception of ESL, especially regarding the level of rigor they should expect. Chinese students' perception of ESL was found to be relative to their expectations for university, and the results posit important perspectives regarding why there was so much disrespect for ESL amongst Chinese students.

Parent Social Capital and Social Networks: University Arrival, Adjustment, and Survival While many participants demonstrated a lack of social capital and social networks via connection, others possessed them both in China and after they arrived in the U.S. To varying degrees, many of the participants demonstrated the advantages of activity in filling obligations of academic success (to their parents) in their activities in both China and the U.S. which included: (1) study-abroad preparation for U.S. K-12, (2) parental social capital $=$ instant social connections, (3) a worthwhile challenge: the social value of cultivating American friendships, (4) Intra-group hierarchy and collectivist social Pressure undermines English acquisition and (5) Chinese community at the university. The following discussion of social capital and social network dimensions by study participants will introduce a "selective code that summarizes each code in "story form". 
According to grounded theory analysis, the selective code represents the story told by study subjects after intense data reduction and analysis (Strauss and Corbin, 1998).

\section{$\underline{\text { Study-abroad Preparation for U.S. K-12 }}$}

Certainly, all the participants were college bound in China. Except for Elaine and Emily, who took Gaokao, the National Higher Education Entrance Examination, the participants all attended study-abroad preparatory high schools, most of which were boarding schools.

The participants who attended study-abroad preparation high schools shared their experiences in general, as well as specific courses with elements such as American culture, discussion, drama using English, and teamwork, which are not commonly implemented in traditional Chinese high schools. Jeff, for example, attended one of the study-abroad preparatory high schools, and he shared this experience: "[The high school] has the programs to for improving English more quickly than traditional high schools. The high school had the American professors. So that really helped me know what American classes are like.” Jeff also shared that his high school curriculum had "very long essays. We had to write one thousand words. One of the topics of essays was to compare the Chinese policy and the American policy... [And] we had one course per week in which you practiced discussion."

Tom also went to a study-abroad preparatory high school. He believed that his high school experience was similar to that of American high school students, saying, "We watched movies, and we discussed in groups." His high school also had English theater, 
about which he recalled, "Every class had to choose an English script, actors, and actresses. We had to show all the people in the in the auditorium."

Although most of the participants started learning English in middle school, Tom started receiving English instruction in elementary school. It was a private boarding elementary school, where he lived in the school dormitory away from his parents from the age of seven. According to Tom, his parents made this choice because this particular school put an emphasis on English instruction. That is a significant demonstration of social capital, and Tom felt obligated to succeed by performing well in China and being admitted into an American university.

Similar to Tom, all the participants attended either study-abroad preparatory schools or elite academic high schools at the insistence of their parents. Their parents believed that they would be well prepared to start academic courses as soon as they arrived to the U.S., not needing an ESL program. In reality, they were provisionally admitted and needed ESL; nevertheless, the preparation in China that the participants gained through study-abroad high schools served most of them well. At the same time, their parents' expectations for a smooth transition to the American academe were tempered by the differences in the English taught in China as opposed to the English taught in the university ESL program. In fact, Tom said that he was willing to speak English with other Chinese classmates in his ESL classes from the beginning, as he had already done so in his high school. Tom said, "I am fine to speak English with Chinese because in my high school we needed to do that thing a lot. We had to have conversation in English with my classmates." But Jeff, who believed that his high school was similar 
to U.S. high schools, found that his preparation was different from what actually occurs in American classrooms. He told me: "When I came to the United States, I found lots of differences."

Therefore, if Chinese students receive the study-abroad preparation that reflects the actual and crucial skills used in the U.S. academic settings, such preparation is a great advantage for their academic success. In contrast, if they receive study-abroad preparation which does not introduce American study skills, yet still believe they are ready, the gap between actual and self-perceived skills may actually hinder their academic achievement, as they are operating with skills that do not match those required in American higher education. Either way, their parents were connected to social networks that understood and valued Chinese prep study-abroad curriculum as the link to American university. In return, they expected success from their children even when their sons and daughters realized the gaps in preparation slowed their adjustment.

The Story: Mirroring Is the First Step to Understanding

In answering the research question, "What are the social, cultural, and academic factors that positively and negatively affect international ESL students' transition into U.S. higher education?," having study-abroad university preparation that mirrors skills and academic rules required by the U.S. higher education can be one positive step in making ESL students' transition smoother. This is exemplified in the case of Tom, who did not find it strange to speak English with his Chinese classmates even though they shared the same first language. At the same time, lack of such preparation or knowledge 
hinders the transition to American higher education, as Chinese ESL students tend to resist adapting to the new academic skills and expectations necessary for success here. $\underline{\text { Parental Social Capital }=\text { Instant Social Connections }}$

Compared to the fact that most of the participants attended study-abroad preparatory high schools, those who had actual social connections leading to study abroad were few. For instance, Tracey had a mother who had graduated from Temple University and relatives living in Detroit, Michigan. With her relatives being in the same state as her university, she was able to come to the U.S. 15 days before the ESL placement test, living with them and acclimating to the new environment. In addition, Tracey continued to talk with her aunt every week on the phone and also talked to her mother frequently. With three people - her mother, aunt, and uncle - serving as her social connections, she could talk about the challenges she encountered in class or on campus and ask any questions to get advice whenever any problems arose.

In a similar circumstance, Tom had his father's friend living in Illinois. Like Tracey, Tom came a week early to the U.S. to acclimate himself and get ready for the placement test. Tom first landed in Chicago, where his father's college friend picked him up. He stayed in White Hall, Illinois for five days, spending time with the family of his father's friend, who later drove Tom to the university. Tom said, "I do not really talk to him anymore because I don't really have problems." Nevertheless, Tom does have a social network in the U.S. in case he needs it.

Anthony studied abroad in Seattle, Washington during one summer in high school, and the experience was critical to his decision to pursue university study in the U.S. 
During the summer camp I lived with American host family, ate with them, and talked with them every day, and attended an American school. I thought they [U.S.] had the best education in the world because it had better environment [to study] than in China. The libraries were much bigger, the professors had good communication skills, and you could communicate with the students from all over the world, not just from China. So [I thought] studying abroad not only would increase my knowledge, but it would help me get more the social experience. Anthony also told me that his father had a friend whose son had graduated from an American university, and that his father arranged a dinner meeting with them before he left for the U.S. Anthony told me that in the meeting, "Both families met in a restaurant to talk about American universities. He [his father's friend's son] introduced some information about education in America, and I asked him some questions about America." Like Tracey and Tom, Anthony had arrived 15 days prior to ESL placement testing to adjust to the local environment even though he had to pay for those 15 days out of his own pocket. With the kind of social connections and the financial benefits contained therein, Tracey, Tom, and Anthony were allowed to prepare for international travel, arrive ahead of time, and to secure advice about how to meet challenges head-on. These advantages were not enjoyed by all the ESL students in this study.

Jeff also enjoyed the benefits of having social connections as his parents had friends who recommended the study-abroad preparatory high school which he transferred to during his senior year. Without his family's social connection, Jeff might not have 
learned about the study-abroad preparatory high school; Jeff's parents also fostered his desire to study abroad by strongly suggesting that he attend this high school so that he would be able to receive instruction to prepare for studying abroad in U.S. higher education. These social connections, however, were not as strong as those of the other participants. He did not have information that Tracey, Tom, and Anthony had regarding international travel and adjusting to a new environment, which ultimately led to a less fluid adjustment.

In contrast to those with good social connections, Jeff and Emily arrived only one day before the placement test, affecting their ability to perform at their best. Emily explained that her failure to perform up to par on the placement test was related to jet lag, saying, "I came to the U.S. on August 18th and had the test on the 19th in the morning. No one told me to come early. I learned about the test only five days or one week before I came here." Jeff's experience was similar to Emily, arriving only a day before the placement test. He told me the reason he decided to come one day prior to the important placement test was because "the university dormitory did not open very early. Also, I ordered my plane tickets a little bit late." Although he had his own planning issues that resulted in not getting an airplane ticket that would have worked better for him, lack of access to a dorm room before the placement test was clearly an issue.

Emily's predicament contrasts with Anthony, whose parents decided to pay for his stay in a hotel for 15 days prior to his dorm room's availability even though that meant paying for lodging out of pocket. Whether being unaware of the option to stay in a hotel, unable to afford it, or simply wanting to save money, many students like Emily 
waited until the dormitory opened, which turned out to be very close to the placement test date. As a result, they took an important test plagued with jet lag and exhaustion.

Tracey, Tom, and Anthony's social connections gave them the critical information they needed to prepare for study abroad ahead of time. Jeff and Emily experienced adjustment issues and subpar placement test experiences because they lacked the social network that passed along the kind of advice that leads to success. The social network provides information about American culture, academic expectations and study skills, and can provide support for both academics and day-to-day life. It also serves as a safety net in case of emergency, helping to meet the challenges of studying abroad. I learned from these interviews that Chinese ESL students with strong social networks had a decided advantage over those who did not; the transition to higher education for those without social networks in the United States was significantly more traumatic.

The Story: Social Capital and Social Connection Facilitate Chinese ESL Students' Transitions into U.S. Higher Education

Social connections provide opportunities to understand and access information about "cultural norms, insight into how organizational unites operate, (e.g., chains of command, explicit and implicit rules)" (Trice, 2004, p. 672). Having social connections definitely helped Tracey, Tom, and Anthony - all of whom came early enough to adjust to the new time zone, local climate, and local environment before the placement test was administered. However, social connections also serve a gatekeeper role within institutions, and lack of social connections can result in more challenges in transitioning into higher education (Trice, 2004). Not having social connections hampered the adjustment of Jeff 
and Emily, who underestimated the effect international travel and time change would have on their ability to perform well on the placement test, due in part to the simple lack of social connections. Having social connections appeared to facilitate Chinese ESL students' transition into American higher education, ensuring that they arrived with solid preparation for their educational experience and providing an ongoing safety net for their continued studies here in the U.S. Those ESL students without social connections, on the other hand, spend extra energy figuring out their problems because they do not know the daily routines, expectations, and rigors of academic life in the U.S. Those whose parents had valuable social capital had instant social networks of support and advice.

\section{A Worthwhile Challenge: the Social Value of Cultivating American Friendships}

Students need to improve their English skills and improve their social capital at the university, yet they struggled to learn about and embrace American ways and people while moving away from the sizable on-campus Chinese community "safety-net." Interestingly, Tracey, Tom, and Anthony showed their own distinct ways of distancing themselves from the overwhelming number of Chinese students on campus. For Tracey, this was not necessarily a "choice", since she was a loner - isolating herself from both Chinese and other students (both American and non-Chinese international students). Of course she had a few good Chinese friends, but she did not worry about not connecting with Chinese student groups. She reported that she didn't feel much peer pressure from Chinese students on campus, saying, "I don't get out of my room and always stay at my dorm. [So] I don't care about there are too many Chinese in the same dormitory or not." As discussed in the previous chapter, her ability to maintain her status as a loner apart 
from the Chinese community may have been due to her strong social network in the same state as well as at home, freeing her from the necessity of establishing a social network through the campus Chinese community, in contrast to so many of her peers. Again, Tracey's "built-in" family social capital freed her from the tendency to depend upon the on-campus Chinese community as a means of support. Her primary support was family, and this benefit was reciprocated by carrying out normal family obligations, such as being a good student.

Unlike Tracey, both Tom and Anthony created distance from the on-campus Chinese community and actively cultivated relationships with American students. Tom joined an Asian American fraternity, while Anthony made friends with American students living on the same floor of the dormitory. Tom described his experience joining the fraternity, "[Fraternity members] all speak English and have a lot of events and in some events I need to talk to people. So it helps me to improve my English.”

For Tom, cultivating relationships with Americans was important for developing his English fluency and his social interactions, but he chose to be a part of an Asian American group because "They are Asian Americans, so it's a lot easier for me to get to know their cultures because they're still Asians, and their habits are lot different from white people." For him, being friends with Asian Americans was an important choice as the fraternity members shared many common cultural traits.

In contrast, Anthony started cultivating relationships with white males, not Asian Americans. He appeared to have positioned himself among white males, with whom he did not feel uncomfortable, and thereby elevated his own status in the Chinese 
community hierarchy. For example, this is how Anthony characterized his relationships with his roommates and American friends in the dormitory:

I have an American roommate, and lots of American guys live in on the same floor. We became friends, and when I feel the English study is hard, boring, and lonely, I usually talk with them, and they encourage me. I bought lots of gifts for them on their birthdays, and they like me. They think I'm a very good guy. We watched movies, and they just tried to teach me drink alcohol. We went to parties, and I met their friends, and we watched football games together. We played basketball and soccer outside. Lots of fun.

Notice that Anthony mentioned that he would buy gifts for American friends' birthdays, and they liked him. Buying gifts appears to have been a big part of Anthony's strategy for friendship building, as he mentioned this practice several times: "With their birthday, I usually buy the gift for them, [but] I don't want to buy anything for myself. I'm frugal for myself, but for other people I will use money." This example is a strategic use or creation of social capital in a transaction which says, "if I buy you gift you owe me and should reciprocate." Anthony was surely accepted and liked by his American friends; he was even welcomed by his roommates' parents.

I like popcorn, and his mother knew it and bought popcorn for me every week. During last semester, his parents thought I didn't have a big coat. So they gave me a very nice coat. I don't know why, but the people like me 
and like to talk with me. Even though our floor has three Chinese people, they just like to talk with me probably because I'm very kind.

Clearly his experience of being liked more than the other Chinese students on his dormitory floor gave him more confidence and feelings of acceptance among his American student circle.

Both Tom and Anthony successfully cultivated relationships with American students. While Anthony's relationships began with his American roommate, Tom came upon the opportunity by chance, as he reported, "I was just walking in front of the basketball court, and someone asked me to join and they had kept calling me since then."

Jeff is another participant who cultivated relationships with American people, but this time through the social network of an on-campus religious group. As seen in Chapter 4, Jeff started attending the Mormon Church because "my friends joined the church. And uh I think going to the Church is interesting to understand different culture." With his self-motivation to study hard and natural curiosity about American culture, the Church members were a good opportunity for Jeff to cultivate relationships with Americans. As he said, "Although I came to the U.S. because this country has advanced education, I am learning different religions, different cultural background and different family values, and lots of things. I am learning lots of things that I did not know before." It is clear that Jeff's ongoing relationships with his Mormon Church friends helped him improve his English skills.

Jeff's network extended beyond campus due to his connection with Mormons - an example of someone who cultivated relationships with local people through a religious 
organization; Tom and Anthony found their American friends on campus. Each of these participants found a group to affiliate with - whether Asian Americans, white males, or a church group. Although the target groups that each of them chose to become friends with were very different, all of them were successful in establishing friendships with Americans in the new social environment.

Not all the participants found opportunities like Tom, Anthony, and Jeff. Indeed, other participants expressed a longing for such opportunities to interact with American students and form friendships with them. Lucy was one of those who had a hard time bonding with Americans. Even though she worked in a cafeteria with the hope that the job would give her an opportunity to become friends with Americans, she was unable to do so. She said, "I wanted to make some friends and understand American culture, when Americans found out I couldn't understand English, they didn't want to talk to me. I want to improve myself and my English, but I don't know how."

Disappointed at being unable to find American students who would be willing to befriend her, she reported that she would have liked the ESL program to offer some activities involving American students. By doing so, the program could take an active role in creating social capital for the international students enrolled in ESL. She said, "We need to practice [English] by speaking with native speakers. That is so important. If the ESL has some activities, we can talk with the native speakers, and it will be a great way to improve." Lucy found that there were not enough opportunities to meet and develop friendships with American students even though she tried through her part-time job on campus. 
Tracey concurred with Lucy, finding a lack of opportunities to interact with American students. She said, “There are so many Chinese students [at the university], and we have few opportunities to talk to native speakers." Tracey also suggested, as Lucy did, that the program should "add native speakers in our [class] group" for ESL students to interact with American students in class.

While Lucy and Tracey found it difficult to have satisfying interactions with American students, Lucy noticed that some of her Chinese friends cultivated opportunities with American students through religious groups as Jeff did. Although religious groups offered a friendly atmosphere that would have given her a chance to interact with Americans and practice English, she was hesitant, feeling guilty about joining religious groups without committing to their religious beliefs. In effect, she did not want to "steal" social capital from a group she did not genuinely belong to.

Meanwhile, her Chinese friends continued going to religious group activities where "some of them have the Bible discussion groups, [but my friends went there] even though they do not like Bible discussion." Lucy articulated a desire to receive more opportunities from the ESL program: "The ESL should talk a lot about providing opportunities for students to interact with Americans because I can work on academic studies at home, but being able to have more opportunities to have more conversation is very important."

In addition to the lack of opportunities, many of the Chinese students were hindered by their own lack of English proficiency, which got in the way of their pursuit of relationships with American students. Elaine explained how nervous she felt using 
English, saying, "I'm afraid of speaking with a group of people. I sometimes don't understand what they are saying. So, I'm always confused and I don't know how to reply to them."

From the analysis of the interviews with these students, it appears that one of the key factors determining whether Chinese ESL students find close relationships with Americans is sheer luck. Some of them were fortunate to have been placed with good American roommates or dormitories with fewer Chinese students, while others were placed in the dormitories with large numbers of Chinese residents where they had Chinese roommates and suite-mates. In terms of the dormitory placement, one of the assistant directors of the ESL program commented that the placement depends on whether students need to stay during the university break period; most American students go home during long university breaks, such as Christmas and summer, and as a result, most dormitories are closed. There are only a couple of dorms open during these extended break periods, and those who need to stay during breaks will be placed there. Since students who need housing during break periods are predominantly international students, and Chinese are by far the majority of the international student population at the university, those few dormitories are consequently full of Chinese residents.

Due to this practice of the housing office - placing Chinese students into one or two dormitories according to their break period plans - many Chinese students have expressed a desire to have more opportunities provided for interaction due to the difficulty they have creating their own. As Lucy and Tracey suggested, providing ESL activities that facilitate interactions with Americans could be one step to help students 
establish stronger relationships with their domestic counterparts. Of course, reconsideration of the current housing placement policy by the campus housing office and the university in the form of intentionally matching Chinese and American students would be another small investment that could provide big dividends.

The Story: Cross-Cultural Communication Creates Strong Social Capital and English $\underline{\text { Skills }}$

Establishing relationships with American students appears to help Chinese ESL students learn English much faster and gain self-confidence about their place in the university campus community. It enhances existing social networks and creates the kind of cross-cultural ties that lead to better language acquisition. Not having relationships with Americans as a form of social capital means lack of "access to resources and networks that lead to opportunities" (Trice, 2004, p. 672). Unfortunately, many Chinese ESL students do not feel they have opportunities to interact and become friends with Americans in spite of their desire for such opportunities; indeed, they hardly need to be persuaded that their English and cultural learning are not developing as quickly as they could if they had more American friends. Having relationships with Americans - or the lack thereof - can have a profound effect on Chinese ESL students' transition in regards to learning English, becoming more confident, adjusting to campus and local community, and understanding American culture.

Intra-group Hierarchy and Collectivist Social Pressure Undermines English Acquisition As reported in chapter 4 , most of the participants shared comments about the existence of a large Chinese community at the university and the issues that have arisen 
because of its size and influence. Many of the participants told of their desire to separate from what they perceived as an excessive number of Chinese students. They expressed concern that there were too many Chinese students in ESL classes, making the learning atmosphere in general and class discussions in particular problematic. Their Chinese classmates would always speak Chinese to each other, and students did not have opportunities to use English outside class since there were so many Chinese students at the university.

Even more basic than the lack of opportunities to establish friendships with Americans is the feeling among Chinese ESL students that they are unable to communicate fluently in English. Jeff, who had one class that consists of many nonChinese classmates felt "lucky that I was in that writing classes because we talked a lot [during the class], and the classmates were from different countries and from different culture and different life, so we're talking about different cultural background." Jeff genuinely enjoyed the contact with non-Chinese ESL students and automatically expanded his social network as a result. Being able to talk with non-Chinese international ESL students enabled him not only to practice English but also to learn and appreciate different cultures. In contrast, his other classes were full of Chinese students - a fact that hindered the process of learning English effectively "because there were many other Chinese people."

Like Jeff, Anthony thought having many Chinese classmates in his ESL classes was bad for learning English, saying, "When teachers introduced new concepts that students did not understand, we [Chinese] talked to each other rather than using English 
to figure out with other international students." Even Anthony, who made friends with Americans in his dormitory, felt that he was disadvantaged by having too many Chinese students enrolled in the university, diminishing his ability to efficiently improve his English. Similarly to Anthony, Lucy felt a definite need for more diversity within the ESL program owing to the challenges she encountered meeting and becoming friends with American students. She put it this way, “I feel that I don't know what I should do. In the university, [there are] so many Chinese people. My roommate and suitemates are all Chinese. Teachers require us to speak English, but almost all the classmates are Chinese." Being surrounded by Chinese students in and out of class, Lucy felt at a loss to improve English by talking to non-Chinese students and making personal connections with them. Therefore, she expressed a desire for the ESL program administrators to intervene, resolving the problem by bringing a more diverse population into the program: "I want to ask the program to put students from different countries, different students together. Then when we're discussing, we will have to speak English to someone not Chinese."

A social network is only as valuable as the strength of commitments or obligations contained therein. For these students, the Chinese student network was valuable in many ways, but a deficit to their attempts to communicate comfortably and competently in English. This deficit caused students like Lucy, Anthony, and Jeff to resent the high number of Chinese international students and to covet separation from them to move closer to Americans. 
Because the desire to separate from other Chinese students was not usually feasible, the students had to regularly deal with in-group issues such as peer pressure and socially reinforced obligations - an aspect of social capital. In addition, Chinese became the default means of communication, as opposed to experimentation with and use of English. All the participants described dealing with this peer pressure, but Elaine shared precisely how difficult it was for her to cope with, explaining, "If other Chinese students are speaking in Chinese but you use English, they will say, 'Why are you speaking English to us?' They will think you are different, and they may have some thoughts in their mind [against you]." In other words, the Chinese social community demands that its members use Chinese to communicate under threat of alienation or group sanctioned punishment. This is an unfortunate artifact of collectivist culture, discouraging acts of social risk-taking, such as using English.

Prior to arriving in the U.S., Elaine and her Chinese classmates believed that they would be forced to speak English here and were disappointed that this did not occur. She said, "Before we came here, everyone thought 'I will speak English every day and my English would be better [in the U.S.]"' The reality, however, was different as she confessed, "We speak Chinese because everybody is speaking it, and when they talk in Chinese, I just speak to them in Chinese."

From the researcher's experiences teaching in the program under study, it is true that ESL teachers frequently struggle to get their Chinese ESL students to use English with their Chinese classmates during the class, and the struggles are often in vain. It is possible that ESL teachers end up forming negative views about Chinese ESL students - 
not wanting to learn English or wasting their parents' investment - since they are not willing to use English in class. However, according to the participants, it is not a simple case of being unwilling or lazy. For Chinese ESL students, the stakes are higher than what the ESL teachers perceive. As Elaine and Tracey noted, by insisting on speaking English with their Chinese classmates, they run the risk of losing potential social connections with those classmates. Consequently, they are prone to speak Chinese because of heavy pressure from their peer group. These in-group pressures are so strong that in order to maintain social capital within their own campus community, these students end up working against the very goal they attended Chinese study-abroad preparatory schools for, undermining their efforts to learn English.

Another concern of the participants was the prejudicial treatment/discrimination they experienced from other Chinese students on campus. Emily was frank about the peer pressure and prejudicial treatment she encountered from Chinese student groups who entered the university without taking any ESL classes:

I have a roommate who is a regular [university] student. She was able to go to academic directly [without taking ESL classes]. I study in the ESL, and she thinks 'oh her family is really rich'. 'Oh she can afford to study at ESL [which indicates that regular university Chinese students believe I am buying the U.S. education, but I am not here because I'm intelligent]'. I think all the Chinese ESL students have the same feeling. Such prejudicial treatment from regular Chinese students on campus affected Emily significantly. She shared another incident where her negative feelings about the 
status of Chinese ESL students on campus led her to falsely conclude that she was not officially welcome:

One day, we went to a dining hall which was not our dormitory dining hall. Usually, I just swipe my ID card, and I can go to different dining halls. But on that day, we were not able to swipe to go to that dining hall. And we thought, [we weren't able to enter] because we were ESL students. [We felt] we were not official students at the university, and that's why we couldn't enter there.

In reality, the incident had nothing to do with her ESL status, but instead was caused by minor mechanical issues with the ID card and the machine that processed the information. However, having been exposed to prejudicial/discrimination from Chinese students on campus, she felt that she was not good enough in the eyes of the larger campus community. She was convinced that she was not an official student, and, therefore, not allowed access to different dining halls.

As mentioned earlier, social capital within the university's Chinese international student community offered extensive benefits. A few of the participants commented on these benefits of belonging to the Chinese community and acknowledged that Chinese student groups were a big part of their lives. Exemplifying this view, Tom shared his observations about some of his Chinese classmates who preferred to hang out only with Chinese:

Some people hang out only with Chinese, and they don't really have American friends. It is maybe because of cultural difference [between 
Chinese and Americans]. Maybe they miss home and feel at home and more comfortable when they hang out with Chinese. But when they hang out with Americans, they need to think a lot such as why they do this, or what the best way is to express themselves.

According to Tom's observation, many Chinese students hang out with other Chinese because they seek the comfort and feelings of home. Connected to familiarity is the fear that goes along with linguistic challenges that caused some Chinese ESL students to hesitate in their efforts to cultivate relationships with Americans. They may prefer to be only with Chinese groups because speaking with Americans means they "need to think a lot" about their own language use and the intentions of American students' behavior. Interacting with American students can seem forced, unnatural, and laced with fear, while interacting with other Chinese is natural and takes no additional work.

Steven is one of the students who preferred hanging out with Chinese rather than American students. He supported Tom's observation, offering his opinion about why he prefers to hang out with Chinese. He admitted that he was aware that interaction with Americans would be good for his adjustment: "I should attend more activities because Americans like to have a party or go to club very much. And in my dorm they also have lots of activities." However, Steven and his Chinese friends did not take advantage of events that would involve interactions with Americans. He said, “Chinese people don't feel interested in them. [Like those Chinese students], I don't have interest in joining activities with Americans." Steven further explained why some Chinese students are not 
interested in cultivating relationships with American students, citing both linguistic and cultural adjustment issues:

We feel uncomfortable talking to Americans because we don't have common topics to talk with them. It is one reason why Chinese don't like to hang out with Americans. Also, Americans always do crazy things like reading loudly or running outside. Chinese won't do this. They [Chinese] will keep silent.

By his own admission, Steven avoids interacting with Americans because of cultural differences and the challenges in using English fluently and appropriately. Instead of considering such differences in culture and language as positive challenges to be embraced for successful transition to the U.S., Steven and many of his peers prefer the comfort and ease of sheltering themselves among their co-nationals.

Elaine, like Steven, preferred hanging out with Chinese students in spite of having had more opportunities to interact with American students when she started the ESL program. She reported, "Last semester, I lived in C Hall. Residents were all Americans. One of my roommates and people in the next room were my [American] friends. They treated me very well." Even though she had opportunities and met good people that befriended her - opportunities which Lucy had badly longed for - Elaine left that dormitory for another in which many Chinese students lived “...because my Chinese friends in the ESL lived there." For Elaine, living much closer to her Chinese friends in the same dormitory was more important than having opportunities to cultivate the kind of relationships with Americans that many other Chinese were seeking. For Elaine, having 
many Chinese students in the ESL and the university was a welcoming trend, simply because "it's easy to get along with [Chinese]."

For others, a simple resistance to change or lack of a sense of any real need to adjust may be the best explanation for why they continue to hang out with only their Chinese peers. Tom put it like this:

Maybe they are not comfortable to change maybe because they had been in China for more than 10 years or even longer. They are just going to study here like for four years and you just tell them to change. For them maybe it doesn't really make any sense.

It appears some Chinese students decide to affiliate mainly with Chinese student groups due to the linguistic and cultural challenges they encounter when trying to hang out with American students. Meanwhile, as Tom noted, other students may view it as nonsensical to adjust themselves to the U.S. and the university campus when they see their educational experience here simply as a means to a degree that will be useful when they return to China. They seem more interested in the piece of paper - the degree - than in taking advantage of all the opportunities for personal growth that the whole studyabroad experience offers, seeing their life in the U.S. and the university as a temporary, albeit necessary, evil.

Nevertheless, higher education institutions should not give up on such Chinese students. These students may arrive with the agenda they carried from China, but that is certainly due in part to the fact that they simply may not know what is available to them. Since most of them are fresh out of high school and not familiar with U.S. higher 
education, ample opportunities for their epistemological development should be fostered. Facilitating the social, cultural and life transitions of these Chinese students should be part of each institution's longitudinal goals.

The Story: the Social Capital that Supports Can Also Be the Social Pressure that $\underline{\text { Undermines }}$

For Elaine and Steven, the Chinese community has been embraced as a great advantage, providing comfort and ease of access to information in ESL classes and campus communities. Certainly in that regard, it can be argued that the large number of Chinese students present at the university has had a positive effect on Chinese ESL students. At the same time, however, the presence of the larger community allows Chinese students to shelter themselves there, avoiding the risks entailed in immersing themselves in American campus life and the opportunities to interact with and learn from Americans and other non-Chinese international students. This idea corresponds to the literature regarding the collectivist culture concept of interdependent self-construal (TingToomey, 1999; Ting-Toomey \& Chung 2005). Since Chinese ESL students in this study were members of collectivist cultures with interdependent self-construal, and they placed "a high value on fitting in with others, interacting with others with appropriate manner, conforming to the values of others, maintaining relational connections and harmony, avoiding direct conflicts, and interacting in discreet, thoughtful manner" (Ting-Toomey, 1999; Ting-Toomey \& Chung 2005). In that sense, the extensive Chinese community at the university has had a negative effect on Chinese ESL students, hindering their transitions into the social, cultural, and academic life of the university. 
Chinese Students' Perception of ESL: What Rigor Should They Respect?

The other axial code developed after rigorous data reduction addressed Chinese students' perception of ESL relative to their expectations upon arrival at the university. Specifically, this code represents what all eight participants taught me about "Chinese students' perception of ESL and exactly what kind of rigor they should expect and respect." The last word is key, as many of these students had little respect for the program. My question is why there was so much disrespect for ESL amongst the Chinese students.

Part of the answer is revealed by Chinese ESL students' understanding of academic requirements for the program and expectations brought with them from China for college level English instruction. Most of the participants attended study-abroad preparatory high schools, and some of them developed their views about the ESL program, its instructors, and their pedagogical practices by comparing U.S. English language instruction with Chinese English language instruction. According to the participants, these comparisons presented challenges that shaped their somewhat negative views about the ESL program, and can be classified into three areas: (1) a misperception of structured control vs. unstructured freedom, (2) “don't ask me, explain” and other failed teacher role expectations, (3) Chinese ways vs. American ways: the roots of pedagogical conflict. In each of these areas, detailed themes emerged from the students' experiences confronting the differences in academic requirements between their Chinese study-abroad preparatory schools and their university ESL courses. Each discussion will close with a discussion of its overall "story" (selective code in accordance) with grounded theory analysis (Strauss and Corbin, 1998). 
Misperception of Highly Structured Control Compared to Unstructured Freedom

One such difference that challenged all the Chinese participants was the discrepancy in how tightly classes are controlled in China and the U.S. The participants were accustomed to tightly controlled classes when they lived in boarding schools in China - classes where they were told what to do, were closely monitored by teachers, and received an overwhelming volume of homework assignments. In contrast, students in U.S. higher education experience much greater autonomy. Although ESL instructors in the university give students assignments, they do not monitor them as closely as Chinese K12 instructors. It is the student's responsibility to study without significant monitoring by authority figures, as control and monitoring have virtually no place in the culture of U.S. higher education.

Interestingly, these differences in experience between Chinese K-12 studies and the U.S. higher education studies appear to contribute to Chinese students' misperception of the value of the instruction they are receiving. The participants often expressed their observations about the workload differences between China and the U.S.; all of them considered Chinese K-12 to be much more intense than the ESL program in the U.S., explaining that during K-12 schooling in China, they were expected to give their full effort to the courses' overwhelming workload. This heavy workload, together with strict monitoring by teachers, was regarded with great respect by the Chinese participants.

When the participants started the ESL program, they compared their past experience in China to their ESL courses and concluded that the ESL program had neither a high level of rigor nor high expectations of their students. As a result of the less 
demanding course load that left abundant free time in their schedule, they considered the ESL courses to be less worthy of respect.

Elaine, for example, recalled that her high school experience had always been busy, requiring long hours of hard work. She said, "[after finishing the day curriculum], we ate dinner and then had three night classes. Then we went back to the dormitory and did the homework until 1 or 2 o'clock [a.m.]." For Elaine, her high school demanded a lot, and the life there "was very busy, but we were very happy."

Echoing Elaine, who had been happy in a high school that demanded a lot, Anthony complained about the lack of an intense workload, noting that the ESL program asked for "very little homework every day." Since Anthony perceived the amount of the ESL assignments to be too few, he had concerns that the ESL classes were not helping him improve his English skills as quickly and efficiently as possible. He said, "It's very hard [to improve English] because you take courses four hours, and after courses you have one hour to do homework." Although Anthony claimed that he only needed an hour to finish his assignments, it is highly likely that many ESL instructors would have planned assignments that would take at least an hour or two, and since Anthony was in four different classes, he should have been spending at least four hours doing homework. Nevertheless, for Anthony, the assignments were too few, and he felt he needed more. He continued, "What about the rest of the day? Teachers should give more practice, more homework, [and] more challenges so that the students increase English skills quickly and efficiently." 
Steven concurred with both Elaine and Anthony, remembering the heavy workload while studying in China. He said, "My high school gave us a lot of homework, and it's very difficult. My teachers always told us when the final test was coming, gave us a new practice book, and asked us to finish it in two days." Steven's idea of rigor was a teacher assigning a new textbook to do in a very short period of time. Because he was required to do such a large amount of homework in China, he had the following to say about the ESL homework load in the U.S.: "Honestly [ESL homework] is not a lot." Like Anthony and Steven, Tom thought it was not difficult to finish the ESL homework, commenting, "I always finish the homework in like in two hours or in one hour [because] it's not that much." In her comments, Lucy likewise expressed a concern about the lack of intensity of ESL studies. She characterized her experience in the ESL program as too "having too much free time". She confided that when she came to the U.S. and started studying ESL, she felt she had excessive free time, and it "made me lazy." She continued, "I just went to sleep very late and got up late because teacher didn't give too much homework, and I had a lot of free time."

The above quotes reveal critical points for consideration. Anthony's complaint is a clear reflection of the common contention among Chinese ESL students that a heavy workload for class assignments is a quicker and more efficient way to improve English language skills. The students were likewise unhappy that the ESL program did not demand the same amount of work and or hold expectations as high as Chinese K-12 schools did. In their own eyes, they were not being challenged intellectually, but were 
nevertheless being held back in the ESL program without opportunities for quick and efficient learning; consequently, they were not happy studying ESL.

\section{$\underline{\text { The Story: Not Enough Rigor = Disconnection and Disrespect }}$}

Teacher control, long hours spent at school, and an intense homework load were what the study participants had come to expect in their Chinese educational experience. Previous research has noted that many international students have found it challenging to adjust to host countries' pedagogical ways (Zhai, 2004; Andrade, 2005; Turner, 2006; De Vita, 2007; Li, Chen, \& Danmu, 2009), and the results from this research support that notion as well. With the perspectives and values of what worked in China, the participants expressed the preference of themselves and their Chinese classmates to continue their old ways, bemoaning the fact that ESL classes and instructors do not offer the same learning environment they had experienced in China. Clearly, their familiarity with Chinese ways - tight control, close monitoring, intense workload - and confidence in the efficacy of these practices seems to have caused challenges for the participants in understanding the expectations of the ESL program and instructors. The mistaken perception that the unstructured freedom of American classrooms represents a lack of academic rigor is difficult for many Chinese ESL students to overcome and can be a great hindrance in their transition to U.S. higher education.

Another important observation worth noting is that the Chinese participants, upon entering the university ESL program, were quick to compare the workload between two different educational settings: K-12 schools in China and the ESL program in the U.S. Being accustomed to an intensive workload in China, this became the norm and 
expectation of what schools and teachers everywhere should provide. Consequently, having much less homework in the ESL courses was at first a surprise, but later a disappointment to these students. Since they expected to receive a workload as intense as they had received from their teachers in China, they interpreted the light workload here as a reflection of the low expectations held by their American ESL instructors.

They also felt that they were not as proud of the program they were part of as they had been in China. They felt the ESL program was neither rigorous nor worthy of respect. This in turn, might be one of the hidden reasons ESL instructors find that some Chinese students are not devoting their full time and energy to their ESL studies and have negative attitudes toward the ESL program in general. Their negative view toward ESL and its "soft" workload was born out of their previous experience in Chinese education. Unfortunately, this "failure" of the ESL program to conform to their preconceived Chinese expectations continues to have an adverse impact on Chinese ESL students' transition to U.S. higher education.

\section{"Don't Ask Me, Explain" and Other Failed Teacher Role Expectations}

In discussions with this group of Chinese students, it was discovered that their expectations for teacher behavior were not being met by their ESL instructors.

Predictably, the ESL teachers' practices differed in significant ways from what they experienced in China. The first difference that the participants identified concerned student relationships with teachers in China compared to those in the U.S. In China, close monitoring of students by teachers for long periods of time was the norm, as many of the students had attended boarding schools. As a result, their K-12 teachers personally knew 
each student quite well. Steven explained the long hours that Chinese teachers spent with their students, saying, "They teach me a long time. And because in my high school, I lived in dorm, I studied all day and could go to office immediately to ask questions if there was any problem."

Easy access to teachers in the boarding school setting allowed Chinese students to find instructors whenever they needed help. Steven not only had constant access to teachers, but also a "homework lab" or "homework class" in which students sat and finished homework. He explained, "Teachers had another role. They monitored our study. If you studied alone in the free time, they monitored you, and they forbade playing games or using cell phones." In contrast to his experience in China, he did not feel that he had such close connections with his ESL instructors in the U.S., saying, "The [ESL] teachers don't really know me. If they finish class, it's always over. They'll go back to office. This is difference between Chinese teacher and here teacher."

Like Steven, Emily felt that she did not have good interactions with her instructors and suggested that she would like to see teachers establish more connections with students. She explained, "I think teacher can choose some ways to get more interaction with students. Teachers can appoint students to answer the questions. [And] if teachers have interactions with everybody in the class, students will feel better in class." For Emily, even appointing individual students to answer questions instead of soliciting volunteers can be a form of personal interaction. She felt that having interaction and "knowing students" would make students feel better about their classes. 
Unlike the Chinese instructors, who develop much closer relationships with their students due to their long time spent at schools and dormitories, ESL teachers only see their students in classes, which meet for only one to two hours daily. With such limited interaction, they cannot develop the close relationships that the participants had with their teachers in China. As a result, some participants felt that their ESL teachers are not "there to help Chinese students," expressing concerns such as "ESL teachers should outreach unsuccessful students," "ESL teachers need to pay more attention to the students," and “ESL teachers advice wasn't useful." Steven shared this perspective about unsuccessful Chinese ESL students:

Some students don't do well in class because they don't go to class or hand in homework. But instructors can send emails or call them. Lots of my friends don't go to class, but their teachers don't connect to them, and it's a bad circle. Teachers don't care because if you don't go to class or turn in homework, it is students' responsibility, not teachers' [responsibility].

Steven acknowledged the problem that his friends were creating by not attending classes or turning in assignments, but he suggested that these unsuccessful ESL students needed attention from their instructors. He felt that if instructors had reached out more to unsuccessful students, they might have done better academically. Particularly interesting is that the fact that he thought ESL teachers "do not care" when unsuccessful students fail to attend classes or hand in homework, as it is 'not their responsibility.' 
Last semester I had 1.5 GPA in my writing class. I thought I failed the class and would have to go back home. I talked to teachers because teachers control my GPA. But the advice was not very useful because they just told me 'you can do better, work harder, and try your best'. I knew this. They didn't give very good advice for me to solve the problems. From this example, it should be noted that there is a definite gap between Steven and his American teachers concerning the notion of responsibility and where the onus lies. For Steven, instructors should contact students and remind them what their learning responsibilities are in ways similar to what his Chinese instructors would have done.

Steven's experience sheds light on the expectation of receptiveness and dependence on the authorities commonly exhibited among students in collectivist cultures (Ting-Toomey, 1999; Ting-Toomey \& Chung 2005). Although he already knew that he ought to study more diligently and try harder, he did not know how and wanted his instructors to provide explicitly detailed instructions on how to improve his grades. In spite of their good intentions, instructors who offer general advice and encouragement without setting out a detailed plan to be followed step-by-step will more than likely be viewed as unhelpful and uncaring in the eyes of their Chinese ESL students. Again, this demonstrates the gap between Chinese students' expectations toward what instructors should do and American instructors' expectations about what the students should know and do. Such a gap should and could be narrowed with thoughtful attention, reflection, planning, and instruction in these matters. 
Another important and often overlooked expectation the participants shared was a desire that their teachers "...not ask [whether they understood the contents or assignments, but] just explain" more details. Tracey, for example, said, "I just want to tell my [ESL] teachers 'don't ask questions, just talk', and they should just write something on the blackboard to make us understand more easily because the Chinese teachers always wrote everything on the blackboard while they were talking, and we took notes." According to the participants, ESL teachers often stop giving explanations in order to ask confirmation questions - whether explanations are clear, if students understood the contents, or if they had any questions. Instead of teachers' spending time on such questions and checking, the Chinese participants preferred that their teachers would just continue their explanations. Moreover, Tracey's comment was a reminder of how much more Chinese teachers wrote information on the blackboard than their American ESL teachers did. As a result, note-taking in China was not the big challenge that it is here; the students simply needed to copy everything that their instructors wrote on the blackboard. The participants noted that ESL instructors here do not write as much information, instead expecting students to make decisions about what does and doesn't need to go in their notes - something the students found to be a daunting exercise. As a group, therefore, the students preferred the familiar Chinese way of directly copying the instructor's notes from the blackboard. 
The Story: Shorter Distances between ESL Faculty and Students Mean Greater

\section{Engagement and Success}

Having been used to much closer and more frequent interactions with Chinese teachers in Chinese K-12 schools, some of the participants felt that the attention that they had received from their ESL instructors was insufficient - lacking in both what they had needed and expected. They also pointed out that some of their Chinese classmates who were not doing well might have benefitted more or learned to become better students if their instructors' had paid closer attention. Their expressed longings for greater attention from instructors to help them better navigate academic life in the U.S. match what Astin $(1984 ; 1996)$ has described in involvement theory. According to Astin (1984), increased interaction with faculty is part of involvement in campus and academic life, and it can enhance students' cognitive and social learning gains. Chickering and Gamson (1987) as well, posit "contact between students and faculty" (p.3) as one of seven principles for good practice in undergraduate education, stating:

Frequent student-faculty contact in and out of classes is the most important factor in student motivation and involvement. Faculty concern helps students get through rough times and keep on working. Knowing a few faculty members well enhances students' intellectual commitment and encourages them to think about their own values and future plans (Chickering and Gamson, 1987).

It appears that lack of involvement and a feeling like they don't matter, which some of the Chinese participants had experienced in China, can affect Chinese ESL 
students' transition into higher education and academic life negatively. Seeing that the participants have expressed these desires, and that the literature of student success in higher education calls for more faculty involvement in mentoring their students, this point ought to be taken seriously and incorporated into the current practices of the ESL program.

Some of the Chinese participants preferred the ways that Chinese teachers used to teach with - explaining all the points clearly and explicitly as well as using blackboards and writing all the details on the board. Accustomed to the Chinese way of being fed all the points in both oral and written (blackboard) form, they find note-taking and understanding oral instruction challenging. The gap between student expectations of how they would receive ESL instructions and the way they are actually are instructed is a big challenge, putting another roadblock in the way of their smooth transition into academic life in the American university. Knowledge of academic rules and expectations plays a very important role in determining success in academic life. Lack of such knowledge can result in students struggling to adjust academically, being frustrated with the courses and instructors because they do not know exactly where the challenges are coming from and why they are not performing well. Chickering and Gamson (1988) advocate for faculty to encourage active learning under the pretense that learning does not occur if students are receptive "by sitting in classes listening to teachers, memorizing repackaged assignments, and spitting out answers" (p.3). Faculty members must encourage students to talk and write about their learning, and make connections between their past experience and what they're learning, as well as applying it to "their daily lives" (p.3). 
Many instructors may already be communicating their expectation of active learning to their Chinese ESL students. However, as seen in the responses from the participants, the idea of active learning does not seem to have taken hold yet, so it is still a challenge for their transition. In light of this, more frequent encouragement of active learning might be necessary.

Chinese Ways vs. American Ways: The Roots of Pedagogical Conflict

According to the participants, the differences in ways of instruction were noteworthy in several ways, each "off-putting" and an impediment to their total engagement with ESL. Firstly, they found that Chinese instructors had provided much more explicit instructions than their American ESL counterparts. This difference manifested itself in the students' desire for their ESL instructors to give more explicit explanation during the class. For example, Emily was adamant that Chinese teachers would explain everything in detail while "sometimes in ESL class, some teachers skip some steps. I felt a little bit confused because we are losing one - two steps. Maybe it's just related to the cultural difference and the different way of thinking between U.S. and China." Emily gave another example of a time she felt she needed more explicit instruction saying "ESL teachers give us assignments, and they want us to ask questions. But most [Chinese] students are shy and they will never ask questions, and then teachers skip. They talk about another thing, and it's tough to understand."

Emily said that Chinese students were not comfortable asking questions, explaining that asking questions of teachers was simply not part of their culture. Emily admitted that American ESL instructors, however, misinterpreted this silence from 
students as a sign that they all understood the assignment and moved on. She often felt confused and wished her instructors would have explained in greater detail about the assignment. When I asked her what she wanted her teachers to do instead of moving on, she said she would prefer if, "the teachers figure out the questions [with the students] because when teachers accompany [us] to solve difficulties, we improve academically."

The idea of teachers' accompanying students to do assignments sounds similar to the common practice in China of a homework lab monitored by teachers. Emily's desire shows her comfort with the ways she had used to learn and study while growing up in China and her discomfort with new (for her) ways of instruction in the United States.

Just as Emily pointed out that Chinese students would not normally ask questions to teachers, the other Chinese participants made observations about modes of instruction that were different between China and the U.S. They mentioned that Chinese classes were lecture-heavy, teacher fronted classes while the ESL classes fronted students more, utilizing such activities as having class discussions, completing projects and doing presentations. Elaine shared this impression her ESL classes:

I think ESL classes are very casual and move around [in class to do group activities]. In China, we sit in one seat and listen to the teacher. And then [in ESL] students have fun [with others from] different countries.

As Elaine explained, Chinese teachers rarely took steps to involve students in classes, and Tracey reiterated the serious atmosphere of the traditional Chinese classroom, saying, "In China, we just listened to teachers and never never connected with them or raised hands to ask questions. They seldom asked students to raise hands and ask 
questions." All of the participants mentioned significant pedagogical differences between Chinese schools and the ESL program, but some of them appeared to enjoy more casual and involving mode of instruction than others. Some of the participants were happy with the U.S. pedagogical forms even though they stood in sharp contrast to the Chinese traditional classroom. Steven shared this opinion:

[ESL] teachers shouldn't give too much time for Chinese students to discuss in class. [Instead] they can teach more because Chinese students adopted this way to study [of being passive receiver of lecture]. But if they give us too much time to talk to each other, we don't know how to do it.

For Steven, it was preferable for ESL instructors to give lectures rather than making them have discussions in class because Chinese ESL students do not know "how to discuss." Having become so accustomed to being receptive learners, some Chinese students struggle to adapt to the new teaching methodologies commonly employed in U.S. classrooms. Along with the issue of dealing with the unfamiliarity of discussion as classroom learning strategy, Tracey shared her struggle to complete the teamwork assignments often required in class: "Teamwork is difficult because if some students are from other countries like Korea or Japan, the team will not talk a lot, or the question will not be solved. If a team includes only Chinese, we will solve questions faster." For Tracey, working together with students from other language backgrounds posed much more of a challenge than working with her Chinese classmates partly because of the unfamiliarity with discussions, but also due to language issues among the different nationalities. Tracey continued saying, "If some students are from other country like 
Pakistan, Iran, Korea or Japan, the team will not talk well because the question will not be solved. If a team includes only Chinese, we will solve the questions more quickly." Tracey continued:

If some students are from other country like Pakistan, Iran, Korea or Japan, the team will not talk well because the question will not be solved. If a team includes only Chinese, we will solve the questions more quickly. She believed her unwillingness to work with diverse groups was due to "language issues" - more specifically, that students from different countries have unfamiliar accents, which makes it "very difficult to understand what they are saying." In my observation, a majority of the ESL students felt the same way, being more receptive to Chinese classmates and rarely completing teamwork with students from diverse backgrounds.

Curricular differences, including differing examination methods, were also cited in discussions of the pedagogical differences between the two countries. It is especially significant to note that the participants frequently mentioned the important role their textbooks played in curriculum and examinations in Chinese English classes. According to the students, Chinese teachers always followed and completed their textbooks. Accordingly, some of the students complained that the ESL teachers did not follow the textbooks, which the students found confusing. Elaine said, "[in China] we always focused textbooks, so [the class' focus] was many books and books' knowledge." Agreeing with Elaine, Anthony explained a big difference between Chinese and American ESL teachers regarding textbooks: 
The [Chinese] teachers just followed the content of the book, but the ESL teachers did not usually follow the textbook. They taught the students depending on what they want to teach. During the last year, our textbook had 12 chapters. However, we just studied four chapters. She [the teacher] didn't teach some chapters she thought easy to understand.

According to Anthony, Chinese teachers would always follow and complete the chapters in the textbooks. Having grown accustomed this approach, covering only certain chapters in the textbooks in their American ESL classes perplexed the participants. Anthony thought the choice of which chapters were covered by his American ESL teachers was rather random - "depending on what the teacher wants to teach." It appears Anthony did not imagine that there might be a rationale for not covering all the chapters in a textbook or the choices of which chapters were taught in the class. Being used to completing whole textbooks in China, other Chinese students felt the same way. Anthony made this observation about his American ESL classes: “(Teachers) usually asked some stuff outside the textbook. Every week we had vocabulary practice, vocabulary exam, and writing practice. These were all practices outside the textbooks." In Anthony's eyes, it was a bit of a mystery as to why ESL teachers here did not cover the whole textbook but gave assignments and work that were not part of the textbooks, as his Chinese teachers "followed only the text books. They would talk about all the part of the textbook." In China, textbooks were not only at the center of instruction, being covered completely in class; they were also the major basis of assignments and source of exam material. According to the participants, homework in China is usually from the textbooks. 
Elaine frankly emphasized that the homework in China was straight "from textbooks." Lucy agreed, saying, "Basically, I just did homework [to study]. And if we had a test, I just reviewed the textbooks because teachers told you what he would put on the test." From the interviews, it is clear that Chinese teachers not only covered all the chapters, but also assigned homework directly from the textbooks; exams were based almost exclusively on the textbooks as well. American ESL teachers, in contrast, covered fewer chapters and less content from the textbooks, instead assigning more outside materials. Like the assignments, exams in the American ESL classes were markedly different from those of China. Anthony said, "ESL teachers wrote the exam contents, but in China the exam was just from the textbooks." Tracey elaborated more about Chinese homework, saying, "Because homework is just about the textbooks, I need to find the answers [in textbooks] and write them as homework. It's easy."

In an earlier section - "a misperception of structured control vs. unstructured freedom," - it was noted that Chinese students are accustomed to the heavy workload given in Chinese schools and that they attach great respect to such intensive demands. Under further analysis, however, the participants' comments about nature of the homework being assigned in China reveal that the modes of homework tended to be rather simple, albeit time-consuming. Assignments were regularly based on textbooks, and as Tracey said, all the students needed to do was to find the answers from the books. Connecting the dots, it becomes clear that Chinese ESL students were accustomed to completing large amounts of relatively easy homework. Compared to the rather simple demands of most homework assignments in China, the ESL homework assigned in the 
U.S. was significantly more onerous. Exemplifying this, Steven commented that ESL homework "...is very challenging for me because ESL teachers always give us different forms of homework. It [the amount of homework] is not very much. It is not a lot of homework, but it is difficult for me to understand."

In his comment, Steven acknowledged that the amount of homework assigned by his ESL teachers was not big compared that required by his Chinese teachers. Nevertheless, he struggled with his ESL assignments since the 'forms' of homework in ESL classes were varied, unlike all the homework that came from the textbooks in China. Steven explained the challenges of completing the varied styles of ESL assignments in this way:

For example, they had me do some interviews and surveys, write words in newspapers or dictionaries, or print information from the internet. They ESL teachers always changed the ways of homework. In China, homework is the same form, but in America, they are different forms of homework.

Again, it was adapting to the changing forms of homework that Steven found challenging. The Chinese participants all commented that their homework in China was much more intensive compared to ESL classes in the U.S., where homework assignments involving different study and thinking skills were assigned, making them believe their studies in China were more rigorous,. In sheer quantity, the volume of assignments in the U.S. was much smaller than what the students had been used to receiving in China, yet rigor cannot be measured in quantity alone. In terms of quality, the majority of Chinese 
homework assignments required little more than finding information in the textbooks and repeating lots of drills, while the American assignments required the exercise of a larger number of skills in a greater variety of tasks.

The Story: Discomfort with American Teaching Methods, Therapeutic Ways from Home

ESL students from China seemed locked in a tug-o-war between their Chinese ways and the "unsettling" instructional techniques utilized by their American ESL instructors. Being pushed out of their comfort zone created a metaphorical "illness" for which Chinese defaults were a therapeutic treatment.

Revisiting the ideas expressed in "a misperception of highly structured control compared to highly structured freedom," the participants have faced multiple challenges because of the instructional differences between their Chinese and American ESL teachers. They seemed decidedly attached to Chinese ways of instruction and thoroughly confounded by the new ways being utilized by their ESL instructors here. Such confusion and longing for the old ways created some negative responses to the current situation, summarily reflected in Steven's comment that “... too much discussion was waste of time." Therefore, information regarding the modes of ESL instruction, including the rationale for the activities used, and how these activities will benefit students should be clearly communicated at the beginning of their experience. Even so, American teachers must understand that adaptation to these unfamiliar ways and acceptance of their usefulness will be neither easy nor immediate. They will need to exercise patience as the Chinese ESL students work their way through this important transition. 
In their interviews, the participants concurred that Chinese K-12 schools gave much more rigorous homework while complaining that their ESL assignments were too easy. Upon further reflection, however, it turned out that their homework in China was all about the textbook, which took a long time, yet was easier for them to complete. Facing different modes of homework requiring different strategies to work with, some participants felt it more challenging to finish the smaller amounts of ESL homework here than the longer (and more tedious) textbook assignments in China. What the ESL programs and instructors must recognize, however, is the very fact that many Chinese students are operating under the sincere opinion that their Chinese textbook-based curriculum, homework, and exams were more rigorous and thus prepared them more efficiently. Obviously, U.S. higher education does not operate under the same assumptions, giving little credence to the value of homework that consists purely of copying from textbooks or memorizing lists of textbook items for the exams. Nevertheless, when Chinese ESL students have no clear understanding of the rationale for the different modes and 'smaller' amounts of homework, or the time expected to be spent on each homework assignment, their academic transition will not proceed as smoothly as the ESL program, instructors, and university might hope and expect.

A tendency similar to that noted in previous sections was observed in regards to pedagogical differences between China and the U.S. The participants and their classmates expressed a decided preference for the educational norms they had become accustomed to in Chinese K-12 schools - sitting quietly, listening to teachers, taking notes, not volunteering to answer questions or speak in class, and anticipating a relaxed and 
easygoing learning environment in the university. When Chinese ESL students judge their experience in the ESL program by these criteria, they are likely to come to the (false) conclusion that the level of instruction they have received is inadequate in quality and insufficient in quantity. This misunderstanding can result in the type of frustration Anthony experienced - a frustration that surely has a negative effect on student transitions.

\section{$\underline{\text { Conclusion }}$}

Two codes out of many different axial codes were selected to represent the Chinese participants' experience while transitioning from Chinese schools to the ESL program in the U.S. Regarding "Parent social capital and social networks: university arrival, adjustment, and survival," some participants already had both social capital and connections upon their arrival in the U.S., while others didn't. The participants who had social capital and social connections regarding how to start the university life, including placement testing and initial acclimation, were able to arrange better travel plans compared to those who had little clue about international travel and preparation for the placement test. A few participants found new social connections with American students which gave them an advantage them in terms of language and culture learning, giving them confidence navigating the challenges of their new social, cultural, and academic life. Those who did not have opportunities to meet and become friends with American students continued to feel uncomfortable speaking English with Americans, struggling to communicate with them and to understand American culture. 
As noted in "Intra-group hierarchy and collectivist social pressure undermines English acquisition," the Chinese community at the university was found to affect Chinese ESL students both positively and negatively, although a few participants felt that Chinese community benefitted them as a resource of social capital and connection on campus, most participants saw it as a negative influence. Since there are so many Chinese students on campus and in the ESL program, most participants felt that their opportunities to improve English and get to know American students and American culture were hindered as a result. Many of them reported that pressure from their Chinese classmates prevented them from speaking English in class.

In regards to the second axial code, "Chinese students' perception of ESL: What rigor should they respect?" it was observed that the Chinese participants had a decided preference for and confidence in the pedagogical practices that they had experienced in China as the standard. From this perspective, some participants found U.S. pedagogy to be confusing and challenging, while others came to the stronger conclusion that the ESL program was not providing efficient or beneficial instruction. Clearly, the academic expectations they had formed in China contributed to their negative view of the ESL program and its practices, or minimally, their struggle to accept and adjust to the new pedagogical norms reflecting the expectations and academic requirements of their American ESL instructors.

This chapter presented the stories and life experiences of the eight Chinese participants as a group, using two selected axial codes - each code and its properties giving voice to the significance of the participants' experiences followed by the selective 
code representing discussions of its overall "story" based on grounded theory analysis (Strauss and Corbin, 1998).

In the following chapter, suggestions for the ESL program, instructors, and the university drawn from both open code analysis in Chapter IV and axial code analysis in this chapter will be presented. 


\section{CHAPTER 6}

\section{Implications for Practice and Suggestions for Future Research}

\section{Summary of the Research}

This research has sought a better understanding of factors that may contribute to Chinese ESL students' successful (or not so successful) transitions. The research is intended to explore responses from international Chinese ESL students regarding their transition experiences in a U.S. institution of higher education by posing the research question, "What are the social, cultural, and academic factors that positively and negatively affect international students' transition into U.S. higher education?' In doing so, the various challenges encountered by Chinese international ESL students in their transition into U.S. higher education were sought by giving Chinese students a voice using a qualitative study with semi-structured interviews and grounded theory analyses.

These findings from open coding, axial coding, and selective coding analyses can make a contribution to instructors, ESL programs, and institutions at large, helping them to understand the perspectives and expectations which Chinese students bring with them from China, and the social, cultural, and academic struggles they experience in their attempt to transition to the university. The findings can also offer critical suggestions on how to make strategic plans to facilitate the successful transitions of these Chinese ESL students, providing tools to apply effective strategies in their instruction, curriculum development, advising, and policy making.

Chapter 4 presented the results from open code analysis, the line-by-line data analysis with recurring themes that emerged in each participant's data. The themes 
emerging from these interviews portray the participants' individual stories in an attempt to narrate their experience, expectations, and perspectives, especially regarding their Chinese K-12 schooling, ESL studies, difficulty adjusting to new ways of living and studying, interaction with the Chinese community at the university, success or failure in making friends with Americans, and self-motivation, among other themes.

In Chapter 5, the results from axial code analysis - the combination of individual themes by their categories and subcategories based on their properties - were introduced. Among numerous axial codes created, two representative axial codes were selected to discuss the phenomena of the Chinese participants' experience as a group: "Parent social capital and social networks: university arrival, adjustment, and survival" and "Chinese students' perception of ESL: what rigor should they respect?" Finally, selective code analysis provided stories which laid the foundation for two theoretical concepts. The results presented in the chapters overlapped, calling for an understanding of Chinese ESL students' perceptions, and a reconsideration of current practices in ESL, as well as campus-wide policies and services.

These recurring themes were indeed an important representation of the voices of Chinese ESL students regarding the challenges, perspectives, and desires they experienced in their transition from Chinese education to the higher education at the university. The following section presents implications for practice gained from these results. 


\section{Implications for Practice}

$\underline{\text { Need of More Detailed Pre-Departure Information }}$

Social capital is a resource that provides "access to resources and networks that lead to opportunities" (Trice, 2004, p. 672). It is a "store of value that facilitates action" (Light, 2004, p. 19) and "includes the social and personal connections or networks that people capitalize on for interpersonal assistance and personal gain" (Wells, 2008, p. 29) with the implied commitment through reciprocity (Coleman, 1998).

This research found that not all the participants possessed the kind of social capital or social connections passed down from families which provide necessary information on international travel, adjustment, and survival in the new environment. Lack of such social capital and social connections cost the participants, specifically in the form of not performing to the maximum potential on the English placement test, resulting in a much lower placement than they had expected or prepared for. As ESL students will continue to arrive with varying degrees of social capital and social connections, it is important for the program and the university to consider how to best serve incoming students who do not possess these assets through their family ties. One way to help these students is to provide more detailed information than is currently offered before they leave China. The institution should provide not only information on important dates such as orientation and placement tests, but also information about international travel and how it affects people, as well as other potential challenges that might arise upon arrival at the university. 
Therefore, it is strongly suggested here that the university provides pre-departure orientations to Chinese incoming international students in China. Today, the university currently sends personnel to recruit more Chinese students and give placement tests in China. Such pre-departure orientations can be added to the existing trips that are currently taking place if not additionally scheduled. In addition to the pre-departure orientations physically offered in China, online pre-departure orientation workshops should also be available to all the incoming international ESL students so that the incoming international ESL students can review necessary information any time they want and need to.

The participants in this study clearly indicated that most Chinese students use study-abroad agencies' services. However, such agencies' quality of services and knowledge of study abroad and universities abroad can vary from an agency to another. Therefore, it is important for the university to have its own advising available in China before the incoming students to leave their home - to provide clear communications and necessary information.

\section{Providing Opportunities to Cultivate Relationships with Americans}

Cultivating American friendships was a significant challenge for many participants in this study. The participants who successfully formed friendships with Americans (mostly male) found it helpful for improving English, learning culture, and building confidence in the American social and academic arena, while their unsuccessful counterparts (mostly female) found it challenging even to identify opportunities to become friends with Americans. The potential differences between male and female students' intercultural friendship formations might be a reflection of how Americans 
communication styles differ by gender. Tannen (1990) suggests that American women form friendships based on conversation, while men form friendships based on doing things together. As the participants in this study confessed, using English fluently was one of the biggest challenges in their social, cultural, and academic transitions. Female students, therefore, may have been at a disadvantage trying to establish friendships with American female students through conversation, as opposed to the Chinese male students, who may have found it easier to successfully form international friendships simply by doing things together (joining events in Asian American fraternity, going to the Church, playing sports with American roommates and dorm friends, etc.). Further research into this gender difference in cultivating relationships will be necessary to come to a fuller understanding of this phenomenon. Regardless, providing more opportunities for ESL students to establish cross-cultural relationships would be in the best interests of the students and the university community, and should receive a higher priority.

In addressing the strong desire for intervention in this area expressed by some students, the residence halls, admissions, international student office, and the ESL program and its instructors all need to become more aware of assistance they can offer. One significant step would be for residence halls to reconsider the current practice of matching Chinese students with their co-nationals instead matching them with Americans of any ethnic background or non-Chinese roommates or suitemates is strongly recommended in its stead. The university's dormitory placement is according to students' needs of housing during long vacation periods. As Chinese ESL students tend to stay in the university during winter vacation period, many of them were given other Chinese 
roommates and suitemates, and their dormitory building tended to have a large number of Chinese students preventing them from having opportunities to socialize with American students. Therefore, it is mandatory that the university re-considers its dormitory assignment - they should set dormitory assignment policy not only based on its economic benefits. As international students contribute to the campus largely economically, they should receive quality campus life in return including being able to socialize and becoming friends with Americans to be full members of campus society.

The results of this study also would suggest that admissions office put an increased effort into recruiting more students from other countries to more greatly diversify the campus and classrooms. The ESL program does not currently recruit students, but if the authority to recruit more non-Chinese students were granted and exercised, the diversity the classes might surely increase, as all the participants wished.

It is also suggested that the university, the ESL program and its instructors, the international student office, and other student services and departments consider facilitating more interaction between ESL students and their American counterparts in the form of excursions, mentoring, conversation partners, and intercultural exchange partners, to name a few. Indeed, no single program or group of instructors should be responsible for making intercultural friendships happen. Instead, it should be approached as a common agenda of the university, with all of the different units of the institution becoming involved. These Chinese students eventually move from the ESL program into the demands of regular academic classes and culture, interacting with all kinds of different classmates, instructors, professors, departments, and student service personnel. 
Another important group of stakeholders are the American students of all ethnic and racial categories on campus. Even though campus-wide efforts are made to facilitate international friendship through various offices and across different departments, it does not happen if American students are not on board. If American students are unwilling to explore relationships with international students, international students will be isolated (Trice, 2007). Indeed, American students of all ethnic and racial groups need to be encouraged to recognize the value of intercultural friendships, enriching their lives and making themselves more competitive in the global economy through the experience of internationalization and cross-cultural interaction on campus (Johnson, 2006). Such an approach not only benefits Chinese ESL students, but also adds to the pursuit of the "common good" of greater unification and cross-racial/cross cultural community amongst all undergraduate population groups (Smith \& Ota, 2013).

Furthermore, there should be an orchestrated effort to recognize the ESL program as a very important and worthy unit of the university. ESL program is where many international students start their U.S. academic career, and the fact that the university does not recognize it as important unit is disservice to ESL students who pays significant amount of money in tuition and living fees. Recognition can be achieved in terms of assigning designated/dedicated classrooms for ESL program or in the buildings where the students can feel that they are part of the university. ESL instructors' should also be regarded as important as professors - having more job security such as a tenure system as well as assigning the workload that allows instructors to be able to teach to their maximum potential should be considered. Unfortunately, under the current practice, ESL 
classrooms are assigned "after" the regular classrooms are assigned. Many ESL teachers are under nine-month contract and have to teach 16 hours of classes per week. This causes job insecurity and lack of time to prepare well for the classes, which in turn causes potential lower quality of instruction. Therefore, to provide the instruction worth ESL students' tuition, the university should make changes to the current practices that are not beneficial to international ESL students and their instructors.

The university's recognizing the ESL department as an important unit equal to other academic departments is also crucial in terms of facilitating ESL students' campus involvement and social engagement with American students of all backgrounds. Without the full collaboration between the university and all its academic and administrative units and the ESL program with all of their instructors, administrators, and students any attempt for the ESL to facilitate interactions and friendships between ESL students and American students will be less effective. In fact if these collaborative efforts are not enacted between two "equal" partners harsh feelings will accompany ineffectiveness. Put another way, a "patriarchal" relationship with an unbalanced power differential favoring the university academic and administrative units will produce unsatisfactory results for the ESL program. The findings from this study support the creation of a reciprocal process that features American students' learning about different cultures, languages, or intercultural communication skills while ESL students' learn about English and American culture in an equal exchange should be the way the norm as well as the overall goal. Again, to be able to have such an equal exchange to occur, none of the department or the university should not consider the ESL less important, rigorous, or lower in the university. 
Finally, Chinese ESL students also need to be reminded to take advantage of opportunities to cultivate relationships with American and other non-Chinese students if such opportunities are presented. This study has found that some Chinese ESL students were unwilling to take advantage of opportunities to form friendships with Americans due to discomfort, linguistic issues, and cultural conflicts. However, both Astin (1984; 1996) and Tinto $(1998 ; 1999)$ call for the need of campus integration/involvement if students are to make successful transitions into higher education and achieve academic success. Taking advantage of opportunities to become friends with American and nonChinese students will enhance their academic transition and success, and therefore needs to be persistently encouraged.

Looking at the big picture, all of the stakeholders - Chinese ESL students, American and other non-Chinese students, the ESL program and its instructors, and those in the wider campus community, including departments, professors, and student services - should be taking active measures to facilitate Chinese ESL students' cultivation of relationships with Americans and to identify opportunities for them to do so. Without a concerted effort from the university community as a whole, change will not be effected. Orientation and Instruction Regarding U.S. Academic Skills and Expectations

The Chinese participants were accustomed to strict teacher control, long hours at school, and an intense homework load in their Chinese schools. By contrasting their previous educational experience with the ESL program, they found their ESL instruction to be less respectable and favorable. A lack of understanding of the expectations of the ESL program and instructors, a misperception of the unstructured freedom of American 
classrooms, and a failure to appreciate the academic rigor in the ESL program stunted the academic transition processes of Chinese ESL students - a reflection of previous research findings that social and academic integration and involvement are correlated to student success (Astin, 1996; Tinto, 1998; 1999; Collier \& Morgan, 2008). Regarding these pedagogical differences between the U.S. and China, ESL programs and instructors need to be aware that Chinese ESL students are accustomed to behaving in ways mandated by teacher-fronted classes in China. Not having adjusted or transitioned into the U.S. classroom pedagogy, they may behave in ways deemed inappropriate in the eyes of U.S. pedagogy, such as being passive and silent in class. Anthony's comment, for instance, regarding how he shaped negative views about American ESL pedagogy is telling: We pay our tuition and we should receive more experience, more skills and social experience from teachers because they have the more experience and knowledge than we do. But they just teach something very boring and very nonsense things because they didn't prepare that much before the courses and they didn't think about what is useful for students and which content they should omit. They didn't think about any more so. Anthony was clearly not happy with the pedagogical approach that the ESL instructors were using. He felt that he didn't receive the skills and experience commensurate with the value of tuition that he had paid. It must be observed, however, that having grown accustomed to being a passive receiver of knowledge in China, Anthony almost certainly failed to grasp the rationale behind the pedagogy of his American ESL courses. Not having understood U.S. ESL classroom pedagogy, Chinese 
ESL students will continue to be unhappy, complaining like Anthony about how boring and useless their classes are. Therefore, providing clear information and orientation about U.S. pedagogy, academic skills, and expectations would do much to address this problem. Since these students hold different notions about how to behave as college students, they should not be blindly blamed for not knowing the kind of classroom skills necessary for U.S. higher education; instead, they must receive the teaching and coaching required for them to acquire such skills (Tinto, 1998; Kingston and Forland, 2004). Such teaching or coaching can take different formats such as an orientation class, online modules, or even being incorporated into everyday ESL classes as a part of the curriculum. However it is done, two things should be remembered, the first being that previous research advocates that teaching of academic expectations and skills should take place during the students' first year of study (Tinto, 1998; Kingston and Forland, 2004). Therefore, careful planning must go into creating such learning opportunities as needed. Secondly, this transition does not happen in a short period of time, in fact, ESL students will need to go through several stages of transition, often accompanied by a significant amount of pain and the discomfort that accompanies major adjustment. Therefore, an ongoing orientation class at least one semester in length should be required, as Collier and Morgan (2008) recommend.

In this study, it was found that parents have the most influence on Chinese ESL students. Therefore, it is crucial to have parents on board so that Chinese ESL students would accept the different pedagogical practices and expectations, and they would adapt to the U.S. pedagogical systems and expectations more smoothly. For instance, parents 
should be informed how important it is to speak English in ESL classes rather than Chinese even to communicate with their Chinese classmates. To be able to have parents on board, orientations specifically targeting parents should be delivered in China in order for them to understand how their children can be successful in the U.S. academic environment.

Finally, reconsideration of rigor in the current ESL pedagogy may be required since the Chinese students of this study considered the ESL program to be "easy" while they desired more rigorous course assignments. Chickering and Gamson (1987) call for communicating high expectations among faculty in order to create better undergraduate environment. The participants in this study did not fell that they received high expectations from their instructors, therefore, the program and instructors need to reevaluate their curriculum and its rigor as well as how to effectively communicate their expectations with students.

In addition to the importance for Chinese ESL students to understand the different expectations and concept of rigors between China and the U.S., it is equally important to increase rigor in ESL classes to meet their needs. One way to achieve this is to provide online learning such as exercises that provide questions and answers for self-study. Another idea is to have former ESL students from China to come back to ESL classes and help new students; their testimonials of having been in ESL classes and now in university classes will help the new Chinese ESL students to know how former ESL students transitioned academically into the U.S. academic life, understanding differences of study skills and expectations of rigor between China and the U.S. 
Teachers Who Care, Students Who Matter

Again, it must be appreciated that transition requires time, with different stages of growth and pain. Therefore, the program and instructors need to be patient while students go through these transitions.

The participants in this study expressed a desire for teachers to give more explicitly detailed instruction - not only giving detailed information, but also providing models of how to do assigned tasks. Another important point is that for Chinese ESL students, it mattered that the instructors be kind to them. Specifically, such kindness includes being patient with the students when responding to their questions and being willing to take time to help them out.

It is also important that those of us involved in higher education as a whole commit to Chinese ESL students' successful transition into U.S. higher education. Chickering and Gamson (1987) assert that instructors need to "respect diverse talents and ways of learning." Critical theory researchers have criticized the dominant paradigm in higher education since students' differences are framed as "a result of individual deficiencies" (Teranishi, Behringer, Grey, \& Parker, 2009; p. 58). In addition, Kingston and Forland (2008) state that the assumption that host countries' social and academic rules that are not shared by minority groups should be adhered to creates cultural clash and tensions. They call for reconsideration of U.K. higher education practices since "students from East Asia are one of the most rapidly expanding groups within the United Kingdom's higher education system, and can no longer to be overlooked" (Kingston and Forland, 2004, p. 1). Following this line of thinking, American higher education 
practitioners need to be aware of and respect the different abilities, perspectives, expectations, and learning styles that Chinese ESL students present, rather than framing them into the academic rules and expectations and rushing into judgments that they are deficient or unsuccessful.

\section{Making It Everyone's Responsibility}

Chckering and Gamson (1987) explain that both teachers and students should be held responsible for undergraduate education with assistance from "college and university leaders, state and federal officials, and accrediting associations that have the power to shape an environment that is favorable to good practice in higher education" (Chickering and Gamson, 1987, p.7). They also describe several qualities that must characterize an undergraduate education environment including:

- A strong sense of shared purposes.

- Concrete support from administrators and faculty leaders for those purposes.

- Adequate funding appropriate for the purposes.

- Policies and procedures consistent with the purposes.

- Continuing examination of how well the purposes are being achieved (Chickering and Gamson, 1987).

Chinese ESL students have come to play a significant part of undergraduate education in U.S. higher education. To make undergraduate education more inclusive of the recent influx of Chinese students, the instructors, the students, and the university, along with all the other helping-hand organizations, need to take responsibility for the 
creation of a healthy environment with good practices in higher education for all of its members, as Chickering and Gamson (1987) call for.

\section{$\underline{\text { National Policy Affecting International Student Recruitment }}$}

In the current economic situations, higher education institutions seek their revenue from international students resulting in aggressive recruitment in certain countries. In the case of the university in this study, China is the predominant country where this aggressive recruitment is taking place. However, this has caused a significant problem of lack of balance in international student population presented on campus. Therefore, it is necessary for the national policy to provide more funds to higher education. In addition, funds to recruit more countries, especially for those who were not able to support studying abroad on their own should be considered. In addition, federally sponsored higher education research regarding study like this to help provisionally admitted ESL students with their transition to American colleges and universities should be necessary in order to provide directives to higher education community.

\section{Limitations}

This qualitative research involving semi-structured interviews and grounded theory technique explored challenges that Chinese international ESL students face during the course of their transition into U.S. higher education. It was expected that this research would reveal the challenges that Chinese ESL students face in their daily lives, and their perspectives on those experiences, consequently contributing to an increased awareness and understanding of these challenges among the instructors, the program, and the university to which these students belong. 
The researcher is well aware of the limitations of this study. First of all, this is a qualitative study with a limited sample size of eight students. Therefore, the results from this research cannot extrapolate to the Chinese ESL student population at large. Secondly, the study only focused on mainland Chinese ESL student challenges, implying that the findings from this study would not necessarily represent any other international ESL students, or international students at higher levels of study. Likewise, as this research focused only on ESL students who have obtained provisional admission from a university, the results of the study may not be directly applicable to ESL students who are in the United States to study English for a shorter period of time. Another limitation of this research is that it focused only on students from an ESL program in the Midwest, implying that similar findings may be applicable only to Chinese international ESL students at institutions in the U.S. which share similar profiles. Based on the limitations of this study, suggestions for the further study are presented in the next section.

\section{Suggestions for Future Research}

This study only interviewed eight Chinese students in an ESL program in the Midwest, and theses students represented only the highest level of the program. Researching experiences of Chinese ESL students in different levels within the same program would reflect wider range of perspectives; the challenges faced by a broader cross-section of students might be different from the participants in the current study, who were more proficient in English than Chinese ESL students in lower level classes. In addition, a greater number of participants in a study like this would strengthen the current limitation, giving more depth to the theory and argument. 
In a similar vein, the eight Chinese students' participation was voluntary, allowing for no control over region of origin, age, socioeconomic status, or parents' educational levels. Having control over such conditions may present different results, perspectives, and experiences among Chinese ESL students.

This study found potential differences between male and female students in regard to establishing relationships with American students, namely, that most male students successfully became friends with Americans while their female counterparts were unable to do so. A study with a more intentional gender-focus on how intercultural friendships are viewed and formed may reveal new insights into Chinese ESL students' intercultural friendship formations.

Furthermore, the participants who volunteered to be part of this research were for the most part motivated and academically successful in their ESL studies. Therefore, this research uncovered only the challenges met by motivated and successful ESL students. Unsuccessful ESL students' experiences may be different in varying degrees. To get a hold of their perspectives and stories, a different sampling strategy (such as making participation mandatory) will be required.

Finally, the ESL program is part of a large traditional research I university in the Midwest. Researching Chinese ESL students in different ESL programs affiliated with different types of institutions (Research, Doctoral, Master, Liberal Arts, Public, and Private) could uncover potential similarities and/or differences in the initial transition experiences of Chinese ESL students. Likewise, a wider geographic representation of 
ESL programs in the U.S. could also reveal potential differences and/or similarities to what this study has found.

\section{Conclusion}

This research sought to shed light on what international Chinese ESL students struggled with, how they felt, and what they expected upon arrival in the U.S. to pursue their studies. It also explored how international Chinese ESL students saw the potential gaps between their own expectations and those of their instructors, programs, and institutions here in the U.S. This research also intended to identify issues that were not yet fully appreciated in terms of international ESL students' academic and socio-cultural transitions into higher education. Although limitations still remain, the researcher strongly believes this research is an important stepping stone to better understanding the barriers that Chinese ESL students face when they arrive on our campuses, enabling instructors, programs, and the higher education community at large, including professors, departments, and administrative executives to craft more appropriate policies, create better curriculums, and develop better services for these students, and to transform the perspectives of current and future ESL administrators and educators in regard to instruction, curriculum development, and program and institutional-level policy setting, enabling them to facilitate the academic success of ESL students in American higher education. 


\section{REFERENCES}

Amin, N. (2004). Nativism, the native speaker construct, and minority immigrant women teachers of English as a second language. In L. Kamhi-Stein (Ed.), Learning and Teaching from Experience (pp. 61 - 80). Ann Arbor, MI: The Michigan University Press.

Andrade, M.S. (2005). International students and the first year of college. Journal of the First Year Experience, 17(1), 101-129. Retrieved from http://fyesit.metapress.com/content/041268nr5126j3n0/

Andrade, M.S. (2006). International students in English-speaking universities: adjustment factors. Journal of Research in International Education, 5, 131 - 154.

DOI: $10.1177 / 1475240906065589$

Astin, A. W. (1984). Student involvement: A developmental theory for higher education. Journal of college student personnel, 25(4), 297-308. Retrieved from https://www.middlesex.mass.edu/tutoringservices/downloads/astininv.pdf

Astin, A. W. (1996). Involvement in learning revisited: Lessons we have learned. Journal of College Student Development, 37(2), 123-133. Retrieved from http://muse.jhu.edu.proxy.lib.pdx.edu/journals/journal_of_college_student_develo pment/

Bensimon, E.M. (2007). The Underestimated significance of practitioner knowledge in the scholarship on student success. The Review of Higher Education, 30(4), 441469. DOI: $10.1353 /$ rhe.2007.0032 
Bernard, H. R. (2006). Research methods in anthropology. Qualitative and quantitative approach. Lanham, MD. Alta Mira Press.

Biggs, J. B. (1993). What do inventories of students' learning processes really measure? A theoretical review and clarification. British Journal of Educational Psychology, 63(1), 3-19. DOI: 10.1111/j.2044-8279.1993.tb01038.x

Bourdieu, P. (1986). The forms of capital. J.G. Richardson (Ed.), Handbook of theory and research for the sociology of education, (pp. 241-258). New York, NY: Greenwood.

Brown, R.A., Gray, P. R., \& Ferrara, M. S. (2005). Attributions for personal achievement outcomes among Japanese, Chinese, and Turkish university students. Information and Communication Studies, 33(1), 1-13. Retrieved from http://sucra.saitamau.ac.jp/modules/xoonips/download.php/BKS0000053.pdf?file_id=16276

Brown, S. \& Joughin. G, (2007). Assessment and international students. In E. Jones and S. Brown (Eds.). Internationalizing higher education. (pp. 57-71). New York, NY. Routledge.

Charmaz, K. (2006). Constructing Grounded Theory: A Practical Guide through Qualitative Analysis. Thousand Oaks, Ca. SAGE Publications Ltd.

Chen, C. P. (1999). Common stressors among international college students: Research and counseling implications. Journal of college counseling, 2(1), 49 - 65. DOI: 10.1002/j.2161-1882.1999.tb00142.x 
Chickering, A.W. \& Gamson, Z.F. (1987). Seven principles for good practice in undergraduate education. The American association of higher education bulletin, $39,3-7$.

Chritsie, H., Cree, V. E., Hounsell, J., McCune, V., \& Tett, L. (2006). From college to University: looking backwards, looking forwards. Research in Post-compulsory Education, 11(3), 351-365. DOI: $10.1080 / 13596740600916591$

Chritie, H., Tett, L., Cree, V. E., Hounsell, J., \& McCune, V. (2008). 'A real rollercoaster of confidence and emotions': Learning to be a university student. Studies in Higher Education , 33(5), 567-581. DOI:

$10.1080 / 03075070802373040$

Coleman, J.S. (1998). Social capital in the creation of human capital. American journal of sociology, 94, S.95-S120. Retrieved from http://www.jstor.org/discover/10.2307/2780243?uid=3739728\&uid=2\&uid=4\&ui $d=3739256 \&$ sid $=21102173334397$

Collier, P. J. (2000). The effect of completing a capstone course on student identity. Sociology of Education, 37, 285-299. Retrieved from http://www.jstor.org/discover/10.2307/2673235?uid=3739728\&uid=2\&uid=4\&ui $d=3739256 \& \operatorname{sid}=21102173334397$

Collier, P. (2001). A differentiated model of role identity acquisition. Symbolic Interaction, 217-235. DOI: 10.1525/si.2001.24.2.217 
Collier, P. and Morgan, D. (2008). "Is that paper really due today?”: differences in firstgeneration and traditional college students' understandings of faculty expectations. Higher Education, 55, 425-426. DOI 10.1007/s10734-007-9065-5.

Cress, M. C. (2008). Creating inclusive learning communities: the role of student-faculty relationships in mitigating negative campus climate. Learning Inquiry, 2, 95-111. $10.1007 / \mathrm{s} 11519-008-0028-2$

Cresswell, J.W. (2007). Qualitative inquiry \& research design. Thousand Oaks, CA: Sage publication.

Cresswell, J.W. (2012). Educational Research. Boston, MA. Person.

De Vita, G. (2007).Taking stock: An appraisal of the literature on internationalizing HE learning. In E. Jones and S. Brown (Eds.). Internationalizing higher education. (pp. 154-167). New York, NY. Routledge

Engle, J. (2007). Postsecondary access and success for first-generation college students. American Academic, 3(1), 25-48. Retrieved from http://www.aft.org/pdfs/highered/academic/january07/Engle.pdf

Gan, Z. (2009). 'Asian learners' re-examined: An empirical study of language learning attitudes, strategies and motivation among mainland Chinese and Hong Kong students. Journal of Multilingual and Multicultural Development, 30(1), 41-58.

DOI: $10.1080 / 01434630802307890$

Gan, Z., Humphreys, G., \& Hamp-Lyons, L. (2004). Understanding successful and unsuccessful EFL students in Chinese universities. The modern language journal, 88(2), 229 - 243. DOI: 10.1111/j.0026-7902.2004.00227.x 
Gu, Q., \& Schweisfurth, M. (2006). Who adapts? Beyond cultural models of 'the' Chinese learner. Language, culture, and curriculum, 19(1), 74 - 89. DOI: $10.1080 / 07908310608668755$

Handa, N. (2004, December). What else did I need to bring with me? International students and their dilemma. In 15th ISANA Conference of the International Students Advisors' Network of Australia (ISANA). Melbourne.

Hellesten, M. \& Prescott, A. (2004). Learning at university: The international student experience. International Education Journal, 5(3), 344 - 350. Retrieved from http://www.iejcomparative.org/data/volumes/v5n3.pdf

Institute of International Education. (2012). Fast facts open doors 2012 [Data file]. Retrieved from http://www.iie.org/en/Research-and-Publications/Open-Doors

Johnson, M.M. (2006). Toward a new foreign-student strategy. NAFSA National Association of International Educators. Retrieved from http://www.nafsa.org/press_releases.sec/press_releases.pg/chronarticle06/

Kingston, E. \& Forland, J. (2004). Bridging the gap in expectations between international students and academic stuff - "At home the teachers feed me with knowledge, but in the UK they help me pick up the spoon and learn to feed myself!" Journal of Studies in International Education, 12(2), 204-221. DOI: $10.1177 / 1028315307307654$

Kingston, E., \& Forland, H. (2008). Bridging the gap in expectations between international students and academic staff. Journal of Studies in International Education 12(2), 204-221. 
Lee, J.J. \& Rice, C. (2007). Welcome to America? International student perception of discrimination. Higher Education, 53(3), 381-400. DOI: 10.1007/s10734-0054508-3

Levy, S., Osborn, M. \& Plunkett, M. (2003). An investigation of international students academic and Social Transition Requirements. First Year in Higher Education 2003 Conference. 1-10. Retrieved November 17, 2006, from http://www.fyhe.qut.edu.au/FYHE_Previous/papers03/Refereed\%20Papers/St udent\%20Pop.\%20\&\%20Div/Levy,Osborn\&Plunkett_ab.doc.

Li, G., Chen. W., \& Danmu, J. (2009). Determinants of international students' academic performance: A comparison between Chinese and other international students. Journal of studies in international education, 14, 389 - 405. DOI: $10.1177 / 1028315309331490$

Lier, L. (2005). Case study. In E. Hinkel (Ed.). Handbook of research in second language teaching and learning (pp. 195 - 208). Mahwah, NJ: Lawrence Erlbaum.

Light, I. (2004). Immigration and entrepreneurship: Culture, capital, and ethnic networks. Piscataway, NJ: Transaction Publishers.

Mahoob, A. (2004). Native or Nonnative: What Do Students Enrolled in an Intensive English Program Think? In L. Kamhi-Stein (Ed.), Learning and Teaching from Experience (pp. 100-120). Ann Arbor, MI: The Michigan University Press. Michigan State University English Language Program. MSUELT. Retrieved from http://elc.msu.edu/testing/msuelt/ 
Michigan State University English Language Program enrollment trend data. (S.M. Gass, personal communication, October 31,2012).

Michigan State University Office for International Student and Scholars. (2003).

Statistical Report. Retrieved from http://oiss.isp.msu.edu/about/statistics.htm Michigan State University Office for International Student and Scholars. (2004).

Statistical Report. Retrieved from http://oiss.isp.msu.edu/about/statistics.htm Michigan State University Office for International Student and Scholars. (2005).

Statistical Report. Retrieved from http://oiss.isp.msu.edu/about/statistics.htm Michigan State University Office for International Student and Scholars. (2006).

Statistical Report. Retrieved from http://oiss.isp.msu.edu/about/statistics.htm Michigan State University Office for International Student and Scholars. (2007).

Statistical Report. Retrieved from http://oiss.isp.msu.edu/about/statistics.htm Michigan State University Office for International Student and Scholars. (2008).

Statistical Report. Retrieved from http://oiss.isp.msu.edu/about/statistics.htm Michigan State University Office for International Student and Scholars. (2009).

Statistical Report. Retrieved from http://oiss.isp.msu.edu/about/statistics.htm Michigan State University Office for International Student and Scholars. (2010).

Statistical Report. Retrieved from http://oiss.isp.msu.edu/about/statistics.htm Michigan State University Office for International Student and Scholars. (2011).

Statistical Report. Retrieved from http://oiss.isp.msu.edu/about/statistics.htm Michigan State University Office for International Student and Scholars. (2012).

Statistical Report. Retrieved from http://oiss.isp.msu.edu/about/statistics.htm 
National Association for College Admission Counseling. (2010). Discussion brief: International interest in U.S. higher education and institutional recruiting practice. Retrieved from http://www.nacacnet.org/studentinfo/InternationalStudentResources/Documents/I nternationalRecruiting.pdf

Morgan, G. (2006). Images of organization. Updated edition of the international bestseller. Thousand Oaks, CA: SAGE Publications.

NAFSA (2011). Educating students for success in the global economy. A public opinion survey on the importance of international education. Retrieved from http://www.nafsa.org/_file/_/2011_edstudentsglobaleconomy.pdf

NAFSA: Association of International Educators. (2012). The economic benefits of international students to the U.S. economy academic year 2011-2012 [Data file]. Retrieved from http://www.iie.org/Research-and-Publications/OpenDoors/Data/Special-Reports/Economic-Impact-of-International-Students

Owens, A. (2011). Supporting and evaluating transitional learning for international university students. Australian Universities' Review, 53(1), 42 - 49. Retrieved from http://www.eric.ed.gov/PDFS/EJ926448.pdf

Plant, E.A., Ericsson, K.A., Hill, L. \& Asberg, K. (2005). Why study time does not predict grade point average across college students: implications of deliberate practice for academic performance. Contemporary Educational Psychology, 30(1), 96-116. doi:10.1016/j.cedpsych.2004.06.001 
Rajapaksa, S., \& Dundes, L. (2002). It's a long way home: International student adjustment to living in the United States. Journal of College Student Retention, 4, 15-28. DOI: 10.2190/5HCY-U2Q9-KVGL-8M3K

Reed, D., Kim, H. \& Ohlrogge, A. (2013, March). Low-level placement testing: theory, research, development, and practice. Paper presented at international TESOL Conference, Dallas, TX.

Rendon, L.I. (1992). From the barrio to the academy: Revelations of a Mexican American "scholarship girl." New Directions for Community Colleges, 80, 55-64. DOI: $10.1002 / \mathrm{cc} .36819928007$

Rendon, L. I., Jalomo, R., \& Nora, A. (2000). Theoretical considerations in the study of minority student retention in higher education. In J.M. Braxton (Ed.) Reworking the student departure puzzle (pp. 127-156). Nashville, TN: Vanderbilt University.

Richards, J.C., Schmidt, R., Kendricks, H. \& Kim, Y. Longman Dictionary of Teaching and Applied Linguistics. London. Person.

Robertson, D.L. (1988). Self-directed growth. Muncie, IN: Accelerated Development.

Robinson, J. (1992). International Students and American University Culture: Adjustment Issues. http://www.eric.ed.gov/ERICWebPortal/search/detailmini.jsp?_nfpb=true\&_\&ER ICExtSearch_SearchValue_0=ED350968\&ERICExtSearch_SearchType_0=no\&a ccno $=\mathrm{ED} 350968$ 
Smith, M.J. (2009). Right directions, wrong maps: understanding the involvement of lowSES African American parents to enlist them as partners in college choice. Education and urban society, 41(2), 171-196. DOI: 10.1177/0013124508324028

Smith, M. J., \& Ota, A. (2013). Matching International Enthusiasm With Diversity Commitment. Journal of College Admission (Winter). 16-21.

Strauss, A. and Corbin, J. (1998). Basics of qualitative research. Techniques and procedures for developing grounded theory. Thousand Oaks, CA: Sage Publications.

Tan, P.L. (2011). Towards a culturally sensitive and deeper understanding of "rote learning" and memorization of adult learners. Journal of studies in international education, 15(2), 124-145. DOI: 10.1177/1028315309357940

Tannen, D. (1990). Sex, lies, an conversation; why is it so hard for men and women to talk to each other? The Washington Post, June 24, 1990. Retrieved from http://www9.georgetown.edu/faculty/tannend/sexlies.htm

Teranishi, R. T., Behringer, L. B., Grey, E. A., \& Parker, T. L. (2009). Critical race theory and research on Asian Americans and Pacific Islanders in higher education. New Directions for Institutional Research, 2009(142), 57-68. DOI: $10.1002 /$ ir.296

Terenzini, P.T., Rendon, L.I, Upcraft, M.L., Miller, S.B, Allison, K.W., Gregg, O.L, \& Jalomo, R. (1993). The transition to college: Diverse students, diverse stories. Research in Higher Education, 35(1), 57-73 DOI: 10.1007/BF02496662 
Teranishi, R. T., Behringer, L.B., Grey, E.A., \& Parker, T.L. (2009) Critical race policy research on Asian Americans and Pacific Islanders in U.S. higher education. New Directions for Institutional Research, 142, 57-68.

Tierney, W. (1992). An anthropological analysis of student participation in college. Journal of Higher Education, 63(1), 603-618. Retrieved from http://www.jstor.org/discover/10.2307/1982046?uid=3739728\&uid=2134\&uid=2 \&uid=70\&uid=4\&uid=3739256\&sid=21102173463107

Ting-Toomey, S. (1999). Communicating across cultures. New York, NY: Guilford Press. Ting-Toomey, S. \& Chung, L.C. (2005). Understanding intercultural communication. New York, NY: Oxford University Press.

Tinto, V. (1988). Stages of student departure: reflections on the longitudinal character of student leaving. The journal of higher education, 59, 438-455. Retrieved from http://www.jstore.org/stable/1981920

Tinto, V. (1993). Leaving college: Rethinking the causes and cures of student attrition. ( $2^{\text {nd }}$ ed.).Chicago, IL: The University of Chicago Press.

Tinto, V. (1998). Colleges as communities: taking research on student persistence seriously. The review of higher education, 21(2), 167- 177. DOI:

10.1353/rhe.1997.0024

Tinto, V. (1999). Taking student success seriously: rethinking the first year of college. NACADA Journal, 19, 5-9. Retrieved from http://fdc.fullerton.edu/events/archives/2005/0501/acadforum/Taking\%20Success\%20Seriously.pdf 
Trice, A.G. (2004). Mixing it up: International graduate students' social interactions with American students. Journal of College Student Development, 45, 671-687. DOI: $10.1353 / \mathrm{csd} .2004 .0074$

Trice, A.G. (2007). Faculty perspectives regarding graduate international students' isolation from host national students. International Education Journal, 8(1), 108117. Retrieved from http://openjournals.library.usyd.edu.au/index.php/IEJ/article/viewFile/6778/7423\# page $=114$

Turner, Y. (2006). Chinese students in a UK business school: Hearing the student voice in reflective teaching and learning practice. Higher Education Wuarterly, 27-51. DOI: $10.1111 / \mathrm{j} .1468-2273.2006 .00306 . x$

Wells, R. (2008). The effects of social and cultural capital on student persistence. Are Community Colleges More Meritocratic? Community College Review, 36(1), 2546. DOI: $10.1177 / 0091552108319604$

Yates, R. \& Muchisky, D. (2003). On reconceptualizing teacher education. TESOL Quarterly, 37(1), 135-147. DOI: 10.2307/3588468

Zhai, L. (2004). Studying international students: Adjustment issues and social support. Journal of international agricultural and extension education, 11(1), 98-104. DOI: $10.5191 /$ jiaee.2004.11111 


\section{APPENDIX A}

\section{Introductory Script}

(During the class visits)

I am a doctoral student in the Graduate School of Education at Portland State University. I am conducting a study for my dissertation research this semester, and I would like to invite 8 students from China whose first semester was fall 2011 and who were full-time ELC students to participate in this study. With your help, I expect to understand more about the challenges - social, cultural, and academic difficulties - that you faced during your first semester in the ELC. If you are under 18 years old, you are not eligible to participate in this study.

Participation is truly voluntary, which means that there is no obligation for you to participate in this study even if you are from China. Also, participation will not affect your course grade. You may also stop participating in this study at any time without affecting your grade and your relationship with me.

If you agree to participate, I will interview you for $90-120$ minutes. I will pay you $\$ 20$ per hour for this interview. While I interview you, I will record the conversation and take some notes, but this information will not be shared with anybody in this program. There is a small chance that I need to interview you for the second time to clarify some points that you mentioned at the first time or in the case we did not finish all the interview questions during the first interview. Of course, you will be paid for the second interview, too.

As I have just mentioned, you will receive $\$ 20$ per hour as a benefit for your participation. Another benefit is that when you express the challenges that you have faced since you started your academic life here in the U.S., we can build a better academic community here in the ELC, at MSU, and in the U.S. Certainly, your participation may help not only my research, but also the ELC program, MSU and the US higher education as a whole.

Again, your data will not affect your course grade, which is based solely on the criteria articulated in the syllabus.

Your name will be kept confidential and will not be mentioned anywhere in the publication or presentation of this research.

If you are interested in participating, please write down your name, e-mail address, and contact phone number on this sign-up sheet, and take my business card. I will be contacting you shortly so that we can meet and discuss more details about this study and interview schedules.

Thank you very much for your consideration. 


\section{APPENDIX B}

\section{Informed Consent Form}

Be part of an important project

Factors influencing social, cultural, and academic challenges while transitioning to the ESL

Akiko Ota from Portland State University's Educational Leadership and Policy

Department is doing a research study on what kind of social, cultural, and academic challenges you have been facing, after starting your ESL program in the United States, and how they affect your studies and life.

\section{What will I have to do?}

If you decide to take part in this project, I will:

- Interview you a time when it is convenient for you. This will take you about 60 90 minutes to complete.

- Record you with audio tape while you are taking part in the interview.

\section{Why have I been asked to take part in this study?}

You have been asked to take part in this study because you are taking a language class in the English Language Center. You do not have to take part in this study.

\section{Are there any risks?}

If you take part in this study:

- There is a small risk that someone will learn your name and find out what your answers are. I make sure that I do everything possible to protect your name and identity.

- There is a small risk that you will feel uncomfortable answering some of the questions. You may skip any question you do not want to answer.

\section{What are you doing to protect me?}

Your privacy is very important to us. We have done several things to protect you:

- I won't tell anyone if you take part in this study or not.

- Your answers on the interview will be kept confidential to the extent allowed by law. This means that the names of the people who take part in the study will not 
be given to anyone else. I will only reveal what you say or do in a way that no one could ever guess or know it was you who said that.

- The audio tapes will be kept in a locked drawer and will only be heard by the researcher on this project. When we write down what you said, we will replace all the names with code names so that no one can know who said or did what.

- Your name and other personal information will be kept locked so that no one other than the researcher will be able to see it. We need to this information to keep track of who participated. For example, this form will be kept in a locked cabinet because it has your name on it.

- When I write or talk about what I learned in this study, I will use code names and leave things out so that no one will be able to tell who we are talking about.

\section{What will I gain by taking part in this study?}

- You will receive $\$ 20$ per hour for participation.

- If you participate, you may be helping me learning how to become better teachers, and so help students in future courses.

\section{What happens if I decide not to take part in this study?}

- You do not have to part in this study. Your participation is voluntary.

- You can change your mind and stop at any time, even if you first said yes.

- It will not affect your course grade if you say no.

- It will not affect your relationship with your teachers in the English Language Center if you say no.

- Your relationship with the researcher (Akiko Ota) will also not be affected if you say no.

\section{Any Questions?}

If you have any questions about this study, this form or the project you can:

- Talk to the researcher (Akiko Ota: 517-884-0568)

- Contact the Chair of the Human Subjects Committee of Portland State University about your rights as a research participant. They can be contacted at: 
The Human Subjects Research Review Committee,

Office of Research and Sponsored Projects,

600 Unitus Bldg.

Portland State University, 1721 Broadway Ave.

Portland, OR 97201.

Telephone: (503) 725-4288 / 1-877-480-4400.

Hours: 9:00 a.m. to 5:00 p.m., Monday through Friday

\section{If I sign, what does it mean?}

This is a consent form. Your signature below means that:

- You have read and understood what this form says.

- You are willing to take part in the study by taking a survey and having us record you while you participate in a language learning activity.

- You know that you do not have to take part in this study. And even if you agree, you can change your mind and stop at any time. No problem.

- If you take part in this study, it has nothing to do with your being part of the ELC program. If you agree to take part, or if you say no, they won't know and it won't matter. They will treat you the same.

- You will get a copy of this form to keep for yourself. 


\title{
APPENDIX C \\ Informed Consent Form Chinese Translation
}

\begin{abstract}
邀请你加入重要的研究企划:
研讨处在ELC (英语语言中心) 的过渡期中, 影响社会, 文化及学术上困境的因

素
\end{abstract}

Akiko Ota（太田晶子）, 波特兰州立大学-教育领导和政策部门（系）, 正在作一 研究, 关于各种不同的社会上、文化上以及学术上会面对到的困难, 当你开始你在 米国的ESL课程, 而这些难题又会如何影响到你在这的生活及学习。

我必须做些那些事: What will I have to do?

如果你决定要参与这项研究企划, 我会---

- 以你方便的时间做访谈, 需约90-120分钟来完成。

- 访谈会被录音记录。

为何我会被邀约参加这个研究? Why have I been asked to take part in this study? 你会被要求考虑参与这个研究, 因为你是English Language Center (英语语言中心) 的学生。但是你要参加与否, 是志愿的, 不是强制的。

有啥么风险吗？Are there any risks?

如果你参与这项研究:

- 有极小的可能是, 那认识你的名字的人可能会发现你的答案。然而, 我会尽 我可能来保护你的名字跟身份。

- 有可能在访谈中, 你会觉得回答某些问题不是很自在。你可以略过任何你不 想回答的问题。

你会做什么来保护我? What are you doing to protect me?

你的隐私是很重要的, 几个预防措施会用来保护你:

- 不会告诉任何人, 你是否有参加这个研究。

- 你在访谈中的回答是在法律认可程度上保密的, 这表示参与这研究的人其名 字不会给其他人。我只会展现你的谈话内容, 但我会以没人可以猜出或知道 是你说的方式来表达。

- 录音记录会被放在上锁的抽屉, 只有这个企划的研究员可以阅听。如果有文 字被写出, 所有的名字会以代号代替, 所以没人可探知谁说了或做了什么。

- 你的名字或其他个人资料会被锁藏, 所以除了研究员, 没其他人可以看到。 我们需要这些资料来追踪谁曾参与, 甚至以这份表格 (同意书) 为例, 也会 被锁藏在柜子里, 因为有你的名字在上面。 
- 当我写或说到研究心得, 我会用代号名并且把一些东西排除, 所以没人可以 知道参与者是谁。

参与这个研究, 我会获得什么? What will I gain by taking part in this study?

- 你的参与每小时会得到 $\$ 20$ 块钱。

- 如果你参加, 你有可能帮助其他人学习如何成为更好的老师, 也同时帮助未 来参与课程的学生。

如果我决定不参与这研究, 会发生什么事?

What happens if I decide not to take part in this study?

- 你不一定要参与这研究, 你的参与不是规定而是志愿的。

- 你可以随时改变心意或停止, 即使你在一开始的时候是答应要参与的。

- 并不会影响你的课堂成绩极使你不参与这研究。

- 你不参与并不会影响到你跟English Language Center 老师的关系。

- 你不参与也不会影响到你跟研究员(Akiko Ota太田晶子)的关系。

\section{还有其他的问题？Any Questions?}

如果你对于这个研究, 这张表格（同意书）, 或这企划, 有任何的问题, 你可以:

- 跟研究员Akiko Ota 谈, Akiko Ota: 517-884-0568

- 联络波特兰州立大学-教育领导和政策部门的主席, 有关你为研究参与者的 权益。

The Human Subjects Research Review Committee Office of Research and Strategic Partnerships, Market Center Building, $6^{\text {th }}$ floor, 1600 SW $4^{\text {th }}$ Ave, Portland OR 97201.

Telephone: (503) 725-4288 / 1-877-480-4400.

Hours: 9:00 a.m. to 5:00 p.m., Monday through Friday

\section{如果我签名了，那代表什么？If I sign, what does it mean？} 这是一张同意书（表）, 你下面的签名代表:

- 你已经读过且了解这张表的内容。

- 你愿意参与这研究, 被访谈, 同意我们在访谈中录音。 
- 你知道你不一定要参与这研究, 即使你同意要参与, 你随时都可以改变心意 或停止-没问题的。

- 如果你参与这研究, 跟你是ELC课程一分子没干系。你同意或不同意参与, 没人会知道也没重要的影响, 你还会是被同样的对待。

- 你会拿到一份这同意书的影本。 


\section{APPENDIX D}

\section{Interview Protocols}

\section{First Interview Protocol}

Disclaimer to the students:

I will ask you some personal questions first, then about some of your experiences starting the ESL program here. In response to my questions, I would like you to give examples and expand as much as you can instead of using only one word or short answers.

$\underline{\text { Personal background information questions }}$

1. Could you tell me how old you are?

2. Could you tell me about your educational experience in China? For example, did you go to a public, private, or international school? Did you go to school from your home, or did you live in the school dormitory?

3. How many years did you study English in China? How many hours per week did you receive English classes at school?

4. What kinds of activities did you do in English classes? What homework assignments did you receive from teachers of English?

5. How did you study for English classes in China?

6. Did you like English classes in China? Why or why not?

$\underline{\text { Social and cultural challenges faced in ESL studies }}$

1. What are some of the challenges you faced dealing with American society when you started the ESL program here?

(Question probes) 
a. Where do you think those difficulties come from? (to solicit open-ended answers from the participants)

b. Are there any of these difficulties due to cultural differences?

i. If yes: Tell me a story about your experience dealing with a difficulty you thought was due to cultural differences.

ii. Are there any difficulties due to attitude differences?

1. If yes: Tell me a story about your experience dealing with a difficulty you thought was due to attitude differences.

2. What are some of the challenges you faced adjusting to East Lansing when you started the ESL program here?

(Question probes)

a. Where do you think those difficulties come from? (to solicit open ended answers from the participants)

b. Are there any of these difficulties due to cultural differences?

i. If yes: Tell me a story about your experience dealing with a difficulty you thought was due to cultural differences.

ii. Are there any difficulties due to attitude differences?

1. If yes: Tell me a story about your experience dealing with a difficulty you thought was due to attitude differences.

3. What are some of the challenges you faced in adjusting to the campus community when you started the ESL program here?

(Question probes) 
a. Where do you think those difficulties come from? (to solicit open ended answers from the participants)

b. Are there any of these difficulties due to cultural differences?

i. If yes: Tell me a story about your experience dealing with a difficulty you thought was due to cultural differences.

ii. Are there any difficulties due to attitude differences?

1. If yes: Tell me a story about your experience dealing with a difficulty you thought was due to attitude differences.

4. When you have difficulties, who do you talk to for help?

5. Tell me a story about difficulties that you have shared with that person.

6. Why do you choose to talk to that person about difficulties?

Academic challenges faced in ESL studies

1. What are some of the challenges you faced in ESL studies?

(Question probe)

a. Where do you think those difficulties come from? (to solicit open ended answers from the participants)

2. Are any of these difficulties due to cultural differences?

(Question probe)

a. If yes: Tell me a story about your experience dealing with a difficulty you thought was due to cultural differences.

b. Are there any difficulties due to attitude differences? 
i. If yes: Tell me a story about your experience dealing with a difficulty you thought was due to attitude differences.

3. Are there any things that you wish your program, school, or teachers would understand, accommodate, or change?

(Question probe)

a. Is there anything you want to add or other difficulties you can think of that Chinese students may face when they start ESL studies here?

4. Do you know any international ESL students who have been successful? (Question probe)

a. If yes: Tell me a story about a time another Chinese student was successful in dealing with ESL studies here.

5. Do you know any international ESL students who were not successful?

(Question probe)

a. If yes: Tell me a story about a time another Chinese student was not successful in dealing with ESL studies here.

6. When you have difficulties with academics, who do you talk to for help? (Question probe)

a. Tell me a story about difficulties that you have shared with that person

b. Why do you choose to talk to that person about difficulties? 


\section{Second Interview Protocol}

1. How many days before placement test did you arrive in East Lansing?

2. Did you know that you were going to take ESL?

3. How did you feel initially about being placed in ESL Level (the participants' initially assigned level in the beginning of the academic year)?

4. Why do you think you were placed in Level___ (the participants' initially assigned level in the beginning of the academic year)?

5. Did the results of placement affect how you study?

6. Why do some Chinese students not like the ESL program??

7. How do you feel about your Chinese classmates' speaking Chinese in class?

8. How do you feel when teachers say "stop speaking Chinese?"

9. Tell me about your favorite teachers in the ESL and why you like them (without their actual names)?

10. Tell me about the teachers in the ESL you did not like and why (without their actual names)?

11. Do you think you come from working class/middle class/upper class background?

12. What are you going to study in the university?

13. Do you think ESL classes will be useful (or prepare you well) once you become full-time university student? If so, what area? If not, why not?

14. Do you have peer pressure from other Chinese students in class?

15. What are some social and cultural pressures/obligations among Chinese students at the university? 


\section{APPENDIX E}

\section{HSRRC Approval Notice}

Research and Strateglc Partnershlps

Dost Ofnce Box 751 (RSP)

Dortand, Oregon $97207-0751 \quad 503-725-8170$ fax

rspopdx.edu

\section{Portland State University HSRRC Memorandum}

To: Akiko Ota

From: Mary Oschwald, Chair, HSRRC 2012

Date: February 23, 2012

Re: Your HSRRC application titled, "Factors inflnencing cultural, social and academic transitions of international students" (HSRRC Proposal \#122013)

In accordance with your request, the Human Subjects Research Review Committee has reviewred your proposal referenced above for compliance with DHHS policies and regulations covering the protection of human subjects. The committee is satisfied that your provisions for protecting the rights and welfare of all subjects participating in the research are adequate, and your project is approved.

Please note the following requirements:

Changes to Protocol: Any changes in the proposed study, whether to procedures, survey instruments, consent forms or cover letters, must be outlined and submitted to the Chair of the HSRRC immediately. The proposed changes cannot be implemented before they have been reviewred and approved by the Committee.

Continuing Review: Ibis approval will expire one year from the approval date. It is the investigator's responsibility to ensure that a Continuing Revien Report (available in ORSP) of the status of the project is submitted to the HSRRC two months before the expiration date, and that approval of the study is kept current.

Adverse Reactions: If any adverse reactions occur as a result of this study, you are required to notify the Chair of the HSRRC immediately. If the problem is serious, approval may be withdrawn pending an investigation by the Committee.

Completion of Study: Please notify the Chair of the Human Subjects Research Review Committee (campus mail code ORSP) as soon as your research has been completed. Study records, including protocols and signed consent forms for each participant, must be kept by the investigator in a secure location for three years following completion of the study. 


\section{APPENDIX F}

\section{IRB Permission from the University}

See below.

-----Original Message-----

From: McGee, Harry

Sent: Tuesday, December 20, 2011 3:07 PM

To: IRB

Subject: RE: IRB inqury

Tonya,

Sorry for the delay - I wanted to check with Judy to make sure I give you the right answer.

As long as what he is doing is not part of his duties at MSU he does not need MSU IRB approval. If I understand correctly his research is for Portland S U degree requirements. He needs to make sure that what he produces references them and not MSU.

Harry

Harry McGee, Chair SIRB

Michigan State University

205 Olds Hall

East Lansing, MI 48824

517-355-2180

"If we knew what we were doing it wouldn't be called research" Albert Einstein

-----Original Message-----

From: IRB [mailto:IRB@ ora.msu.edu]

Sent: Tuesday, December 20, 2011 9:56 AM

To: mcgeeh@msu.edu

Subject: FW: IRB inqury

Importance: High

Dear Harry:

Can you please review the below scenario and advise?

Thanks,

Tonya 
-----Original Message-----

From: Akiko Ota [mailto:otaakiko@msu.edu]

Sent: Monday, December 19, 2011 3:18 PM

To: irb@msu.edu

Subject: IRB inqury

My name is Akiko Ota, instructor of English as a Second Language at the English

I received my employment at the ELC as a full-time instructor when I completed all the coursework of my doctoral degree in Educational Leadership at Portland State University, Portland, Oregon. Now I am defending my dissertation on 1/13/2012, and will be ready to conduct my dissertation research.

My dissertation focuses on international ESL students' social, cultural, and academic challenges while transitioning into American higher education. Therefore, I plan to recruit 8-10 upper level ESL students from China studying at the ELC in MSU. I will use semi-structure interview as research methodology, and the interviews will be digitally recorded and notes will be taken. In addition, the recordings will be transcribed, analyzed to find out potential themes to identify challenges and needs that ESL students from China have felt here at the ELC.

So, here is my question to the IRB office;

I am an fixed-term instructor who is using the student population at MSU, but this study is for a degree outside MSU (for Portland State University). As a part of dissertation requirement, I will be filing my IRB forms to Portland State University. Do you need a separate application to MSU IRB or can you accept a copy of the approval letter from IRB office at Portland State University?

If I need to file an application to MSU besides to my own institution, when can I file it? As a student of Portland State, I cannot file my IRB request until my proposal gets approved. However, I am an employee but not a student. So, does it mean I could apply for an IRB approval anytime soon?

Thank you very much for your assistance to figure out this complicated situation, and I appreciate your guidance.

Sincerely,

Akiko Ota

Instructor

English Language Center

Michigan State University 
A742 Wells Hall

otaakiko@msu.edu

517-884-0568 


\section{APPENDIX G}

Participants' information

\begin{tabular}{|c|c|c|c|c|c|c|c|c|}
\hline & $\stackrel{\grave{3}}{3}$ & 奇 & 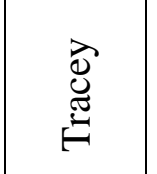 & 窵 & $\stackrel{\varpi}{\stackrel{⿹}{心}}$ & छี & 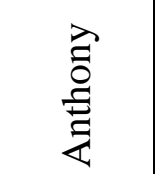 & $\begin{array}{l}\tilde{D} \\
\dot{0} \\
\dot{0}\end{array}$ \\
\hline$\underset{\&}{80}$ & $\stackrel{\infty}{-}$ & $\stackrel{2}{ }$ & 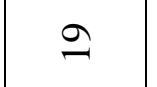 & તి & 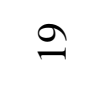 & ণి & 2 & 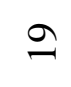 \\
\hline 竭 & 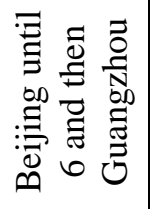 & $\begin{array}{l}8 \\
\stackrel{8}{0} \\
\stackrel{3}{Z}\end{array}$ & 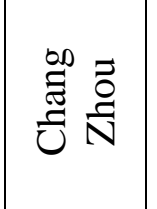 & $\begin{array}{l}\widetilde{\Xi} \\
60 \\
\text { E్ } \\
\text { Uี }\end{array}$ & స & $\stackrel{\circ}{:}$ & $\begin{array}{l}00 \\
\tilde{0} \\
\tilde{\Xi}\end{array}$ & 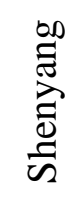 \\
\hline 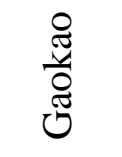 & $\stackrel{\circ}{ }$ & $\stackrel{\infty}{\infty}$ & ż & $\sum^{\infty}$ & 之o & Z & $\stackrel{\circ}{z}$ & $\stackrel{\circ}{ }$ \\
\hline 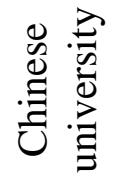 & ż & z & ż & 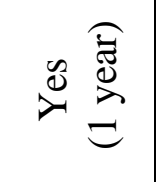 & 之े & ż & ż & $\stackrel{\circ}{z}$ \\
\hline 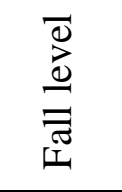 & $m$ & $\sigma$ & $\nabla$ & $m$ & $N$ & $N$ & $N$ & $\nabla$ \\
\hline 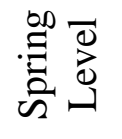 & in & in & in & 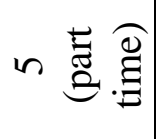 & in & $n$ & n & in \\
\hline 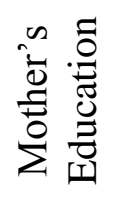 & 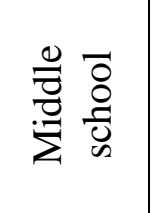 & 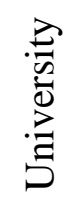 & 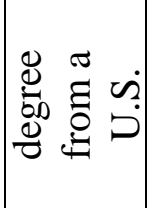 & 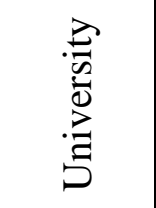 & 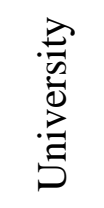 & 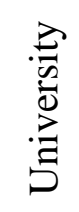 & 总总 & 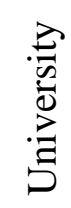 \\
\hline 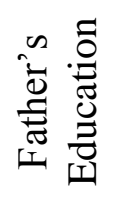 & 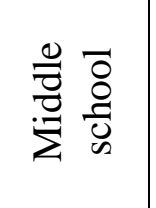 & 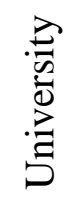 & 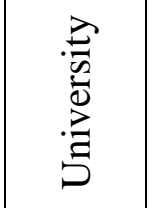 & 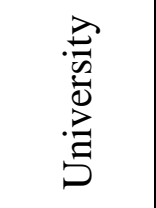 & 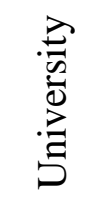 & 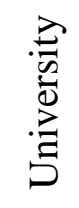 & 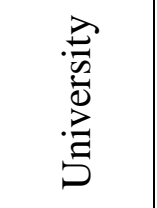 & 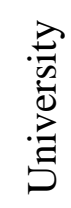 \\
\hline
\end{tabular}

